\author{
UNIVERSIDADE DE SÃO PAULO \\ ESCOLA DE ENGENHARIA DE SÃO CARLOS
}

André Luís Dias

Diagnóstico de anomalias em aplicações de acionamento de motores elétricos a partir de dados de processo de rede PROFINET e aprendizagem de máquinas

São Carlos 



\section{André Luís Dias}

Diagnóstico de anomalias em aplicações de acionamento de motores elétricos a partir de dados de processo de rede PROFINET e aprendizagem de máquinas

Tese apresentada à Escola de Engenharia de São Carlos da Universidade de São Paulo, para obtenção do título de Doutor em Ciências - Programa de Pós-Graduação em Engenharia Elétrica.

Área de concentração: Sistemas Dinâmicos

Orientador: Prof. Assoc. Dennis Brandão

Trata-se da versão corrigida da tese. A versão original se encontra disponível na EESC/USP que aloja o Programa de Pós-Graduação de Engenharia Elétrica.

São Carlos 
AUTORIZO A REPRODUÇÃO TOTAL OU PARCIAL DESTE TRABALHO POR QUALQUER MEIO CONVENCIONAL OU ELETRONNICO, PARA FINS DE ESTUDO E PESQUISA, DESDE QUE CITADA A FONTE.

Ficha catalográfica elaborada pela Biblioteca Prof. Dr. Sérgio Rodrigues Fontes da EESC/USP com os dados inseridos pelo(a) autor(a).

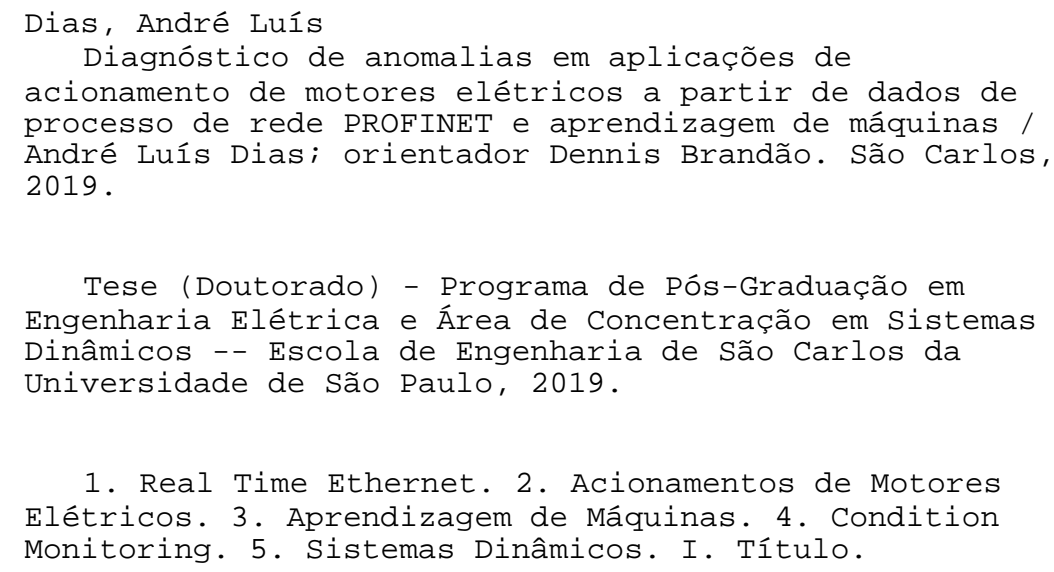

1. Real Time Ethernet. 2. Acionamentos de Motores Elétricos. 3. Aprendizagem de Máquinas. 4. Condition Monitoring. 5. Sistemas Dinâmicos. I. Título.

Eduardo Graziosi Silva - CRB - 8/8907 


\section{FOLHA DE JULGAMENTO}

Candidato: Engenheiro ANDRÉ LUÍS DIAS.

Título da tese: "Diagnóstico de anomalias em aplicações de acionamento de motores elétricos a partir de dados de processo de rede PROFINET e aprendizagem de máquinas".

Data da defesa: 06/06/2019

Comissão Julgadora:

Prof. Associado Dennis Brandão

(Orientador)

(Escola de Engenharia de São Carlos/EESC)

Prof. Titular Ivan Nunes da Silva

(Escola de Engenharia de São Carlos/EESC)

Prof. Associado Rodrigo Nicoletti

(Escola de Engenharia de São Carlos/EESC)

Prof. Dr. Marcio José da Cunha

(Universidade Federal de Uberlândia/UFU)

Prof. Dr. Jose Guilherme Sabe

(Escola de Engenharia de São Carlos/EESC)
Resultado:
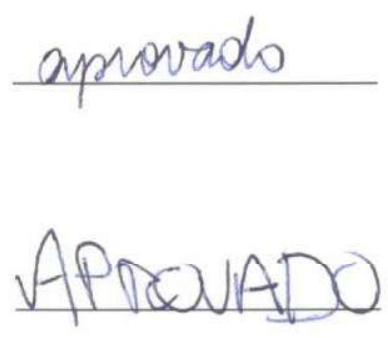

Aprovado

aprovado

Coordenador do Programa de Pós-Graduação em Engenharia Elétrica:

Prof. Associado Ivan Nunes da Silva

Presidente da Comissão de Pós-Graduação:

Prof. Titular Murilo Araujo Romero 

Dedico este trabalho aos meus pais, Libertad e Paulo, e minha esposa Livia. Pelo amor e carinho durante toda minha vida. O suporte de vocês foi essencial para minhas conquistas. Muito obrigado! 



\section{AGRADECIMENTOS}

O desenvolvimento desta tese de doutorado foi fruto de uma longa jornada que exigiu muita inspiração, transpiração, pensamento analítico e dedicação de muitas e muitas horas de estudo e reflexão. Ela foi fruto da contribuição de muitas pessoas no decorrer do processo de desenvolvimento, cada uma com sua contribuição, porém todas muito importantes para mim.

Dou início aos agradecimentos a minha família. Em especial ao meu grande amor e esposa Lívia, pelo incentivo e motivação desde antes do início das minhas atividades de mestrado, pelos elogios e críticas, pelo companheirismo e carinho de sempre. Esta etapa não teria sido alcançada sem você.

Aos meus pais Libertad e Paulo, e minha irmã Sandra, por todo o amor, carinho e incentivo que sempre me proporcionaram.

Ao orientador e amigo Prof. Assoc. Dennis Brandão, pela oportunidade que me ofereceu de sua tutoria, pela paciência e confiança depositada em mim para fazer parte de sua equipe do Laboratório de Automação Industrial, pela orientação não somente deste trabalho, mas também para formação ética e profissional, pelo flexibilidade e liberdade que nos oferece para condução dos projetos e horários para realização das atividades.

Aos amigos Afonso Turcato e Guilherme Sestito, pela parceria durante toda a jornada de meu desenvolvimento como pesquisador, pelas longas conversas, pelas inúmeras reflexões, pela amizade. Com certeza este trabalho foi construído com muita ajuda de vocês. É gratificante poder trabalhar com pessoas tão competentes. Muito obrigado de coração.

Ao amigo Raphael Menuzzo, pelo suporte na implementação dos experimentos, pelas inúmeras ligações de suporte técnico por telefone, e principalmente pela amizade desde o início da graduação.

Ao meu sogro Geraldo Martins Filho, por sempre estar disposto a ajudar, dar e implementar ótimas ideias, mesmo não sendo da área.

Ao amigo Sebastião Mendes de Sertãozinho, que com todo sua vivência na indústria, deu dicas, emprestou e adaptou equipamentos para os experimentos.

Aos amigos Fernando Guimarães, Fernando Fortuna, Murilo Silveira Rocha, Luísa Liboni, Rodrigo Pantoni e Helena Barbosa pela troca de ideias e companheirismo.

Ao Instituto Federal de São Paulo, pela flexibilidade e liberação de tempo para a elaboração deste trabalho, e pelo suporte de seus servidores. Ao Eliseu, pelas conversas e ajuda na fabricação de peças mecânicas, ao Diretor Geral do Câmpus Sertãozinho, Prof. 
Dr. Eduardo Mossin, pelo incentivo na condução de pesquisas dentro do IFSP.

A empresa Siemens Ltda, pelo suporte e empréstimo de equipamentos para condução dos experimentos, e pela oportunidade da experiência em ter trabalhado por quase 10 anos, vivenciamento o mundo de automação industrial. Em especial ao Eng. Eduardo Cardozo e Olímpio Correa.

Ao Prof. Assoc. Rodrigo Nicoletti pelo incentivo, mentoria e sempre estar disponível para conversas no decorrer de todo o meu processo de aprendizagem, desde época da graduação.

Ao Prof. Ivan Nunes pelos valiosos ensinamentos transmitidos, dentro e fora das inúmeros disciplinas que tive a oportunidade de cursar.

À Escola de Engenharia de São Carlos e funcionários do Departamento de Engenharia Elétrica e de Computação que ofereceram todo o suporte, em especial a Marisa e Daniel.

À todos que de alguma maneira contribuíram para que este trabalho fosse possível.

À Deus, por me dar sabedoria e saúde para alcançar meus objetivos profissionais e pessoais. 
"Never consider study as an obligation, but as the opportunity to penetrate the beautiful and wonderful world of knowledge." 



\section{RESUMO}

DIAS, A. L. Diagnóstico de anomalias em aplicações de acionamento de motores elétricos a partir de dados de processo de rede PROFINET e aprendizagem de máquinas. 2019. 142p. Tese (Doutorado) - Escola de Engenharia de São Carlos, Universidade de São Paulo, São Carlos, 2019.

Este trabalho propõe investigar, desenvolver e validar uma metodologia de projeto para sistemas de diagnóstico para detecção de falhas e anomalias em aplicações de acionamento de motores elétricos, comumente utilizados na indústria de manufatura. A metodologia proposta é baseada na coleta e interpretação de dados de processo de redes PROFINET, perfil PROFIdrive, e ferramentas de aprendizagem de máquinas. Técnicas de extração e redução de atributos são aplicadas nos dados de processo coletados. Estes atributos são utilizados em algoritmos para reconhecimento de padrões, os algoritmos investigados são o $k$-Nearest Neighbor, Redes Neurais Artificiais, Support Vector Machines, e adicionalmente uma adaptação da metodologia é feita utilizando um algoritmo para detecção de novidades. A avaliação da metodologia considerou quatro cenários para estudos de caso, para falhas comuns em aplicações de máquinas rotativas. Os resultados alcançados demonstram a eficácia da metodologia, que foi capaz de detectar as falhas e anomalias investigadas de maneira satisfatória, similares a trabalhos correlatos, com o diferencial de não exigirem sensores adicionais dedicados na coleta de dados. Desta maneira, o trabalho contribui para área de redes de comunicação industrial, mais especificamente o protocolo PROFINET, diagnósticos de anomalias em máquinas acionadas por motores elétricos, e ferramentas de aprendizagem de máquinas.

Palavras-chave: Real Time Ethernet. Acionamentos de Motores Elétricos. Aprendizagem de Máquinas. Condition Monitoring. Sistemas Dinâmicos. 



\section{ABSTRACT}

DIAS, A. L. Diagnostics of anomalies in motion control applications based on process data of PROFINET networks and machine learning tools. 2019. 142p. Tese (Doutorado) - Escola de Engenharia de São Carlos, Universidade de São Paulo, São Carlos, 2019.

This work proposes to investigate, develop and validate a methodology to design diagnostic systems to detect faults and anomalies in motion control applications, commonly used in manufacturing industry. The proposed methodology is based on collection and interpretation of process data from PROFINET networks, PROFIdrive profile, and machine learning tools. Feature extraction and selection techniques are applied to the collected process data. These features are used in algorithms for pattern recognition problems. Investigated algorithms are k-Nearest Neighbor, Artificial Neural Networks, Support Vector Machines and in addition, an adaptation of the methodology is held for novelty detection. Four scenarios were considered as case of studies for methodology evaluation, based on common faults in rotating machine applications. The results proved the methodology effectiveness for diagnostic system design, which were able to detect satisfactorily the investigated faults and anomalies, similar to related work, with the differential of not requiring additional dedicated sensors for data collection. In this way, the work contributes to the area of industrial communication networks, more specifically in PROFINET protocol, diagnostic systems for fault detection in motion control applications, and machine learning tools.

Keywords: Real Time Ethernet. Motion Control Applications. Machine Learning. Condition Monitoring. Dynamic Systems. 



\section{LISTA DE FIGURAS}

Figura 1 - Quantidade de publicações sobre tecnologia PROFINET nos últimos anos. . . . . . . . . . . . . . . . . . 26

Figura 2 - Quantidade de publicações sobre ferramentas de manutenção preditiva em máquinas. . . . . . . . . . . . . . . . . . . . . 27

Figura 3 - Patentes depositadas no mundo sobre protocolo PROFINET. . . . . . 28

Figura 4 - Patentes sobre Condition monitoring no mundo. . . . . . . . . . . . 29

Figura 5 - Estrutura básica de um sistema de diagnóstico de falhas. . . . . . . . . 37

Figura 6 - Participação no mercado de protocolos de comunicação industrial. . . . 40

Figura 7 - Exemplo de rede PROFIdrive e seus respectivos dispositivos. . . . . . . 42

Figura 8 - Arquitetura geral do Drive Object. . . . . . . . . . . . . . . . . . 43

Figura 9 - Esquemático da Classe de Aplicação 1. . . . . . . . . . . . . . . . . . . 44

Figura 10 - Esquemático da Classe de Aplicação 4 . . . . . . . . . . . . . . . . . . 45

Figura 11 - Exemplo de dados estruturados utilizados em Aprendizagem de Máquinas. 52

Figura 12 - Esquemático do algoritmo CFS. . . . . . . . . . . . . . . . . . . 55

Figura 13 - Direção da primeira componente principal $\mathbf{v}$ de um conjunto de dados com dois atributos. . . . . . . . . . . . . . . . . 56

Figura 14 - Classificação utilizando algoritmo kNN com k=5. . . . . . . . . . . . . 57

Figura 15 - Neurônio Artificial. . . . . . . . . . . . . . . . . . . . . . . . . 59

Figura 16 - Perceptron multicamadas. . . . . . . . . . . . . . . . . . . 62

Figura 17 - Hiperplanos de separação de classes (a) Possível hiperplano (b) Hiperplano de separação com margem maximizada. . . . . . . . . . . . . . . 65

Figura 18 - Interferência do parâmetro $\gamma$ no kernel Gaussiano. Banco de Dados de IRIS do MATLAB. . . . . . . . . . . . . . . . . . . . . . . . . 68

Figura 19 - Exemplos de hiperplanos de separação empregando OCSVM. . . . . . . 69

Figura 20 - Exemplo otimização de parâmetros utilizando Otimização Bayesiana para hiper-parâmetros de um sistema SVM. . . . . . . . . . . . . . . . 72

Figura 21 - Exemplo de curva de aprendizagem. . . . . . . . . . . . . . . . . 73

Figura 22 - Fluxograma da metodologia proposta. . . . . . . . . . . . . . . . 75

Figura 23 - Esquema de coleta de dados da metodologia proposta . . . . . . . . . 76

Figura 24 - Esquemático do sniffer e inserção de estampa de tempo. . . . . . . . . 77

Figura 25 - Tela do Wireshark com uma coleta de dados de uma rede PROFINET 78

Figura 26 - Funções desenvolvidas em MATLAB para interpretação do perfil PROFIdrive

Figura 27 - Funções desenvolvidas em MATLAB para interpretação do perfil PROFIdrive 
Figura 28 - Exemplo de dados de processo coletada empregando funções desenvolvidas em coletas com perfil PROFIdrive . . . . . . . . . . . . . . . . 81

Figura 29 - Exemplos de sinal de posição utilizado para extração de características.

a) Identificação do ciclo de operação b) Tratamento do sinal. . . . . . . 82

Figura 30 - Metodologia proposta apresentada graficamente. . . . . . . . . . . . . 85

Figura 31 - Metodologia proposta apresentada graficamente. . . . . . . . . . . . . 88

Figura 32 - Adaptação da metodologia proposta apresentada graficamente. . . . . . 91

Figura 33 - Esquema geral da estrutura da bancada experimental. . . . . . . . . . 94

Figura 34 - Esquemático da aplicação para controle de posição do motor. . . . . . 95

Figura 35 - Inércias utilizadas no cenário (a) Alguns tipos de inércia (b) Fixação no eixo do motor. . . . . . . . . . . . . . . . . . 9 97

Figura 36 - Acoplamento flexível utilizado para transmissão de torque entre eixo do motor e redutor. . . . . . . . . . . . . . . . . . . . . . 98

Figura 37 - Desbalanceamento em cargas rotativas (a) Representação esquemática da carga desbalanceada (b) Foto do disco utilizado para gerar níveis de desbalanceamento. . . . . . . . . . . . . . . . . 9 98

Figura 38 - Tipos de desalinhamento e indicação de valores. . . . . . . . . . . . . . 99

Figura 39 - Tipos de desalinhamento e indicação de valores. . . . . . . . . . . . . . 100

Figura 40 - Tipos de desalinhamento e indicação de valores. . . . . . . . . . . . . . 100

Figura 41 - Exemplos de amostras coletadas na rede PROFINET para condição de inércia normal e anormal. . . . . . . . . . . . . . . 106

Figura 42 - Distribuição das amostras no cenário 1 em função dos atributos selecionados por CFS. . . . . . . . . . . . . . . . . . . . . 108

Figura 43 - Distribuição das amostras no cenário 1 em função de duas componentes principais. . . . . . . . . . . . . . . . . . . 109

Figura 44 - Separação de classes utilizando SVM pela metodologia proposta. . . . . 110

Figura 45 - Sinal do erro no controle de velocidade da aplicação de algumas amostras coletadas. . . . . . . . . . . . . . . . . . . 111

Figura 46 - Distribuição das amostras no cenário 1 utilizando CFS e PCA com indicação das condições de operação. . . . . . . . . . . . . . . . . . . . 112

Figura 47 - Curva de aprendizado do cenário 1. . . . . . . . . . . . . . . . . 113 


\section{LISTA DE TABELAS}

Tabela 1 - Estrutura do telegrama padrão 1, 16 bits. . . . . . . . . . . . . 47

Tabela 2 - Estrutura do telegrama padrão 3, para UM sensor. . . . . . . . . . . 47

Tabela 3 - Algumas funções kernel utilizadas em SVM. . . . . . . . . . . . . . . 68

Tabela 4 - Lista de atributos extraídos das amostras . . . . . . . . . . . 83

Tabela 5 - Lista de hiper-parâmetros a serem ajustados para o classificador corres-

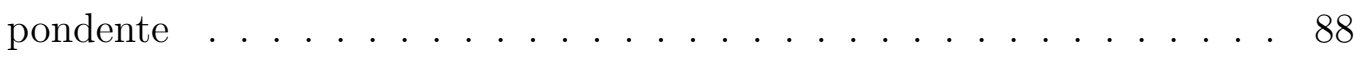

Tabela 6 - Lista de equipamentos. . . . . . . . . . . . . . . . 94

Tabela 7 - Descrição das Inércia utilizadas no experimento. . . . . . . . . . . . . 96

Tabela 8 - Massas utilizadas para desbalanceamento da carga. . . . . . . . . . . 99

Tabela 9 - Variações de parâmetros investigados. . . . . . . . . . . . . . 101

Tabela 10 - Resultados do algoritmo para identificação do ciclo de operação. Diferença entre tempo de ciclo real e resultante do algoritmo em milissegundos.104

Tabela 11 - Quantidade média de pacotes utilizada por amostra de acordo com tempo de ciclo parametrizado após identificação do ciclo de operação da máquina. . . . . . . . . . . . . . . . . . . . . . . . 105

Tabela 12 - Resultados para falha de aumento de inércia utilizando CFS a partir de um único atributo. . . . . . . . . . . . . . . . . . 107

Tabela 13 - Resultados para aumento de inércia utilizando CFS a partir de dois atributos. . . . . . . . . . . . . . . . 107

Tabela 14 - Resultados para falha de aumento de inércia utilizando PCA. . . . . . 109

Tabela 15 - Resultados para falha de aumento de inércia utilizando condições de operação separadamente. . . . . . . . . . . . . . . . . . . . . . . . . . 112

Tabela 16 - Resultados para falha de aumento de inércia empregando todos atributos extraídos. . . . . . . . . . . . . . . . . . . 114

Tabela 17 - Resultados para falha de aumento de inércia utilizando detecção de novidades. . . . . . . . . . . . . . . . . . . . 115

Tabela 18 - Resultados para identificação de falha de aumento excessivo de inércia frente a dados de desbalanceamento . . . . . . . . . . . . . . . . . 116

Tabela 19 - Resultados para falha de desacoplamento. . . . . . . . . . . . . . 117

Tabela 20 - Resultados para falha de desacoplamento utilizando detecção de novidades.118

Tabela 21 - Resultados para identificação de falha de desacoplamento frente a dados de desalinhamento. . . . . . . . . . . . . . . . . . . . . . . 119

Tabela 22 - Resultados para falha de desbalanceamento. . . . . . . . . . . . . . . . 121

Tabela 23 - Resultados para falha de desbalanceamento utilizando detecção de novidades. . . . . . . . . . . . . . . . . . . . . . . 122 
Tabela 24 - Resultados para identificação de falha de desbalanceamento frente a dados de aumento excessivo de inércia. . . . . . . . . . . . . . . . . . 122

Tabela 25 - Resultados para falha de desalinhamento angular. . . . . . . . . . . . 123

Tabela 26 - Resultados para falha de desalinhamento linear. . . . . . . . . . . . . . 124

Tabela 27 - Resultados para falha de desalinhamento utilizando detecção de novidades.126

Tabela 28 - Resultados para identificação de falha de desacoplamento frente a dados de desalinhamento. . . . . . . . . . . . . . . . . . . . . . 127

Tabela 29 - Resultados do sistema de detecção de falhas proposto. . . . . . . . . . . 128

Tabela 30 - Resultados do sistema de detecção de falhas proposto. . . . . . . . . . . 129 


\section{LISTA DE ABREVIATURAS E SIGLAS}

\begin{tabular}{|c|c|}
\hline AR & Application Relationship \\
\hline CFS & Correlation based Feature Selection \\
\hline CLP & Controlador Lógico Programável \\
\hline CR & Communication Relationship \\
\hline DSC & Dynamics Servo Control \\
\hline EQM & Erro Quadrático Médio \\
\hline FFT & Fast Fourier Transform \\
\hline FN & Falso Negativo \\
\hline FP & Falso Positivo \\
\hline IO AR & Input/Output Application Relationship - \\
\hline IO CR & Input/Output Communication Relationship \\
\hline $\mathrm{kNN}$ & $k$-Nearest Neighbor \\
\hline OCSVM & One-Class Support Vector Machine \\
\hline PCA & Principal Component Analysis \\
\hline PI & Profibus International \\
\hline PMC & Perceptron multicamadas \\
\hline RFN & Razão de Falsos Negativos \\
\hline RFP & Razão de Falsos Positivos \\
\hline RNA & Redes Neurais Artificiais \\
\hline RPM & Rotação por Minuto \\
\hline RTE & Real Time Ethernet \\
\hline SCADA & Supervisory Control and Data Acquisition \\
\hline SVM & Support Vector Machine \\
\hline $\mathbf{V N}$ & Verdadeiro Negativo \\
\hline VP & Verdadeiro Positivo \\
\hline
\end{tabular}





\section{SUMÁRIO}

INTRODUÇÃO $\ldots \ldots \ldots \ldots \ldots \ldots$

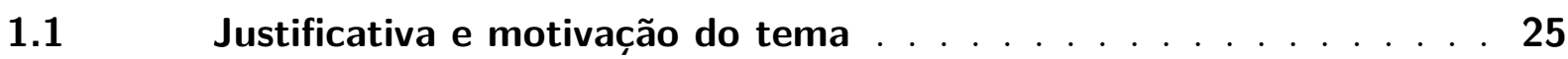

1.1.1 Pesquisa Bibliográfica . . . . . . . . . . . . . . . . . 25

1.1 .2 Patentes . . . . . . . . . . . . . . . . . . 27

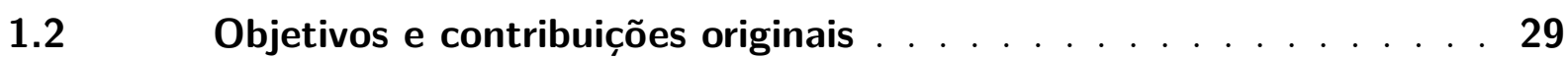

1.2.1 Objetivos Gerais e Específicos . . . . . . . . . . . . . . . 30

1.2 .2 Contribuições Originais . . . . . . . . . . . . . . . . . 31

1.3 Trabalhos submetidos para publicação e publicados . . . . . . . 31

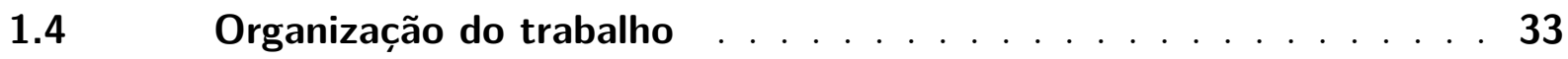

2 ASPECTOS DE APLICAÇÕES COM ACIONAMENTOS DE MO-

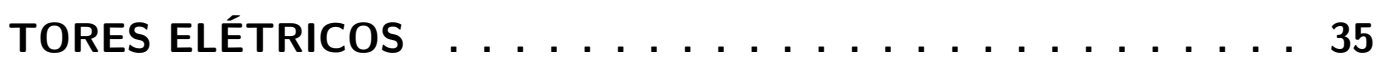

2.1 Sistemas de Diagnósticos em Máquinas Rotativas . . . . . . . . . . 35

2.2 Trabalhos correlatos na detecção de falhas e anomalias . . . . . . 37

$2.3 \quad$ Perfil PROFIdrive do protocolo PROFINET . . . . . . . . . . 40

2.3.1 Serviços de comunicação . . . . . . . . . . . . . . . . . . . . . 42

2.3.2 Classes de Aplicação . . . . . . . . . . . . . . . . . . . . . . . . . 44

2.3.3 Telegramas Padrão PROFldrive . . . . . . . . . . . . . 46

3 FERRAMENTAS MATEMÁTICAS E COMPUTACIONAIS . . . . 49

3.1 Conceitos sobre Aprendizagem de Máquinas e Mineração de Dados 49

$3.2 \quad$ Extração e Redução de atributos . . . . . . . . . . . . . . 52

3.2.1 Correlation-based Feature Selection (CFS) . . . . . . . . . . 53

3.2.2 Principal Component Analysis (PCA) . . . . . . . . . . . 54

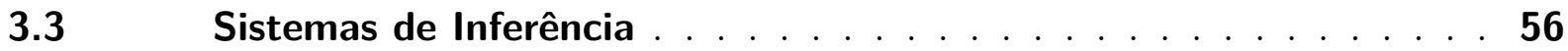

3.3.1 k-Nearest Neighbor $(k-N N) \ldots \ldots \ldots \ldots 6$

3.3.2 Redes Neurais Artificiais $(\mathrm{RNA}) \ldots \ldots \ldots$

3.3.3 Support Vector Machine $(\mathrm{SVM}) \ldots \ldots \ldots . \ldots . \ldots . \ldots 64$

3.3.4 One-Class Support Vector Machine (OCSVM) . . . . . . . . . . . . 68

3.4 Validação Cruzada e Otimização de Desempenho . . . . . . . . . 70

3.4.1 Validação cruzada . . . . . . . . . . . . . . . . . . . . 70

3.4.2 Otimização de hiper-parâmetros . . . . . . . . . . . . . . 72

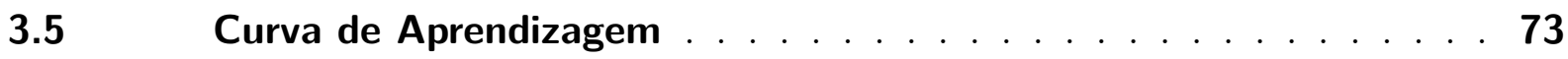

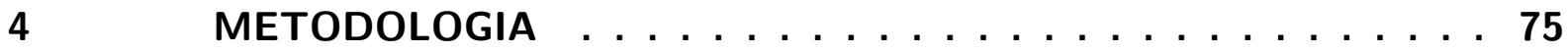

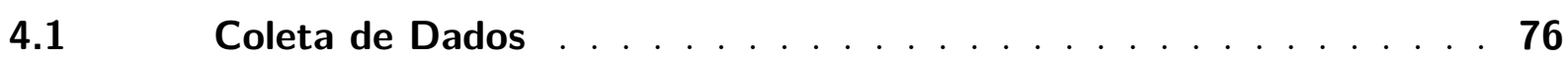


4.2 Interpretação de dados de processo do perfil PROFIdrive . . . . . . 78

$4.3 \quad$ Extração de Atributos . . . . . . . . . . . . . . . . . . . 81

4.4 Seleção de Atributos . . . . . . . . . . . . . . . . 85

$4.5 \quad$ Classificadores . . . . . . . . . . . . . . . . . . 86

$4.6 \quad$ Avaliação de Desempenho e Validação . . . . . . . . . . . . . . 87

4.7 Adaptação da Metodologia para a Estratégia de Detecção de Novidades . . . . . . . . . . . . . . . . . . . . . . . 90

5 EXPERIMENTOS E ESTUDOS DE CASO . . . . . . . . 93

5.1 Bancada Experimental . . . . . . . . . . . . . . 93

$5.2 \quad$ Cenários para os Estudos de Caso . . . . . . . . . . . . . . . . 95

6 RESULTADOS E DISCUSSÃO . . . . . . . . . . . . . . 103

$6.1 \quad$ Aumento excessivo da inércia da carga . . . . . . . . . . 103

6.2 Desacoplamento de carga . . . . . . . . . . . . . . . . 117

6.3 Desbalanceamento da carga . . . . . . . . . . . . . . . . . 120

$6.4 \quad$ Desalinhamento . . . . . . . . . . . . . . . . . . . 123

6.4 .1 Desalinhamento Angular . . . . . . . . . . . . . . . . 123

6.4.2 Desalinhamento paralelo . . . . . . . . . . . . . . . 124

6.5 Discussões finais . . . . . . . . . . . . . . . . . . . . 127

7 CONCLUSÕES . . . . . . . . . . . . . . 131

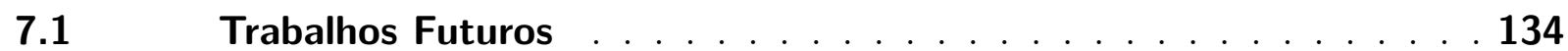

REFERÊNCIAS . . . . . . . . . . . . . . . 137 


\section{CAPÍTULO 1 INTRODUÇÃO}

O emprego de motores elétricos nos processos produtivos do setor industrial é de extrema importância. O consumo de energia elétrica deste setor representou 31,8\% do total de eletricidade produzida no Brasil em 2017 (ENERGéTICA, 2018). De acordo com a Comissão Europeia, os motores elétricos representam 50\% do consumo de eletricidade na Europa, desempenhando um importante papel no acionamentos de máquinas para os mais variados segmentos do mercado. McCoy e Douglass (2014) indicam que este tipo de carga representa o consumo de 38,4\% de toda a energia elétrica produzida nos Estados Unidos. Já a Profibus International (PI), uma associação de empresas e universidades que regulamenta dois protocolos de comunicação industrial, introduz que acionamentos de motores é uma das mais importantes aplicações em automação industrial, representando $60 \%$ de toda transformação da energia elétrica em mecânica empregada em indústrias (PROFIBUS NUTZERORGANISATION E.V., 2015).

Os motores elétricos correspondem a $89 \%$ dos mecanismos que produzem força na indústria de manufatura (ARREDONDO et al., 2015). Assim, aplicações para controle de máquinas de produção comumente empregam acionamentos de motores, conhecido como aplicações de controle de movimento. Esses acionamentos agem como atuadores em máquinas responsáveis pelos mais diversos processos industriais, executando tarefas diversas em velocidade de rotação fixa e variável em cargas como bombas, ventiladores e compressores; controle de posicionamento e velocidade de eixos únicos, como aplicações de deslocamento, ajuste e posicionamento; e servo acionamentos com interpolação central, como em máquinas ferramentas de controle numérico, robôs manipuladores, empacotadeiras e máquinas de produção em geral(PROFIBUS NUTZERORGANISATION E.V., 2015).

Suetake (2012) reforça a importância de estudos relativos aos acionamentos de motores elétricos em relação à melhoria da eficiência energética, dimensionamento adequado, técnicas de controle preciso, qualidade de energia elétrica, manutenção preventiva, e até mesmo na identificação de falhas elétricas e mecânicas.

Problemas relacionadas a falhas em máquinas acionadas por motores elétricos são indicadas como uma das principais fontes de custos em uma empresa, não apenas pelo custo do reparo do equipamento, mas também pela perda da oportunidade de produzir devido a interrupções não programadas causadas pela indisponibilidade da máquina (DWIPUTRANTO; SETIAWAN; AJI, 2017; HENAO et al., 2014).

Arredondo et al. (2015) cita que cerca de 40\% das falhas ocorridas em motores de indução estão relacionadas a aspectos mecânicos. As condições de operação de uma 
máquina podem ser alteradas durante sua operação, como por exemplo modificações da inércia e alteração da carga acionada, falhas mecânicas na transmissão do movimento como em redutores, correias e polias, desbalanceamento, desacoplamento e desalinhamento das cargas acopladas, entre outras que podem comprometer ou até impedir o seu correto funcionamento.

Diante da grande quantidade e diversidade de máquinas na indústria de manufatura, torna-se importante a utilização de sistemas de diagnóstico automáticos para seu monitoramento, verificando se estão operando em condições para o que foram projetadas. Estes sistemas podem identificar falhas e anomalias na operação, e consequentemente, podem evitar perdas de produção, aumentar a disponibilidade do processo e reduzir custos de manutenção corretiva (SANTOS, 2013; DRIF; CARDOSO, 2014; GHANBARI, 2016; FOURNIER et al., 2015).

Estas técnicas são chamadas de condition monitoring ou Monitoramento de Condição, e objetivam a detecção de falhas ou um processo de degradação que tenha ganhado um certo nível sintomático, provendo uma indicação de anormalidade antes que uma parada funcional ocorra (VANRAJ et al., 2016).

Considerando que dispositivos para controle de velocidade variável, desde conversores de frequência básicos até servo-controladores para aplicação de controle de movimento de alta dinâmica estão sendo cada vez mais conectadas a sistemas de controle de malha aberta e malha fechada em plantas e sistemas automatizados através de interfaces digitais (PROFIBUS NUTZERORGANISATION E.V., 2015), que podem disponibilizar grande volume de dados do processo. A integração de sistemas de automação de processos industriais para gerenciar a dinâmica dos acionamentos de motores elétricos, criou a necessidade de redes industriais que forneçam recursos, como: suporte a aplicações em tempo real, determinismo, maior volume de dados (DIAS; SESTITO; BRANDAO, 2017). Neste sentido, tem ocorrido desenvolvimento significativo de equipamentos de comunicação industrial, e atualmente existem vários tipos de protocolos que oferecem capacidade para operar em aplicações de tempo real possuindo determinismo compatível. Neste contexto, surgiram as redes Real Time Ethernet (RTE) definidas pela norma IEC 61784-2, onde o PROFINET se destaca pela quantidade de aplicações em crescimento nos últimos anos, sendo um dos protocolos mais promissores para o futuro (FERRARI et al., 2011; YANG; LI, 2014). Este protocolo oferece alguns perfis de utilização, onde o PROFIdrive aparece como um perfil do PROFINET que define estratégias e telegramas específicos para aplicações de controle de movimento em máquinas, para controle de velocidade e posicionamento de eixos. A medição destas variáveis são necessárias para controle das tarefas, e normalmente empregam encoders instalados no eixo do motor.

Assim, no contexto da Industria 4.0, muitas estratégias ligadas a inteligência artificial e ferramentas de aprendizagem de máquinas tem sido empregadas para se tornar 
possível a extração de informações relevantes de grandes e complexos volume de dados gerado pela indústria em seu processo produtivo.

Busca-se então a utilização de dados de processo de máquinas que trafegam na rede de comunicação, normalmente utilizados puramente para propósitos de controle, para o desenvolvimento de um sistema de diagnóstico automático de anomalias e falhas em aplicações de acionamentos de motores, sem a necessidade de instalação de sensores adicionais dedicados, como utilizado habitualmente.

A análise dos dados transmitidos pela rede de comunicação industrial é realizada com utilização de técnicas de mineração de dados e aprendizagem de máquinas, podendo assim prover informações que garantem ganhos aos usuários em relação a operação e manutenção de suas plantas. Assim, busca-se extração do conhecimento do processo industrial baseado nos pacotes de mensagens transmitidas pela rede de comunicação.

Para verificação de desempenho e validação dos resultados, alguns cenários são criados em laboratório como estudos de caso, inspirados em máquinas voltadas a indústrias de manufatura, que executam operações cíclicas, exigindo controle de velocidade e posição do eixo do motor através de inversores de frequência, servo motores e encoders.

Este tipo de abordagem não foi verificado em busca de bibliografia em algumas das principais bases de dados de engenharia, como IEEEXplore, Web of Science e Scopus, conforme apresenta a seção a seguir, dando caráter inovador a metodologia proposta.

\subsection{Justificativa e motivação do tema}

Duas abordagens foram utilizadas como justificativa da inovação e motivação ao tema proposto, uma em relação a busca de trabalhos na comunidade científica e outra relacionada a patentes.

\subsubsection{Pesquisa Bibliográfica}

Uma pesquisa bibliográfica quantitativa foi realizada para buscar trabalhos correlatos nas principais bases de dados de engenharia, buscando entender quais e como as falhas de máquinas elétricas rotativas são diagnosticadas e se existem publicações que relacionem essas falhas com utilização de dados de processo do sistema de controle das máquinas em redes de comunicação industrial. A pesquisa bibliográfica foi realizada nas bases de dados IEEE Xplore, Web of Science e Scopus.

Inicia-se com uma pesquisa em relação a tecnologia PROFINET, os seguintes critérios de inclusão são empregados: palavra-chave profinet, publicações de 2010 à 2018, em idioma inglês. Os seguintes critérios de exclusão foram utilizados: publicações onde o foco não era o protocolo PROFINET, que tratavam de marketing de produtos ou apenas 
o protocolo era citado. A figura 1 apresenta a quantidade de publicações por ano, até o ano de 2018.

Figura 1: Quantidade de publicações sobre tecnologia PROFINET nos últimos anos.

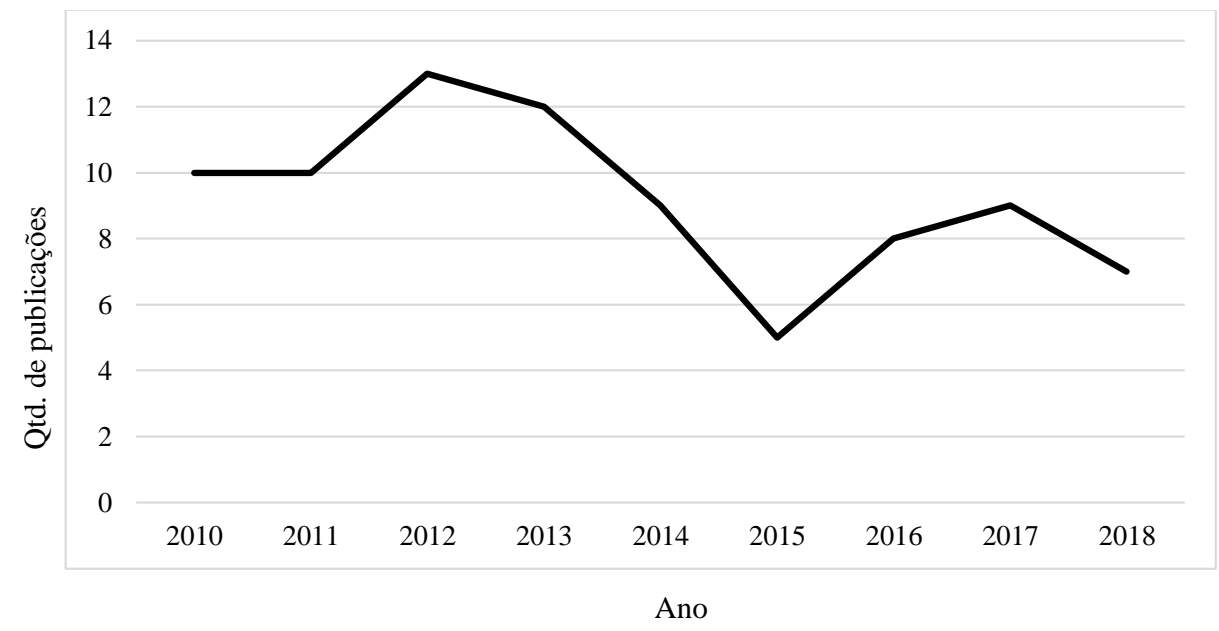

Fonte: Elaborada pelo autor.

Verifica-se uma continuidade de publicações sobre a tecnologia PROFINET nos últimos anos. Dias et al. (2018) apresenta um trabalho mais completo, apresentando o panorama, desafios e oportunidades desta tecnologia, por meio de uma pesquisa bibliográfica que agrupou diversos temas de pesquisa. Destaca-se nesta pesquisa a necessidade de desenvolvimento de ferramentas de diagnóstico e identifica-se uma lacuna em relação a estudos relacionados aos perfis de aplicação do protocolo PROFIBUS e PROFINET, onde o perfil PROFIdrive se enquadra em aplicações de controle de movimento.

Já em relação ao tema de manutenção preditiva em máquinas, com utilização de ferramentas relacionadas a diagnóstico de falhas e condition monitoring, emprega-se a estrutura:

KEY ("condition monitoring"OR "predictive maintenance" $O R$ "diagnosis system "OR "anomaly detection"OR "fault detection") AND KEY ("electrical machinery"OR "electric motors" OR "induction motors" OR "machine tools" OR "electrical drives "OR "motion control") AND PUBYEAR > 2009 AND LANGUAGE (english)

A figura 2 apresenta os resultados encontrados nas bases de dados investigadas.

Verifica-se um grande número de publicações nos últimos 10 anos que relaciona ferramentas de diagnóstico em motores ou máquinas elétricas, indicando a importância do tema na comunidade científica. Nota-se uma tendência para aumento das publicações sobre este tópico.

Finalmente verifica-se trabalhos que relacionem ferramentas de condition monitoring 
Figura 2: Quantidade de publicações sobre ferramentas de manutenção preditiva em máquinas.

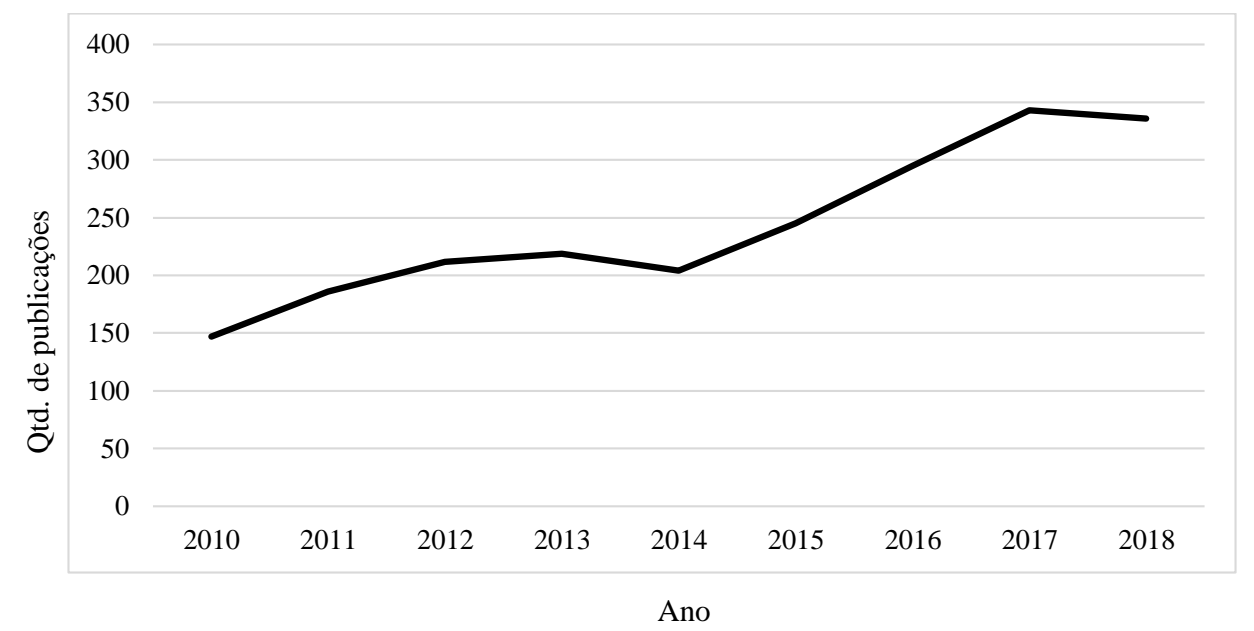

Fonte: Elaborada pelo autor.

e protocolos de comunicação Real Time Ethernet (RTE), como o PROFINET. A seguinte estrutura de pesquisa é utilizada:

KEY ("condition monitoring"OR "predictive maintenance"OR "diagnosis system "OR "anomaly detection"OR "fault detection") AND KEY ("electrical machinery"OR "electric motors"OR "induction motors"OR "machine tools"OR "electrical drives" OR "motion control") AND KEY ( profinet OR "Real Time Ethernet") AND PUBYEAR > 2009 AND $L A N G U A G E$ ( english )

A pesquisa não retorna resultados de publicações com estas palavras chaves. Assim, verifica-se que apesar da grande quantidade de pesquisas correlatas no que tange detecção de anomalias em motores e máquinas e publicações na área de redes PROFINET, nenhum método para diagnosticar aplicações de controle de movimento relacionado a redes de comunicação ou dados de processo transmitidos pela rede, é conhecido nas principais bases de dados de engenharia investigadas.

\subsubsection{Patentes}

Para verificação de patentes depositadas pelo mundo, relacionadas a esta tese, foi utilizado o sistema Orbit Intelligence da empresa Questel que disponibiliza consulta e análise de patentes em diversos países do mundo, possibilitando a construção de estratégias de busca baseadas em palavras chave, classificação de patentes entre outros campos.

Inicialmente, verifica-se a tecnologia PROFINET procurando este termo dentro dos campos "Título", "Resumo", "Objeto da Invenção", "Vantagens em relação a problemas anteriores" e "Reivindicações independentes". Encontra-se para este caso 821 patentes pelo 
mundo, sendo a empresa Siemens o principal titular de patentes, com 58 no total. O país que possui maior número de patentes em relação a tecnologia é a China, com 529 patentes, muito superior a Alemanha que é o segundo colocado com 72 patentes.

A classificação internacional mais encontrada foi a H04L-029/06, que diz respeito a arranjos, aparelhos, circuitos ou sistemas caracterizados por um protocolo de comunicação. A figura 3 apresenta o aumento de depósitos de patentes em relação a tecnologia, onde se pode observar um crescimento com o tempo. É importante ressaltar que é natural haver uma queda nos últimos anos, devido ao tempo entre o depósito das patentes, e sua disponibilização pública que fica em torno de 18 meses.

Figura 3: Patentes depositadas no mundo sobre protocolo PROFINET.

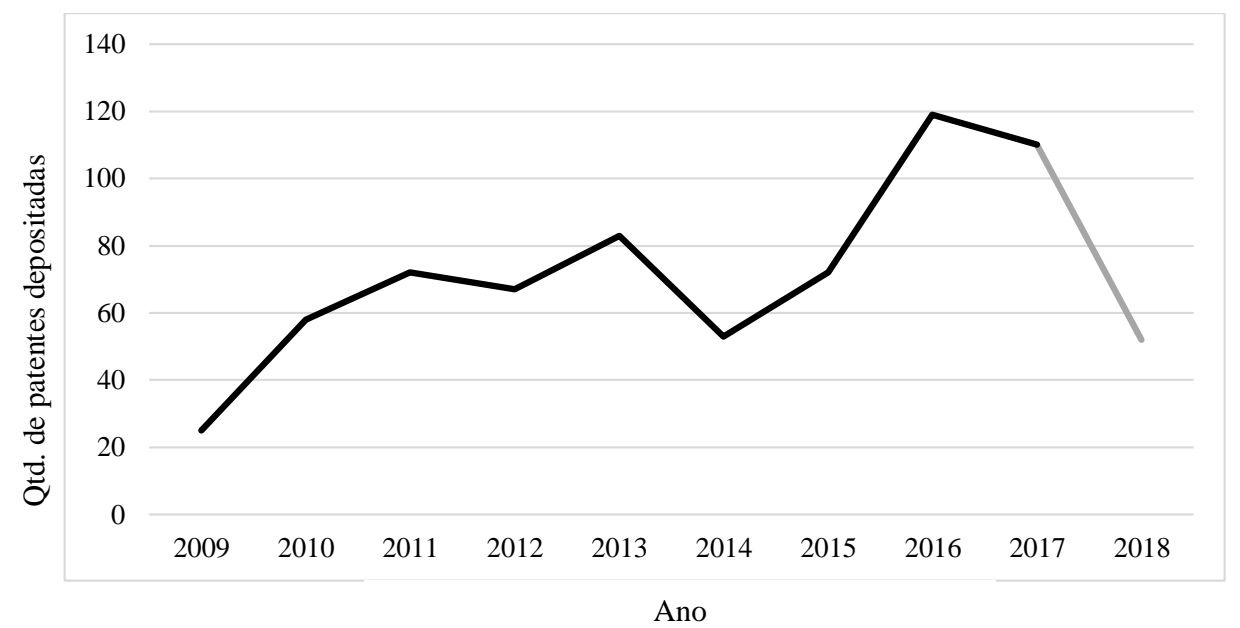

Fonte: Dados da plataforma Orbit Intelligence

Assim, a análise das patentes em relação a tecnologia PROFINET, reforça a tendência de utilização desta tecnologia no mercado.

Em seguida, para verificação de patentes que incluíam sistemas de diagnóstico para detecção de anomalias ou falhas, que normalmente utilizam estratégia denominada de condition monitoring, dentro do tema de manutenção preditiva, e que estejam ligadas a aplicações de acionamentos de motores máquinas e motores elétricos, foi utilizado a seguinte estrutura de pesquisa para maior amplitude dos resultados:

(condition monitoring OR predictive maintenance OR diagnosis system OR anomaly detection OR fault detection) AND (electrical machinery OR electric motors OR induction motors OR machine tools OR electrical drives OR motion control OR motor applications)

No total foram encontradas 477 patentes depositadas no mundo, destacando-se novamente o China com 195 patentes, seguida pelos Estados Unidos com 106. Ademais, verifica-se a importância deste tipo de sistema no mundo, devido a grande cobertura de 
mercado das patentes observado na figura 4. Pode se chegar nesta conclusão uma vez que empresas fazem depósitos de patentes em seus mercados consumidores, protegendo sua propriedade intelectual contra concorrentes. O Brasil aparece com 9 patentes depositadas em relação a procura realizada.

Figura 4: Patentes sobre Condition monitoring no mundo.

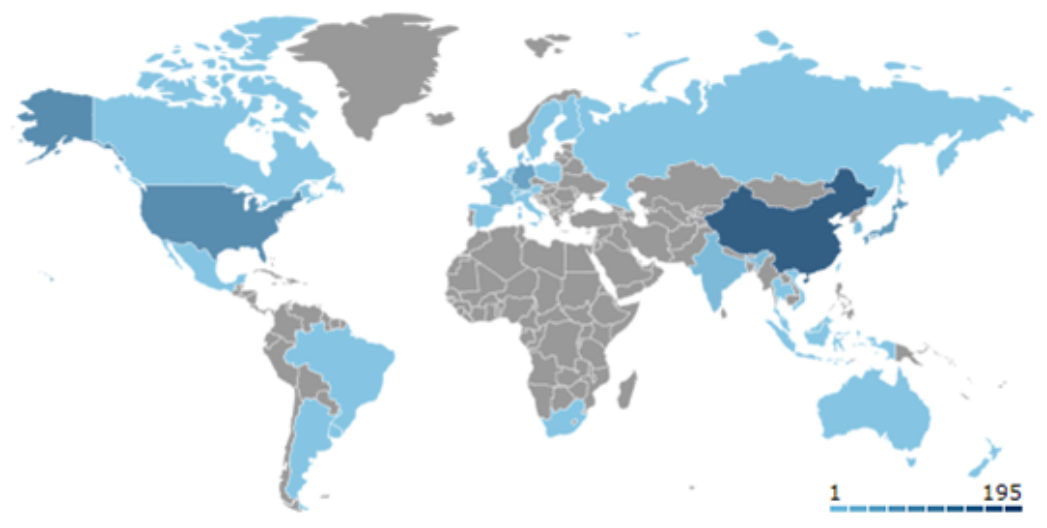

Fonte: Dados da plataforma Orbit Intelligence

Destacam-se como principais titulares das patentes as empresas Mitsubishi Electric com 18 patentes, Fanuc com 13, General Electric e Siemens com 10 patentes cada.

Finalmente, verifica-se a utilização do tipo de sistema supracitado que utilize adicionalmente alguma rede de comunicação digital. Para isto, o seguinte termo foi utilizado.

(condition monitoring OR predictive maintenance OR diagnosis system OR anomaly detection OR fault detection) AND (electrical machinery OR electric motors OR induction motors OR machine tools OR electrical drives OR motion control OR motor applications) AND (digital communication OR realtime ethernet OR profinet)

Para este condição, não foram encontradas patentes no mundo, ratificando a análise realizada pela pesquisa bibliográfica que o estudo realizado por esta tese trata-se de um tema inovador.

\subsection{Objetivos e contribuições originais}

Diante da importância do tema, esta tese propõe uma metodologia para desenvolvimento de sistemas de diagnóstico de falhas e anomalias em aplicações de acionamentos de motores elétricos, para máquinas que operam em processos cíclicos, próprios de indústrias de manufatura, e que utilizam protocolo PROFINET para sistema de controle e automação.

Aborda-se a utilização de mensagens trocadas entre dispositivos em uma rede PROFINET que empregam perfil PROFIdrive, coletados por um determinado período 
de tempo, que representa um ciclo de operação da máquina. Os dados de processo das mensagens são interpretados e características importantes dos sinais de velocidade e posição são extraídas. Algumas técnicas são analisadas para seleção de um conjunto menor de características mais relevantes, que são inseridas em classificadores para identificação de ocorrência de eventos (falhas ou anomalias) em cenários investigados.

\subsubsection{Objetivos Gerais e Específicos}

O objetivo geral desta pesquisa é investigar, desenvolver e validar um método de monitoramento e diagnóstico de anomalias em aplicações de acionamento de motores elétricos, utilizando dados de processo de rede de comunicação PROFINET, perfil PROFIdrive, sem necessidade de instalação de sensores e sistema de medição dedicados, por meio de ferramentas de mineração de dados e aprendizagem de máquinas.

Verifica-se um caráter desafiador ao objetivo, uma vez que a utilização de dados de processo do perfil PROFIdrive restringe apenas informações de velocidade e posição do eixo do motor como variáveis de entrada para extração de informação sobre falhas no sistema eletromecânico como um todo, que muitas vezes utilizam sistemas de diagnóstico baseado em técnicas de condition monitoring que exigem sensores específicos instalados em posições estratégicas no corpo das máquinas.

Dentro deste contexto os objetivos específicos a serem atingidos pela metodologia proposta são:

- Empregar um sistema para coleta de dados de redes PROFINET que utilize o perfil PROFIdrive em aplicações de controle de movimento, interpretando as variáveis de processo posição e velocidade disponível;

- Aplicar e investigar técnicas de mineração de dados para a extração e seleção de atributos das variáveis de processo coletadas;

- Selecionar, aplicar e investigar sistemas de inferência para reconhecimento de padrões de falhas e anomalias nas aplicações;

- Testar e validar a metodologia proposta, por meio de indicadores de desempenho e abordagens de validação cruzada em quatro cenários de anomalias: aumento excessivo de inércia da carga, desacoplamento, desbalanceamento e desalinhamento (angular e paralelo) da carga;

- Comparar os resultados obtidos nos cenários desenvolvidos em laboratório com pesquisas correlatas para verificação de eficiência da metodologia proposta. 


\subsubsection{Contribuições Originais}

A principal inovação desta pesquisa está relacionado ao modo de aquisição dos sinais físicos do sistema eletromecânico de acionamento de motor elétrico, que utiliza apenas dados de processo da rede PROFINET (perfil PROFIdrive) transmitidos entre controlador e servo motor, que já estão disponível para propósitos de controle, não demandando sensores adicionais instalados nas máquinas (como acelerômetros, sensores de temperatura, corrente e tensão) ou adaptações na programação do sistema de automação como é exigido em outras técnicas de condition monitoring verificado na literatura correlata.

Portanto, a principal contribuição original é:

- Comprovar que extraindo, selecionando e classificando características relevantes de dados de processo do perfil PROFIdrive, é possível desenvolver um sistema de diagnóstico capaz de detectar falhas em aplicações de acionamento de motores elétricos, que possui robustez e alto desempenho.

Outras contribuições são:

- Análise das variáveis setpoint de velocidade enviada do controlador do processo para o servo motor e velocidade e posição atual do servo motor enviada para controlador durante um ciclo de operação da máquina como sinais para identificação de diversas falhas e anomalias do sistema eletromecânico;

- Uso de novos atributos não abordados na literatura e atributos empregados em outros tipos de aplicações como em detecção de falhas em sistemas elétricos de potência para extração de características dos dados de processo disponíveis na aplicação de acionamentos de máquinas rotativas.

- Disponibilizar uma metodologia factível para usuários da tecnologia PROFINET como estratégia de engenharia na identificação de anomalias e variações de processo na operação de máquinas em operações cíclicas, reduzindo tempo de parada de máquinas, custos com manutenção corretiva, resultando no aumento da disponibilidade do sistema produtivo e verificando condições de operação que possam comprometer o nível de eficiência energética e precisão do controle da aplicação.

\subsection{Trabalhos submetidos para publicação e publicados}

A relevância e importância do tema resultou em algumas publicações e submissões para conferências e periódicos da área. Houve contribuição direta durante o desenvolvimento da pesquisa os seguintes trabalhos: 
- DIAS, A.L.; TURCATO, A. C.; SESTITO, G.S.; NICOLETTI, R.; ROCHA, M.S.; BRANDAO, D.. A method for detecting load anomalies in motion control applications using PROFIdrive and machine learning techniques. (Submetido para o periódico, sob análise)

- SeStito, G. S.; TURCATO, A. C.; DIAS, A.L.; FlAUZINO, R. A.; BRANDAO, D.. Detection of Anomalies Related to the Operation of the Profinet Network Through Feature Extraction and Classification. IEEE Latin America Transactions, v. 16, n. 7, p. $1855-1861,2018$

- SESTITO, G. S.; TURCATO, A. C.; DIAS, A. L.; ROCHA, M. S.; SILVA, M. M.; FERRARI, P.; BRANDAO, D.. A Method for Anomalies Detection in Real-Time Ethernet Data Traffic Applied to PROFINET. IEEE Transactions on Industrial Informatics, v. 14, n. 5, p. 2171-2180, 2018.

- DIAS, A.L., SESTITO, G.S.; BRANDAO, D., Performance Analysis of Profibus DP and Profinet in a Motion Control Application. Journal of Control, Automation and Electrical Systems, 28(1), pp. 86-93. 2017.

\section{Conferências Internacionais}

- DiAS, A. L; SESTITO, G. S.; TURCATO, A; BRANDAO, D.. Panorama, challenges and opportunities in PROFINET protocol research, 2018 13th IEEE International Conference on Industry Applications (INDUSCON), São Paulo, Brazil, 2018, pp. 186-193. doi: 10.1109/INDUSCON.2018.8627173

- SESTITO, G.S.; DIAS, A. L.; TURCATO, A. C.; BRANDÃO, D.; FERRARI, P.. The panorama and challenges of PROFIBUS technology in brazilian market, 2018 13th IEEE International Conference on Industry Applications (INDUSCON), São Paulo, Brazil, 2018, pp. 692-697. doi: 10.1109/INDUSCON.2018.8627204

\section{Conferências Nacionais}

- HAlfeld, V.; DiAS, A.L.; TURCATO, A.C.; BRANDÃO, D. Método para Interpretação de Dados de Processo em redes PROFINET Aplicadas a Acionamentos de Motores Elétricos. 9º Congresso de Inovação, Ciência e Tecnologia do IFSP, 2018.

- TURCATO, A.C.; DIAS, A.L.; SESTITO, G.S.; FLAUZINO, R.A. Ferramenta em Software Baseado em Web para Pré-Processamento de Tráfego de Redes Real Time Ethernet. 9º Congresso de Inovação, Ciência e Tecnologia do IFSP, 2018.

- DiAS, A. L.; SESTITO, G. S. ; TURCATO, A. C. ; ROCHA, M. S. ; MOSSIN, E. A. ; BRANDAO, D. . Sistemas de Medição para Redes de Comunicação Industrial 
Baseada em Ethernet. In: IV Congresso de Automação e Inovação Tecnológica Sucroenergética, 2016, Sertãozinho-SP. IV Congresso de Automação e Inovação Tecnológica Sucroenergética, 2016.

\subsection{Organização do trabalho}

A tese foi organizada em capítulos que apresentam aspectos dos trabalhos desenvolvidos. O capítulo 2 mostra os conceitos técnicos sobre sistemas de diagnóstico e condition monitoring para aplicações na identificação de falhas em máquinas rotativas acionadas por motores elétricos, trabalhos correlatos e aspectos do protocolo PROFINET, focando principalmente o perfil PROFIdrive e suas aplicações. Em seguida, o capítulo 3 descreve características das ferramentas matemáticas e computacionais de aprendizagem de máquinas, empregados para obtenção do sistema de diagnóstico, como técnicas de mineração de dados para extração e seleção de atributos, conceitos de sistemas inteligentes para reconhecimento de padrões e validação dos resultados. No capítulo 4 a metodologia proposta é descrita detalhadamente, juntamente com o sistema de medição para coleta de dados e estratégias para alcance dos objetivos especificados. Em seguida é apresentada no capítulo 5 a bancada experimental, que cria quatro cenários distintos de falhas em máquinas acionadas por motores elétricos, com lista de equipamentos utilizados, estratégias para criação de bancos de dados a partir da variação de parâmetros para a aplicação de controle de movimento. O capítulo 6 mostra os principais resultados obtidos e sua discussão, comparando-os com pesquisas correlatas. Finalmente, o capítulo 7 são reportadas as conclusões e diretivas para trabalhos futuros. 



\section{CAPÍTULO 2 \\ ASPECTOS DE APLICAÇÕES COM ACIO- NAMENTOS DE MOTORES ELÉTRICOS}

Este trabalho ataca problemas que ocorrem em aplicações de máquinas rotativas acionados por motores elétricos. Detalha-se nas próximas seções alguns tipos de sistemas de diagnósticos e trabalhos correlatos desenvolvidos pela comunidade científica; e aspectos do protocolo PROFINET e perfil PROFIdrive que servirá de base para o desenvolvimento da pesquisa.

\subsection{Sistemas de Diagnósticos em Máquinas Rotativas}

A metodologia proposta por esta tese, permeia pela grande área do conhecimento denominada manutenção preditiva. Trata-se de um conjunto de técnicas científicas que podem ser utilizadas para predizer possíveis falhas nos processos industriais, que pode não ser observável através de um plano de manutenção preventiva ordinário (VANRAJ et al., 2016), além de prever um plano para correção destas falhas. A implantação de manutenção preditiva tem sido cada vez mais importante com os altos níveis de exigência de produtividade e redução de custos na indústria de manufatura, além de trazer diversos benefícios como: reparos ou ajustes passam a custar bem menos que uma quebra e consequentemente a interrupção da produção, permite que a manutenção fique permanentemente sabendo o estado real do equipamento, permite programar os reparos de pequena ou grande monta entre outros (NEPOMUCENO, 2014). O emprego de técnica de manutenção preditiva apresenta uma redução de custos global de $15 \%$ e $20 \%$ daquele observado com a manutenção clássica (NEPOMUCENO, 2014).

O conceito denominado de condition monitoring tem como principal função a detecção de falhas ou de um processo de degradação que tenha ganho certo nível sintomático, fornecendo uma indicação da anormalidade a tempo antes que uma parada funcional ocorra (VANRAJ et al., 2016). Assim, as técnicas de condition monitoring são bases para o desenvolvimento de sistemas de diagnóstico, que são ferramentas para monitoramento de parâmetros de operação de máquinas realizado normalmente por sensores dedicados.

Uma abordagem para implementação de sistemas de diagnóstico é a partir da utilização de modelos computacionais do sistema dinâmico a ser analisado. No entanto, eles podem não ser desenvolvidos de acordo com a complexidade necessária, e simplificações que geram incertezas sobre seu real funcionamento podem ser consideradas (LIBONI, 2017) (DWIPUTRANTO; SETIAWAN; AJI, 2017).

Por esta razão, outra abordagem para desenvolvimento de sistemas de diagnóstico, 
baseada em sinais advindos diretamente de um sistema de medição, como sensores instalados no sistema dinâmico real a qual se deseja monitorar, têm sido vastamente utilizada pela literatura científica nos últimos anos. A complexidade de se realizar a modelagem de sistemas eletromecânicos (GHANBARI, 2016), como é o caso do cenário proposto por este trabalho, reforça esta tendência, e assim optou-se por esta abordagem.

Um sistema de condition monitoring empregado como técnica em sistemas de diagnóstico baseados em sinais, consistem na análise de variáveis do sistema dinâmico e técnicas de processamento de sinais com o objetivo de extrair características relevantes que possam detectar a ocorrência de um evento anormal ou variação do sistema monitorado, como por exemplo um conjunto de servo motor e carga acoplada (LIBONI, 2017).

Geralmente, a aquisição dos sinais necessários para aplicação da técnica de condition monitoring envolve o contato direto de sensores dedicados instalado em pontos específicos no corpo das máquinas.

Diversas técnicas podem ser utilizas para processamento dos sinais coletados (LIU et al., 2018):

- Análise no domínio do tempo: parâmetros como média, desvio padrão, variância e kutosis são baseados diretamente do sinal no tempo;

- Análise no domínio da frequência: parâmetros como análise de magnitude e fase e transformada rápida de Fourier (FFT).

- Análise tempo-frequência: parâmetros como transformadas Wavelet, decomposição esparça, transformada de Hilbert-Huang.

A partir a extração deste tipo de características dos sinais, técnicas de mineração de dados em conjunto com sistema inteligentes e de aprendizagem de máquinas são ajustados para classificação de padrões normais e anormais de operação, que podem ser por exemplo uma falha no motor, na carga acionada ou mesmo em variações de todo o conjunto de um sistema eletromecânico.

Nos últimos anos, muitas ferramentas para classificação de padrões em sistemas considerados saudáveis e com anomalias tem sido oferecidas, como redes neurais artificiais(RNA), sistemas fuzzy, random forest e Support Vector Machine(SVM) (BORDOLOI; TIWARI, 2019).

A figura 5 apresenta uma estrutura básica de um sistema de diagnostico de falhas para sistemas de engenharia.

Falhas e anomalias podem ocorrer durante a operação de máquinas acionadas por motores elétricos, assim o equipamento deixa de operar em uma condição considerada saudável e passa a trabalhar em uma condição anômala, muitas vezes causadas por falhas 
Figura 5: Estrutura básica de um sistema de diagnóstico de falhas.

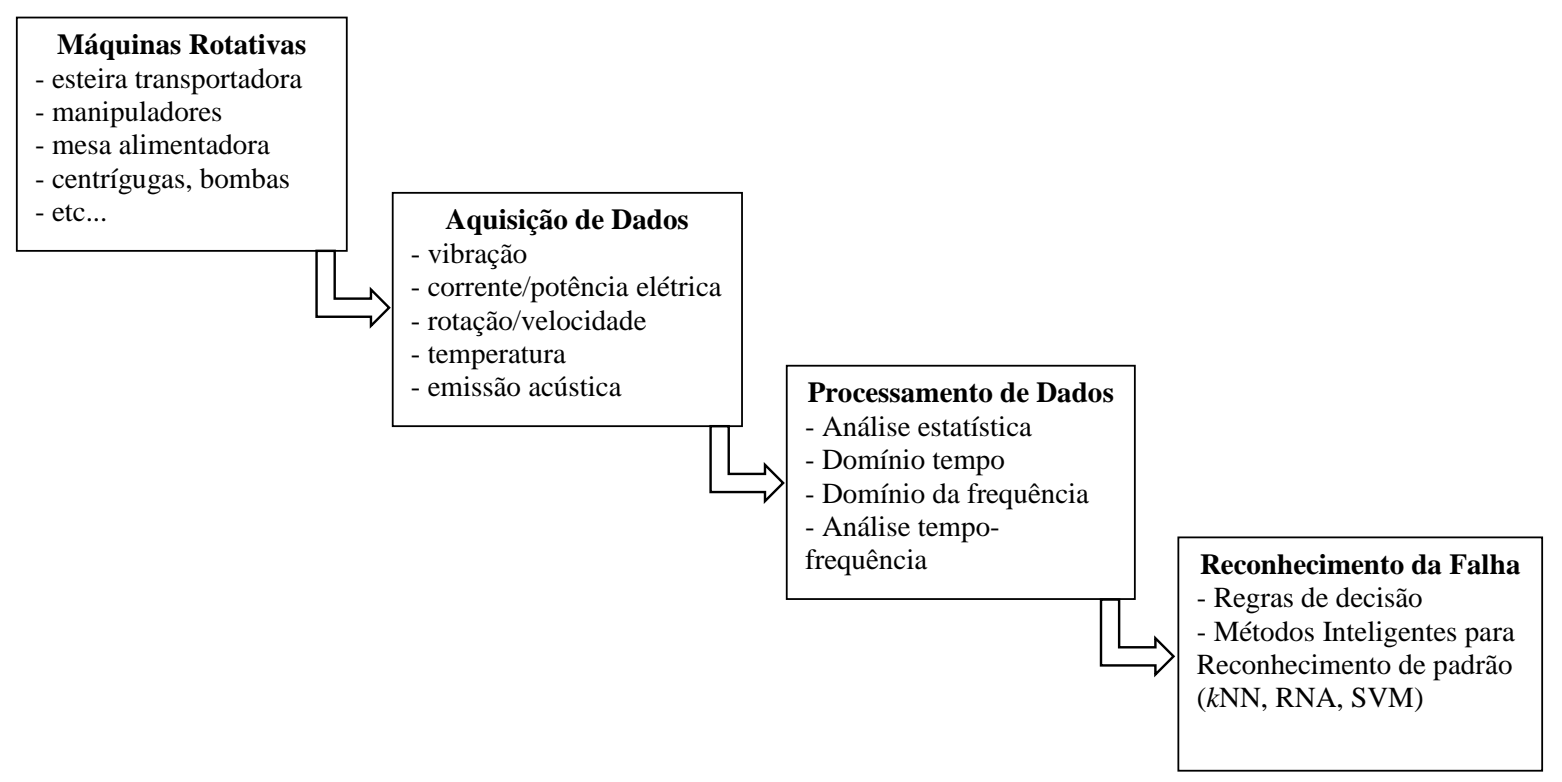

Fonte: Adaptado de Liu et al. (2018)

mecânicas. As principais falhas mecânicas em máquinas acionadas por motores elétricos, são o desbalanceamento e desalinhamento do rotor ou cargas a ele acopladas; e problemas nos rolamentos dos mancais tanto do motor como da carga (BORDOLOI; TIWARI, 2019; ANTONINO-DAVIU; POPALENY, 2018).

Além destes tipos de falhas, pode-se elencar a necessidade de identificação de problemas no sistema de transmissão de movimentação entre eixo do motor com a carga mecânica, normalmente feito por acopladores, redutores mecânico de velocidade e sistema de correia e polias(ANTONINO-DAVIU; POPALENY, 2018). Ademais, problemas relacionados a aumento excessivo da inércia da carga, podem influenciar tanto no desempenho da máquina do ponto de vista do sistema de controle, como também em relação a eficiência energética do acionamento. No capítulo 5, essas falhas serão apresentadas mais detalhadamente.

\subsection{Trabalhos correlatos na detecção de falhas e anomalias}

O diagnóstico de falhas em máquinas rotativas desempenha um papel importante para a confiabilidade e segurança de sistemas industriais modernos, uma vez que este tipo de equipamento é um dos mais importantes no setor produtivo de fábricas e com o rápido desenvolvimento tecnológico, se tornam cada vez mais complexo e funcional(LIU et al., 2018).

Um sistema de diagnóstico deste tipo, trata-se de uma técnica para detecção e identificação da falha, que pode ser aplicado na informação sobre a condição de operação do equipamento (JARDINE; LIN; BANJEVIC, 2006), normalmente provenientes de sinais de sensores dedicados instalados no equipamento. Devido à variabilidade e riqueza dos sinais 
de resposta, é quase impossível reconhecer padrões de falha diretamente, e normalmente um sistema de diagnóstico de falhas consiste em duas etapas principais: processamento de dados (tratamento e extração de características dos sinais) e reconhecimento de falhas (normalmente com utilização de um sistema inteligente para a tarefa de reconhecimento de padrões) (LIU et al., 2018).

Na literatura correlata sobre sistemas que utilizam técnicas de condition monitoring empregadas no sistema de diagnóstico, verifica-se a utilização de medidas de algumas variáveis para sensoriamento do corpo da máquina, motores e seu acionamento elétrico, como: potência, corrente e tensão elétricas, temperatura, vibrações mecânicas, torque, velocidade, posição, emissões acústicas entre outras. Adicionalmente, verifica-se emprego de diversas ferramentas de inteligência artificial para análise destes sinais.

Certamente, a análise vibracional é a técnica mais comumente utilizada para detectar falhas em máquinas rotativas (AMIR; GUL; KHAN, 2016; BORDOLOI; TIWARI, 2019; ANTONINO-DAVIU; POPALENY, 2018; VANRAJ et al., 2016; DWI et al., 2015), ou seja, a verificação de características de sinais de vibração de componentes mecânicos, como carcaças de redutores, eixos, acoplamentos entre outros.

Análise da assinatura vibracional para detecção de falhas em rolamentos foi estudado por Amir, Gul e Khan (2016), que emprega extração de atributos nos sinais de vibração instalados em mancais e aplica SVM para a classificação. Patil et al. (2010) discute sobre a influência do tamanho do defeito, da carga e da velocidade de rotação em alguns tipos de falhas em rolamentos de máquinas, Prieto et al. (2013) também propõe um esquema para detecção de alguns tipos de falhas em rolamentos, baseados em características no domínio do tempo dos sinais de vibração e empregando classificadores tipo RNA.

Sampaio e Nicoletti (2016) utilizam sinais de vibração por meio de um algoritmo chamado de Entropia Aproximada (EnAp) para detectar trincas e desalinhamentos em eixos rotativos. A EnAp é um valor estatístico usado para quantificar irregularidades de sinais discretos. Hai, Tsui e Zuo (2012) também investigam acerca de identificação de níveis de quebras em redutores de engrenagens, utilizando sinais de sensores de vibração instalados na carcaça do equipamento, utilizando seleção de atributos e um classificador do tipo kNN. Soualhi, Medjaher e Zerhouni (2015) utilizou transformada de Hilbert-Huang para extrair informações sobre a saúde de componentes críticos em mancais e classificou estes estados através de um sistema SVM.

Dwi et al. (2015) empregou análise de vibrações em conjunto com RNA para identificar desbalanceamento de carga em alguns cenários de máquinas rotativas em laboratório. Tahir et al. (2016) empregou análise do espectro de frequência de sinais de vibração multi eixos para detectar, a partir de utilização de SVM, diferenças entre falhas de desbalanceamento e desalinhamento de máquinas. 
Martinez-Morales et al. (2010) adicionalmente emprega corrente elétrica em conjunto com SVM para identificar três tipos de falhas (desbalanceamento, desalinhamento e falhas em mancais).

No entanto, outras variáveis são utilizadas em sistema de condition monitoring, como medição de corrente elétrica, velocidade e posição de motores elétricos (denominados como Assinatura de Movimento). Bansal, Evans e Jones (2005) utilizam estes sinais aplicando RNA para identificar variações na inércia para diferentes cargas acionadas, inicialmente utilizando simulações e depois em uma aplicação de micro furadeira. Pandarakone et al. (2017) utiliza corrente e velocidade do motor com classificadores de padrão do tipo SVM para identificar falhas em rolamentos de mancais empregados em diferentes condições de carga acionada. Fournier et al. (2015) propõe uma método chamado de "Espectro de Kurtosis com Referencial"para detectar falhas por desbalanço em motores, utilizando a frequência instantânea da corrente do estator do motor, tendo sucesso para diversas variações de cargas. Ebrahimi et al. (2014) também utiliza análise da assinatura da corrente do estator de motores síncronos de imã permanente para identificar falhas de excentricidade, empregando atributos baseados em transformada Wavelet e outras técnicas de análise de tempo-frequência do sinal, em conjunto com classificadores tipo SVM.

Yongjie et al. (2013) utiliza dados de temperatura de um redutor mecânico coletada por historiadores de um sistema supervisório do tipo SCADA (Supervisory Control and Data Acquisition), para detectar desempenho anormal em turbinas eólicas. Yang et al. (2008) validou um método para verificação de condição de operação em turbinas eólicas utilizando um filtro adaptativo baseado em Wavelet, que extrai informações de potência elétrica, e não empregando dados de vibração e óleo lubrificante como tradicionalmente.

Metwalley e Abouel-seoud (2013) empregaram uma análise monitorando o nível de pressão sonoro em uma caixa de redução para identificação do tempo de vida útil do dispositivo, antes da quebra de um dente de engrenagem, otimizando políticas de troca e manutenção dos redutores. Da mesma maneira, Li, Wang e Jiang (2011) empregou sinais de emissões acústicas e classificadores tipo SVM para diagnosticar e predizer tipos de falhas em diferentes profundidades de rachaduras em rotores. Em suma, verifica-se que a literatura aborda diversos técnicas de inteligência artificial e aprendizagem de máquina na identificação de falhas e anomalias, a partir da análise de diversos tipos de sinais de sensores instalados nos equipamentos. Nota-se que esta estratégia tem sido aplicada em uma ampla faixa de problemas em máquinas rotativas.

O PROFIdrive utiliza apenas dados de velocidade e posição em acionamentos de motores elétricos para propósitos de controle. A próxima seção o apresenta mais detalhadamente, uma vez que será utilizado como meio para coleta de dados de operação das máquinas a serem empregados na metodologia proposta. 


\subsection{Perfil PROFIdrive do protocolo PROFINET}

Os protocolos de comunicação RTE atualmente são amplamente aceitos e utilizados em ambiente industrial e suas aplicações vêm aumentando muito rapidamente nos últimos anos (FERRARI et al., 2011) (YANG; LI, 2014). Entre os protocolos RTE padronizados pela norma IEC61874-2, o PROFINET se destaca devido a significativa variedade de dispositivos no mercado e base instalada em crescimento, também devido a grande base instalada do protocolo PROFIBUS (DIAS; SESTITO; BRANDAO, 2017).

A figura 6 apresenta as principais tecnologias de redes de comunicação digital empregas em ambiente industrial.

Figura 6: Participação no mercado de protocolos de comunicação industrial.

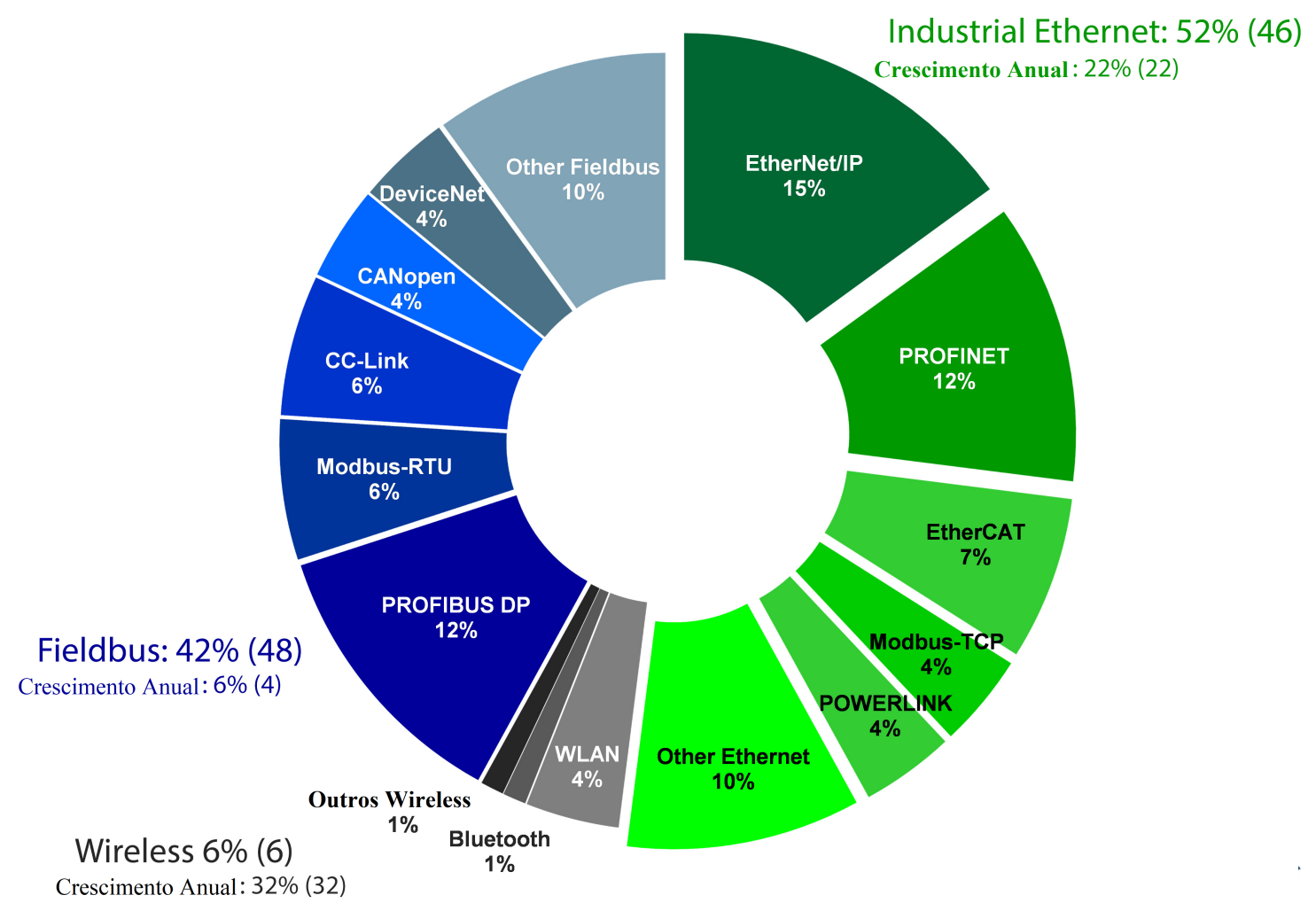

Fonte: Adaptado de HMS (2018)

Observa-se que os protocolos Real Time Ethernet (RTE) já possuem $52 \%$ da base instalada no mercado mundial, e possuem uma taxa de crescimento de $22 \%$ ao ano, muito superior em relação aos protocolos industriais seriais, chamados de fieldbuses, que possuem taxa de crescimento anual de $6 \%$. O protocolo PROFINET aparece em segundo lugar com $12 \%$ do mercado mundial.

O PROFIdrive é o perfil de comunicação para controle e acionamento de motores elétricos utilizado pelos protocolos PROFINET e PROFIBUS. O restante desta seção 
faz um descrição sobre este perfil baseado no documento Profile Drive Technology PROFIdrive Profile, conforme referência PROFIBUS Nutzerorganisation e.V. (2015).

O perfil PROFIdrive define um comportamento e uma técnica de acesso aos dados dos dispositivos que fazem parte de uma aplicação de controle de movimento. Como característica do PROFIdrive, os dispositivos de acionamentos de motores elétricos em um sistema de controle de velocidade ou posição respondem da mesma maneira, de forma padronizada, significando menores custos de engenharia e desenvolvimento aos usuários e maiores chances de sucesso no mercado aos produtos dos fabricantes que aderem a este perfil. Desta maneira, verifica-se que ferramentas inteligentes para o perfil PROFIdrive poderão ser utilizadas para qualquer dispositivo que possua esta tecnologia, independentemente do fabricante dos equipamentos. Quando utilizados em redes de comunicação PROFINET, os dispositivos PROFIdrive são mapeados conforme os seguintes objetos:

- Controller: representado por um IO-Controller está sempre associado a um ou mais eixos (acionamentos), podendo ser um CLP, PC Industrial entre outros;

- P-Device: dispositivo periférico, representado por um IO-Device, relacionado a um eixo do sistema de automação, e tipicamente associado a um ou mais Controllers. Pode ser um inversor de frequência, relé inteligente, entre outros.

- Supervisor: representado por um IO-Supervisor, é normalmente uma estação de engenharia que gerencia os dados de parametrização e configuração, além de coletar dados para diagnose de P-Devices e Controllers.

A Figura 7 representa um exemplo de rede de comunicação industrial PROFIdrive, com os dispositivos apresentados.

A comunicação entre estes dispositivos é realizada através de relacionamento de comunicação (Communication Relationship) que podem ser da seguinte maneira:

- Comunicação entre Controller e P-device é feito pelo IO AR (Input/Output Application Relationship)

- Comunicação entre Supervisor e P-device feito pelo Supervisor AR (Supervisor Application Relationship)

Não existe um canal de comunicação específico para troca de dados entre P-devices. Esta troca pode ser realizada utilizando comunicação do tipo Multicast. 
Figura 7: Exemplo de rede PROFIdrive e seus respectivos dispositivos.

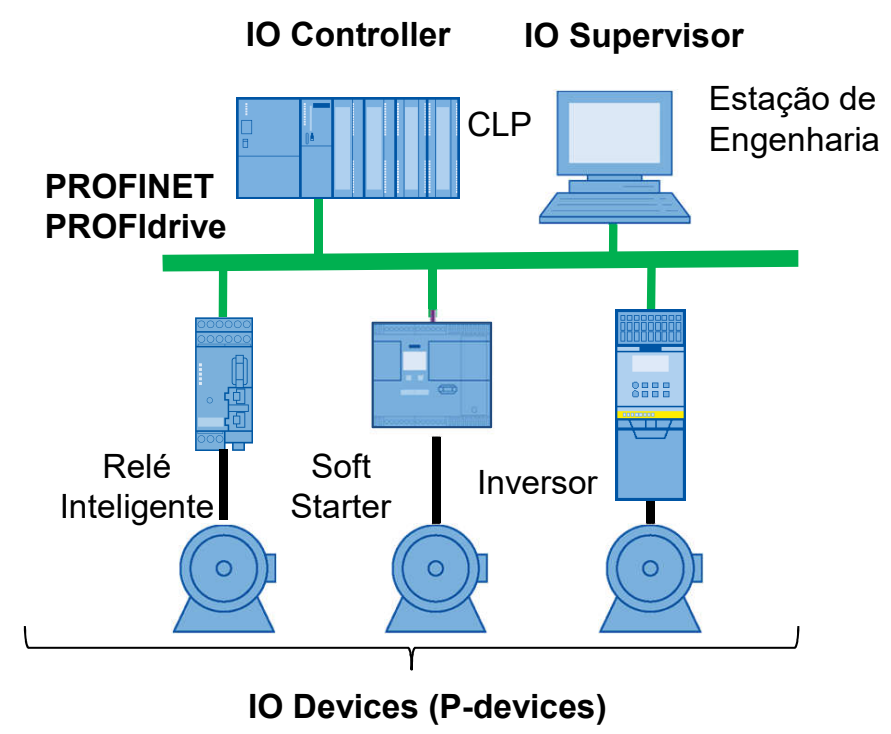

Fonte: Elaborada pelo autor

\subsubsection{Serviços de comunicação}

A norma também define os serviços de comunicação do modelo de base do PROFIdrive. Estes serviços são disponibilizados pelos dispositivos que compõem a rede, são eles:

- Troca de dados Cíclica, que significa comunicação cíclica, ou seja, transferência de dados de processo em um determinado slot de tempo repetidamente. Normalmente contém dados de setpoint e valores atuais de velocidades e posição das aplicações e também palavras de controle e status. No PROFINET chama-se IO Data ASE que é realizada pelo IO CR (Input/Output Communication Relationship) que é parte do IO AR, capaz de realizar troca de dados cíclica entre Controller e P-Device;

- Troca de dados acíclica, que significa comunicação acíclica realizada apenas quando necessário. Normalmente para transferência de dados não-críticos, como download de firmware e conjunto de parâmetros. No PROFINET chama-se Record Data ASE e é feita pelo Record Data CR;

- Fila de alarme, informações de alarme são sinalizadas em tempo real, assim o Controller é capaz responder a um evento no P-Device o mais rápido possível. O PROFINET utiliza o serviço Alarm ASE, realizado pelo Alarm CR; 
- Operação com sincronismo de tempo, que garante que tarefas sejam realizadas em diferentes dispositivos simultaneamente, com um jitter mínimo. O PROFINET utiliza o serviço Isochronus Mode Application ASE para operações com sincronismo de tempo, como interpolação de diversos eixos.

Estes serviços de comunicação são empregados nas operações de comando e controle de motores elétricos. A especificação técnica do perfil PROFIdrive apresenta o Drive Object (objeto de acionamento). A figura 8 apresenta a arquitetura de um Drive Object utilizando diversos serviços em uma aplicação.

Figura 8: Arquitetura geral do Drive Object.

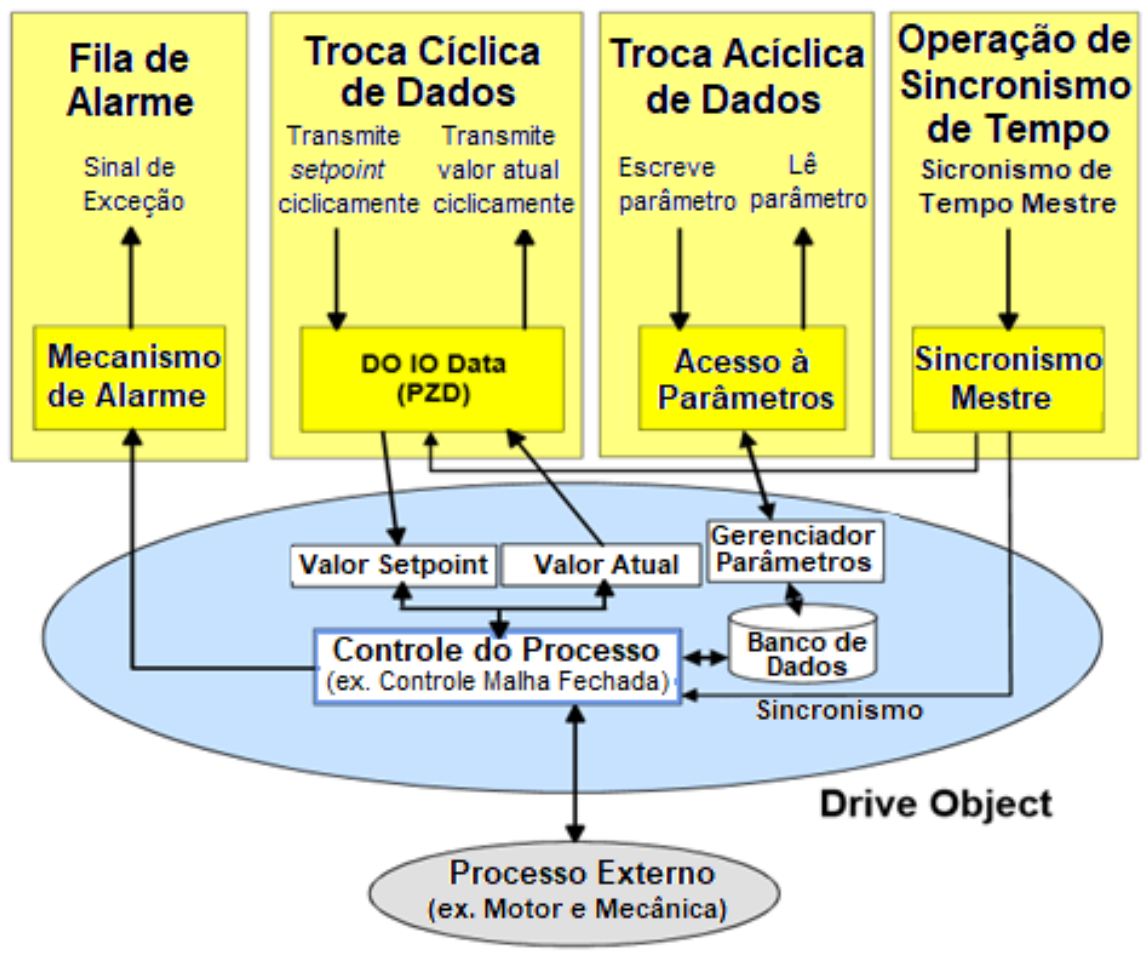

Fonte: Baseado de PROFIBUS Nutzerorganisation e.V. (2015)

O elemento central é a tarefa "Controle do Processo" que é responsável pelo controle do eixo do motor elétrico. Os parâmetros são gerenciados pelo "Gerenciador de Parâmetros" e armazenados no "Banco de Dados" através do serviço de comunicação acíclica. Para o transporte periódico dos valores de setpoint do controlador para o eixo e os valores atuais (velocidade e/ou posição) do eixo para o elemento de controle, o serviço de comunicação cíclica é utilizado. Situações fora do normal são informadas pelo mecanismo de alarme para o elemento de controle. Na necessidade de sincronismo de diversos Drive Objects o serviço "Operação de Sincronismo de Tempo" deve ser utilizado para gatilho de tarefas de controle. 


\subsubsection{Classes de Aplicação}

Aplicações de acionamentos de motores podem ser realizadas empregando diversas abordagens. A norma PROFIdrive define seis tipos de classes de aplicação que estão relacionadas a estratégia utilizada para o controle e acionamento de motor, incluindo os dados que trafegam pela rede de comunicação, conectando o controlador e os drives, como servo motores ou inversores de frequência por exemplo. As classes de aplicação podem servir como referência pelos fabricantes de equipamentos de maneira a seguir o padrão da norma. As classes de aplicação são:

AC1: Standard drive - o servo motor é controlado via um setpoint de velocidade enviado pelo sistema de automação, onde o fechamento da malha de controle é realizado completamente pelo servo, porém as funções tecnológicas para automação do processo ficam no controlador. Neste caso a troca de dados é cíclica, utilizando-se o envio de uma palavra de controle e setpoint de velocidade do sistema de automação para o drive e uma palavra de status e valor atual de velocidade do eixo do motor para o sistema de automação. As definições destas palavras são apresentadas na seção 2.3.3. A Figura 9 representa o esquemático desta classe.

Figura 9: Esquemático da Classe de Aplicação 1.

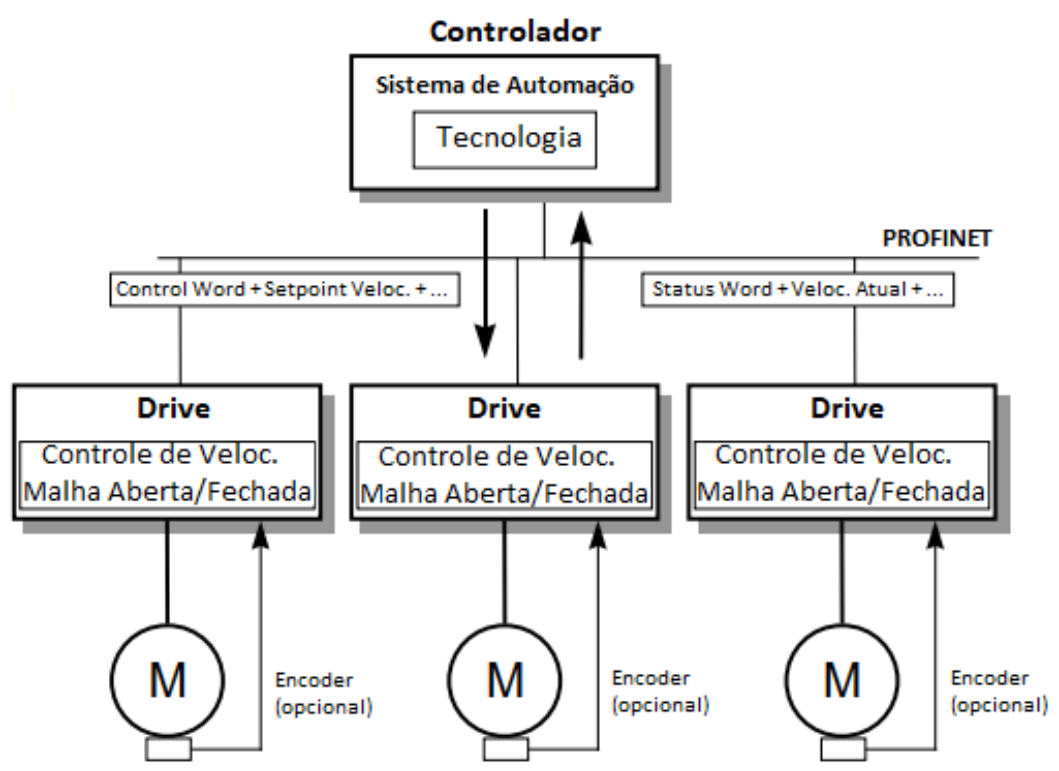

Fonte: Baseado de PROFIBUS Nutzerorganisation e.V. (2015)

AC2: Standard drive com tecnologia de controle distribuída - neste caso tem-se uma aplicação mais flexível com funções tecnológicas não somente no controlador, mas também nos drives. Possibilidade de sincronismo de velocidade entre drives, possibilitando comunicação entre P-Devices. Alguns exemplos de aplicação são setpoints em cascata e sincronismo de velocidade entre eixos, como em máquinas de embalagem. 
AC3: Posicionamento de eixos com controle de movimento local - nesta classe de aplicação ocorre o controle de posição do motor. Interpolação, controle de posição e velocidade são implementadas diretamente no drive. O controlador envia o setpoint de posição para o drive que o executa. Exemplos de aplicação são o fechamento de tampas em máquinas de envase e posicionamento de uma máquina de corte.

AC4: controle de movimento com interpolação central e interface de setpoint de velocidade - neste tipo de aplicação a malha de controle de posição utiliza a rede de comunicação. Setpoint de velocidade, valores atuais de velocidade e posição são transferidos via troca de dados cíclica. O controlador pode fazer a interpolação de diversos eixos para trajetórias específicas. Adicionalmente, a funcionalidade Dynamics Servo Control (DSC) pode aumentar a rigidez e resposta dinâmica da malha de controle. Alguns exemplos são manipuladores e aplicações de braços robóticos.

A figura 10 representa esta classe de aplicação, que é utilizada até esta etapa do projeto de pesquisa.

Figura 10: Esquemático da Classe de Aplicação 4.

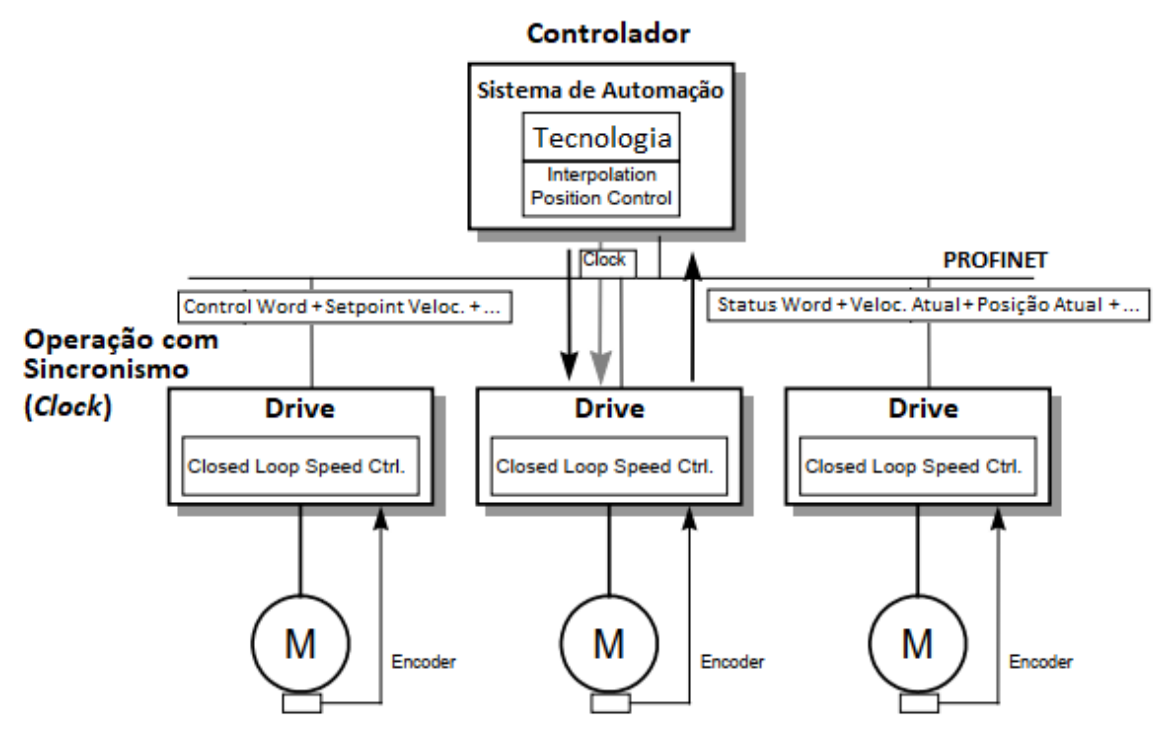

Fonte: Baseado de PROFIBUS Nutzerorganisation e.V. (2015)

AC5: controle de movimento com interpolação central e interface de setpoint de posição - similar a classe anterior, porém a interpolação é feita pelo controlador, enviando o setpoint de posição para cada drive, o que pode ser alcançada com a classe de aplicação 4 e funcionalidade DSC.

AC6: controle de movimento para processos sincronizados - aplicações como engrenagens elétricas, operação de sincronismo angular com troca de dados cíclica e operação com sincronismo de tempo são exigidas. Essas aplicações são normalmente 
realizadas com um drive mestre que gera informações do processo (posição atual) para os demais drives escravos que coordenam seus movimentos.

As classes de operação empregam diferentes tipos de telegramas padrões para sua operação e troca de dados entre o Controller e o P-device.

\subsubsection{Telegramas Padrão PROFIdrive}

O PROFIdrive define alguns telegramas padrões para interface de velocidade e posição entre dispositivos que compõem a aplicação de controle de movimento. Estes telegramas definem uma estrutura de dados para este tipo de aplicação utilizando palavras de controle, status, setpoint e valores atuais de variáveis de acordo com as diversas classes de aplicações, entre outras informações. Os telegramas são configurados no momento da parametrização do sistema. Algumas das principais palavras que compõem os pacotes ou telegramas PROFIdrive são apresentadas abaixo:

STW1 - Control Word 1: define o modo de operação da aplicação

STW2 - Control Word 2: define dados adicionais de controle, alguns específicos para cada fabricante

ZSW1 - Status Word 1: indica o estado de operação da aplicação

ZSW2 - Status Word 2: define dados adicionais de status, alguns específicos para cada fabricante

NSOLL__ - Setpoint de velocidade: informa o valor de referência de velocidade desejada pela aplicação $(-200 \%$ a $+200 \%$ da velocidade nominal $)$

NIST_x - Valor de velocidade atual: informa o valor da velocidade do eixo no instante atual

Gx_STW - Control Word: controla a funcionalidade do sensor (encoder)

Gx_ZSW - Staus Word: indica estado do sensor (encoder), reconhecimento de alarmes e mensagens de erro

Gx_XIST1 - Posição Atual 1: Valor da posição atual

Gx_XIST2 - Posição Atual 2: Valor adicional da posição atual

Os telegramas padrões do PROFIdrive são compostos por algumas palavras, as tabelas 1 e 2 apresentam as estruturas dos telegramas padrão empregados nesta tese.

Ainda são definidos os telegramas padrão 2, derivado do telegrama padrão 1, porém com setpoint de velocidade de 32bits, o telegrama padrão 4, derivado do telegrama 3 para dois sensores. Os telegramas padrão 5 e 6 são derivados dos telegramas 3 e 4 com a utilização adicional do Dynamics Servo Control (DSC). O telegrama 7 e 9 são designados para aplicações de posicionamento para classe de aplicação 3 e o telegrama 
Tabela 1: Estrutura do telegrama padrão 1, 16 bits.

\begin{tabular}{|c|c|c|}
\hline No Palavra & Setpoint & Valor Atual \\
\hline 1 & STW1 & ZSW1 \\
\hline 2 & NSOLL_A & NIST_A \\
\hline
\end{tabular}

Fonte: PROFIBUS Nutzerorganisation e.V. (2015).

Tabela 2: Estrutura do telegrama padrão 3, para UM sensor.

\begin{tabular}{|c|c|c|}
\hline No Palavra & Setpoint & Valor Atual \\
\hline 1 & STW1 & ZSW1 \\
\hline $\begin{array}{l}2 \\
3\end{array}$ & NSOLL_B & NIST_B \\
\hline 4 & $\begin{array}{l}\text { STW2 } \\
\end{array}$ & ZSW2 \\
\hline 5 & G1_STW & Z1_ZSW \\
\hline $\begin{array}{l}6 \\
7\end{array}$ & & G1_XIST1 \\
\hline $\begin{array}{l}8 \\
9\end{array}$ & & G1_XIST2 \\
\hline
\end{tabular}

Fonte: PROFIBUS Nutzerorganisation e.V. (2015).

8 para classe de aplicação 5 são classes não utilizadas nesta tese. O telegrama padrão 20 exclusivamente definido para interface de setpoint de velocidade de acordo com as recomendações VIK-NAMUR para utilização na classe de aplicação 1.

É importante ressaltar que algumas classes de aplicação utilizam telegramas específicos para troca de dados cíclicas de processo, como é o caso das classes 2 e 6 . Outros telegramas definidos pelo perfil PROFIdrive são utilizados por todas as classes para outras funcionalidades como telegramas de configuração, de falhas e alarmes. 



\section{CAPÍTULO 3 FERRAMENTAS MATEMÁTICAS E COM- PUTACIONAIS}

Nesta tese utiliza-se diversas ferramentas matemáticas e computacionais para a extração e redução de atributos dos dados de processo de redes de comunicação industriais, utilizadas no acionamento de motores elétricos, sistemas de inferência para reconhecimento de padrões baseados em ferramentas de aprendizagem de máquinas e estratégias para verificação e otimização do desempenho do sistema de diagnóstico proposto. Detalha-se então nas próximas seções, os modelos e algoritmos utilizados.

\subsection{Conceitos sobre Aprendizagem de Máquinas e Mineração de Dados}

O termo Machine Learning ou Aprendizagem de Máquinas trata-se de uma área de estudo derivada da Inteligência Artificial.

Ferramentas de aprendizagem de máquinas são utilizadas em uma ampla variedade de aplicações, como em reconhecimento de padrões: diagnósticos médicos, filtro de emails, visão computacional, reconhecimento de voz, detecção de vírus em computadores, ataques maliciosos em redes de comunicação, entre outros; e resolução de problemas e controle: controle de um robô móvel, dirigir veículos, jogar vídeo games, resolver problemas matemáticos, entre outros. Estas tarefas são normalmente inviáveis de serem feitas através de sistemas especialistas, que é desenvolvido a partir de um algoritmo que possui instruções específicas para desempenho da tarefa (KHANNA; AWAD, 2015).

Desta maneira, algoritmos advindos de Aprendizagem de Máquinas constroem um modelo matemático a partir de um conjunto de dados, conhecido como dados de treinamento, para fazer previsões ou decisões sem ser explicitamente programado para executar a tarefa (KHANNA; AWAD, 2015). Ou seja, o modelo matemático que resulta destes algoritmos foram "ensinados" ou "aprenderam"o comportamento de uma determinada tarefa ou sistema a partir destes dados de treinamento. A fonte dos dados de treinamento pode advir de diversas formas, como por exemplos aleatórios que podem ser de apenas um tipo de classe ou de várias classes; através de um conjunto de exemplos específicos; ou até mesmo diretamente de forma automática a partir de simulação ou interação com o ambiente.

Segundo Khanna e Awad (2015), os tipos de treinamentos podem ser classificados de acordo com os dados disponíveis:

- Treinamento Supervisionado: técnicas de aprendizagem que extraem associações 
entre atributos independentes e uma saída, que é conhecida ou rotulada. Este tipo utiliza dados de treinamento para desenvolver modelos preditores que necessitam de valores de entrada e saída. Assim, o algoritmo prevê a saída de uma nova amostra a partir dos dados de seus atributos.

- Treinamento Não-supervisionado: técnicas de aprendizagem agrupam as amostras sem o conhecimento de sua saída ou classe. Algoritmos de clusterização e redução de dimensionalidade normalmente são não-supervisionados.

Algoritmos de aprendizado automático quando treinados a partir de grande quantidade de dados, podem ser capazes de extrair um padrão de comportamento. Neste contexto, o termo mineração de dados pode ser definido como o processo de descoberta de padrões em um universo grande de dados que pode extrair informações significativas, provendo vantagens na aplicação de determinada tarefa a ser executada, normalmente vantagens econômicas (WITTEN; FRANCK, 2015). Assim, a mineração de dados caracteriza-se pelo processo de busca de informações relevantes a partir de uma massa de dados muito grande utilizando-se ferramentas matemáticas, de maneira automatizada ou semi automatizada (WITTEN; FRANCK, 2015). Os algoritmos de Aprendizagem de Máquinas podem ser utilizados como algoritmo de mineração de dados.

Por meio da mineração de dados busca-se solucionar problemas baseado na análise de dados que foram coletados e processados, envolvendo recursos multidisciplinares como ferramentas estatísticas, otimização, sistemas inteligentes para reconhecimentos de padrões, entre outros (LIBONI, 2017). Devido a grande variabilidade dos sinais disponíveis para análise, é quase impossível o reconhecimento de padrões de falhas diretamente, e portanto um sistema de diagnóstico se torna uma excelente alternativa (LIU et al., 2018).

Os algoritmos de aprendizagem de máquinas podem ser construídos conforme apresenta Khanna e Awad (2015):

1. Coleta de dados: Seleção de um conjunto de dados que podem ser úteis para a resolução do problema. Utilização de uma grande quantidade de características pode ser desnecessário e até contraprodutivo.

2. Pré-processamento de dados: Apresentar os dados de maneira que fique entendível para os consumidores destes dados, como classificadores para reconhecimento de padrão. Normalmente são executadas etapas de formatação, para correta apresentação de dados em um formato utilizável; limpeza, que trata-se da tarefa como remover inconsistências, normalizar valores, discretizar valores entre outros); e finalmente executar amostragem, definir o intervalo de amostragem. 
3. Transformar os Dados: Transformar os dados para utilização no algoritmo e de forma a aprender o comportamento do problema. Pode ser na forma de seleção de atributos, decomposição ou agregamento de características importantes.

4. Treinar o Algoritmo: Selecionar os conjuntos de treinamento e teste dos dados transformados. O conjunto de treinamento é utilizado no processo de aprendizagem do algoritmo de maneira que seja capaz de extrair conhecimento ou informação do comportamento do sistema. O conjunto de teste avalia seu desempenho.

5. Testar o Algoritmo: Avalia-se o desempenho do algoritmo, normalmente utilizando alguns indicadores que serão apresentados na seção 4.6. Caso o desempenho não seja satisfatório, os passos anteriores devem ser repetidos alterando aspectos como dados, taxa de amostragem, transformações, remoção de outliers, entre outros.

6. Aplicar Reforço de Aprendizagem: Pode-se empregar técnica chamada de reequilíbrio de desempenho dinâmico para que o algoritmo aprenda com as consequências das interações com o ambiente, sem um treinamento explícito, como é o caso do treinamento supervisionado.

7. Executar o Algoritmo: Aplicar o modelo validado para executar a tarefa de predição proposta. O processo de treinamento pode coexistir com a tarefa real de prever o comportamento futuro.

Um requisito importante para as técnicas de Aprendizagem de Máquinas é que elas sejam capazes de lidar com dados imperfeitos, denominados ruídos. Muitos conjuntos de dados apresentam esse tipo de problema. Alguns erros comuns são a presença de dados com rótulos e/ou atributos incorretos (LORENA; CARVALHO, 2007). Outro conceito comumente empregado em Aprendizagem de Máquinas é o de generalização de um classificador, definida como a sua capacidade de prever corretamente a classe de novos dados. No caso em que o modelo se especializa nos dados utilizados em seu treinamento, apresentando uma baixa taxa de acerto quando confrontado com novos dados, tem-se a ocorrência de um superajustamento ou chamado (overfitting). É também possível induzir hipóteses que apresentem uma baixa taxa de acerto mesmo no subconjunto de treinamento, configurando uma condição de subajustamento (underfitting). Essa situação pode ocorrer, por exemplo, quando os exemplos de treinamento disponíveis são pouco representativos ou quando o modelo obtido é muito simples (LORENA; CARVALHO, 2007).

A utilização de redes de comunicação industrial e equipamentos inteligentes com mais funcionalidades em aplicações de acionamentos de motores elétricos criam uma estrutura capaz de disponibilizar uma grande quantidade de dados sobre o funcionamento e status das máquinas, possibilitando além do controle do processo, o gerenciamento e diagnóstico dentro do sistema produtivo. Por isso, justifica-se a utilização de algoritmos de 
Aprendizagem de Máquinas para desenvolvimento de uma metodologia para desenvolver sistemas de diagnóstico proposto por esta tese.

\subsection{Extração e Redução de atributos}

Os sinais gerados pelo sistema de medição utilizados na instrumentação de sistemas dinâmicos carregam grande quantidade de informação sobre a aplicação monitorada, como é o caso de acionamentos de motores elétricos, onde suas condições de operação podem gerar sinais com diferentes comportamentos ou assinaturas.

A extração de atributos de um sinal visa se obter para cada amostra coletada um vetor de características que a descrevem, ou seja, se extraem valores matemáticos que possuem informações relevantes do sinal, ou seja, da aplicação, que pode ser analisado, por exemplo com ferramentas de mineração de dados e aprendizagem de máquinas.

A figura 11 representa de forma simplificada um conjunto com $n$ amostras ou instâncias. Cada dado $x_{i}$ possui $m$ atributos ou características. Assim, uma amostra pode ser descrita como um conjunto de características $x_{i}=\left(x_{i} 1, \ldots, x_{i} m\right)$. As variáveis $y_{i}$ representam as classes de cada amostra.

Figura 11: Exemplo de dados estruturados utilizados em Aprendizagem de Máquinas.

\begin{tabular}{|c|c|c|c|c|c|}
\hline \multirow{5}{*}{ 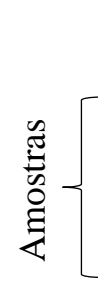 } & \multicolumn{4}{|c|}{ Atributos } & \multirow{2}{*}{ y } \\
\hline & $\mathrm{X}_{11}$ & $\mathrm{X}_{12}$ & $\ldots$ & $\mathrm{X}_{1 \mathrm{~m}}$ & \\
\hline & $\mathrm{X}_{21}$ & $\mathrm{X}_{22}$ & $\ldots$ & $\mathrm{X}_{2 \mathrm{~m}}$ & $\mathrm{y}_{2}$ \\
\hline & $\ldots$ & $\ldots$ & $\ldots$ & $\ldots$ & $\ldots$ \\
\hline & $\mathrm{X}_{\mathrm{n} 1}$ & $\mathrm{X}_{\mathrm{n} 2}$ & $\ldots$ & $\mathrm{X}_{\mathrm{nm}}$ & $\mathrm{y}_{\mathrm{n}}$ \\
\hline
\end{tabular}

Fonte: Elaborado pelo autor.

A quantidade de atributos pode ser muito elevada, comprometendo a eficácia da utilização de ferramentas de aprendizagem de máquinas diretamente, devido a necessidade de recursos computacionais elevados. Alguns algoritmos para reconhecimento de padrões podem obter uma piora em seu desempenho quando empregados com grande quantidade de atributos. Segundo Witten e Franck (2015), um número elevado de atributos irrelevantes pode "atrapalhar" ferramentas de classificação de padrões em sua decisão.

Assim, a redução de dimensionalidade ou seleção de atributos em um problema de identificação de padrões, é de suma importância pois faz-se possível levantar um conjunto de atributos menor, com informações mais relevantes ou úteis para a identificação de um certo padrão. Torna-se importante verificar quais atributos ou combinação de atributos estão mais relacionados a um certo padrão ou classe apresentado. 
Liboni (2017) diz que a seleção de atributos oferece aos sistemas de aprendizado um conjunto de dados mais compacto e relevante, melhorando o desempenho destes algoritmos no problema de identificação de padrões proposto.

Consequentemente, para a utilização de sistemas de inferência na classificação de padrões deste trabalho, não é recomendado a utilização de todos os atributos extraídos, tornando necessário a seleção de atributos que servirão como entrada para estes sistemas, de maneira a reduzir a dimensionalidade do problema estudado, evitando problemas de classificação e reduzindo o esforço computacional.

Na comunidade científica se encontram diversos algoritmos para seleção de atributos de forma automática empregando diferentes heurísticas. Normalmente emprega-se medidas estatísticas, como ganho de informação e correlação linear.

Segundo (GUYON et al., 2002) existem três abordagens possíveis para seleção de atributos:

- Filter: que exigem menor esforço computacional em relação a outras abordagens e são independentes do algoritmo de aprendizagem de máquinas utilizado, porém podem resultar em problemas de generalização. São recomendados quando existe grande quantidade de atributos;

- Wrapper: selecionam as melhores características para cada tipo de algoritmo específico, resultando em boa precisão, porém exigindo grande esforço computacional;

- Embarcados: incorpora o processo de seleção de atributos no processo de aprendizagem do algoritmo, e portanto são específicos para cada algoritmo.

Para este trabalho foram utilizadas as técnicas do tipo filter devido a grande quantidade de atributos envolvida. As seguintes técnicas serão investigadas: Correlationbased Feature Selection (CFS) e Principal Component Analysis (PCA).

\subsubsection{Correlation-based Feature Selection (CFS)}

O CFS é um algoritmo que seleciona as características mais importantes de um conjunto de dados de acordo com sua correlação com a saída, baseado numa função de avaliação heurística. Pode-se considerar adicionalmente a correlação entre características selecionadas, ou correlação mútua. Assim, em um problema de classificação de padrões, as características selecionadas são as que possuem maior correlação com o padrão a ser identificado, ou classe desejada, e que possuem menor correlação mútua. Trata-se de um algoritmo supervisionado, uma vez que requer a informação ou rótulo da classe para 
cálculo dos atributos. Uma métrica muito utilizada, é o mérito do subconjunto de atributos selecionados, dado pela equação 3.1 .

$$
M_{s}=\frac{k \overline{r_{c f}}}{\sqrt{k+k(k-1) \overline{r_{f f}}}}
$$

onde $M s$ é a heurística "Mérito"de um subconjunto de atributos que contém $k$ atributos selecionados; $\overline{r_{c f}}$ é o valor médio da correlação entre atributo e classe e $\overline{r_{f f}}$ é o valor médio da correlação mútua entre atributos (HALL, 1999).

O valor da correlação pode ser obtido de diferentes maneiras, quando todos os atributos do conjunto de dados são numéricos, a correlação linear de Pearson pode ser empregada (HALL, 1999). Esta correlação é dada pela equação 3.2. O valor deste tipo de correlação deve ser empregado para conjunto de dados contínuos.

$$
r=r_{x y}=\frac{\sum x_{i} y_{i}-n \overline{x y}}{\sqrt{\left(\sum x_{i}^{2}-n \bar{x}^{2}\right)} \sqrt{\left(\sum y_{i}^{2}-n \bar{y}^{2}\right)}}
$$

O algoritmo CFS é uma técnica capaz então de gerar um ranking com todos os subconjuntos de características possíveis de acordo com o valor do seu mérito, assim definindo-se o melhor subconjunto de atributos capaz de representar as classes. O software WEKA, de livre distribuição, possui a técnica do CFS implementado utilizando algumas estratégias de busca do melhor subconjunto, uma vez que a verificação de todas os subconjuntos possíveis pode ser computacionalmente proibitivo. Alguns exemplos são: hill climbling, best first e gridystepwise. Mais detalhes acerca do algoritmo CFS podem ser encontrados em Hall (1999). A figura 12 apresenta graficamente o processo de seleção de atributos.

\subsubsection{Principal Component Analysis (PCA)}

O PCA é outro algoritmo muito utilizado na redução de dimensionalidade para grande volume de dados. Trata-se de um algoritmo do tipo não-supervisionado. Ele utiliza uma transformada ortogonal que converte um conjunto de dados que são possivelmente correlatos em um conjunto de dados linearmente não correlacionados, chamado de componentes principais (Feng et al., 2018). Desta maneira um conjunto de dados que possuem correlação elevada, pode ser representado sem perda significativa de informação por um conjunto menor de dados, representados pelas componentes principais, que possui menor dimensão. Todas as componentes principais são ortogonais entre elas, não existindo portanto informação redundante a ser utilizada nos classificadores.

Considerando um conjunto de variáveis $\mathbf{X}=\left(X_{1}, \ldots, X_{p}\right)$ é possível encontrar uma combinação para produzir índices $\mathbf{Y}=\left(Y_{1}, \ldots, Y_{p}\right)$, não correlacionados e que descrevam as variações dos dados, de forma que a maior parcela da variação seja representada por 
Figura 12: Esquemático do algoritmo CFS.

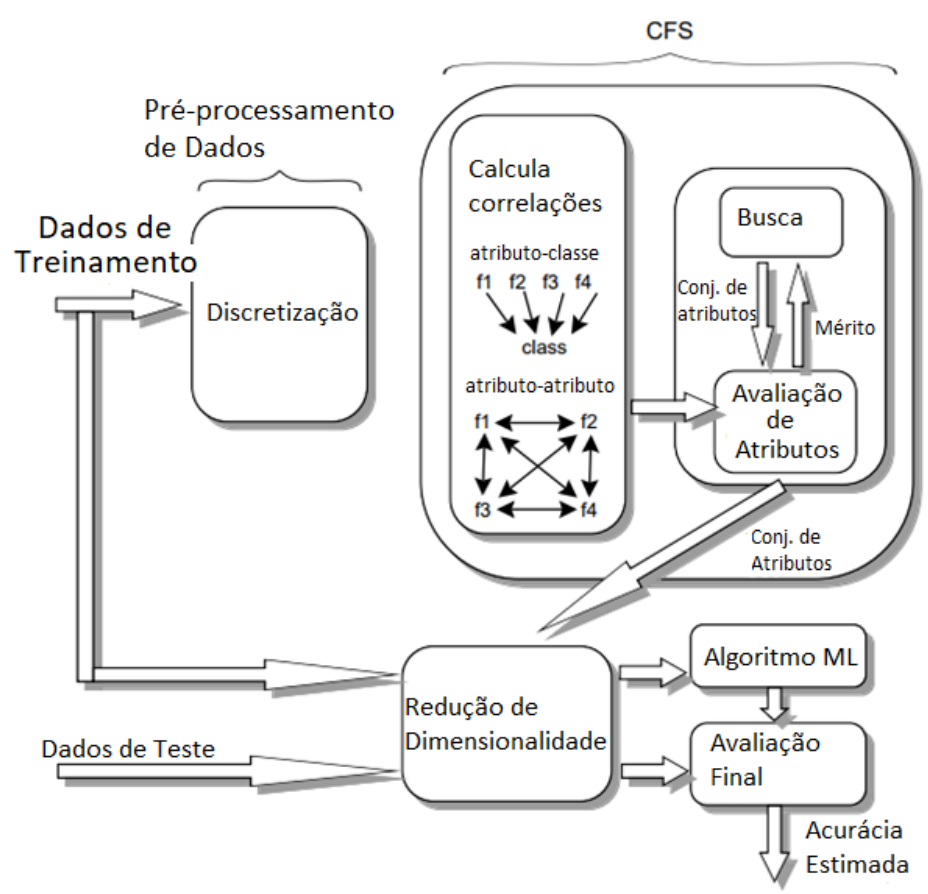

Fonte: Adaptado de Hall (1999).

poucos atributos de $\mathbf{Y}$. Assim, deseja-se encontrar a combinação linear dos elementos do vetor $\mathbf{X}$, dado pela equação 3.3 .

$$
Y=a^{t} X=a_{1} X_{1}+\ldots+a_{p} X_{p}
$$

Sendo matriz de covariância de $\mathbf{X}$ dado por $\Sigma$, cujos autovalores são $\lambda_{1} \geq \lambda_{2} \geq$ $\ldots \geq \lambda_{p}$ e os autovalores associados $e_{1}, \ldots, e_{p}$, tem-se que as seguintes combinações lineares conforme equação 3.4 :

$$
Y_{i}=a_{i}^{t} X=a_{i} 1 X_{1}+\ldots+a_{i} p X_{p}
$$

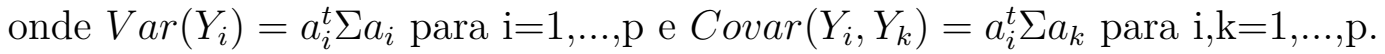

Finalmente, escolhe-se os valores de $a_{i}$ como sendo os autovetores $e_{i}$ da matriz de covariância, chega-se a equação 3.5, da $i$-éssima componente principal.

$$
Y_{i}=e_{i}^{t} X=e_{i} 1 X_{1}+\ldots+e_{i} p X_{p}
$$

onde $\operatorname{Var}\left(Y_{i}\right)=e_{i}^{t} \sum e_{i}$ para $\mathrm{i}=1, \ldots, \mathrm{p}$ e $\operatorname{Covar}\left(Y_{i}, Y_{k}\right)=e_{i}^{t} \Sigma e_{k}$ para $\mathrm{i}, \mathrm{k}=1, \ldots, \mathrm{p}$.

Para utilização da técnica PCA como redução de atributos, emprega-se um número inferior de componentes principais em relação a quantidade de atributos do conjunto 
original, que seja capaz de representar todo o conjunto de dados. Neste trabalho, a metodologia a ser descrita adiante, sugere a utilização de uma quantidade crescente de componentes principais de um conjunto de dados como entrada de um classificador para detecção de anomalias, até que se obtenha acurácia satisfatória.

A figura 13 apresenta um exemplo de utilização da técnica PCA, representando graficamente uma componente principal de um conjunto de dados bidimensional.

Figura 13: Direção da primeira componente principal v de um conjunto de dados com dois atributos.

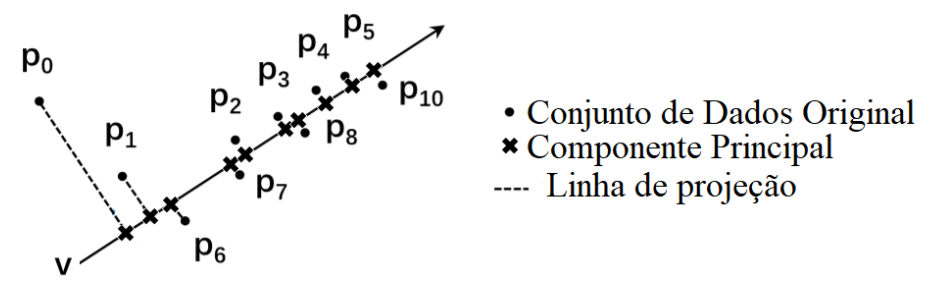

Fonte: Adaptado de Feng et al. (2018)

Nota-se que o conjunto de dados é composto por dois eixos ou atributos, e que a utilização de uma única componente principal a partir da técnica PCA resulta em um único atributo, que é uma correlação linear dos atributos.

Mais detalhes sobre análise teórica desta técnica estão fora do escopo deste trabalho e podem ser encontradas em Johnson e Wichern (2007) e McNames (2001).

\subsection{Sistemas de Inferência}

Sistemas de inferência foram empregados na metodologia desenvolvida com objetivo de classificar padrões na operação de acionamentos de motores elétricos. O objetivo é identificar máquinas operando em condição saudável ou condição anômala ou faltosa. Essas ferramentas são baseadas em técnicas de aprendizagem de máquinas.

\subsection{1 $k$-Nearest Neighbor $(k-\mathrm{NN})$}

O $k$-Nearest Neighbor é um algoritmo de aprendizado supervisionado, também conhecido como aprendizado baseado em instâncias ou exemplos e aprendizado tipo "lazy". Este algoritmo foi apresentado por Aha, Kibler e Albert (1991). Neste algoritmo, novas amostras são classificadas com base na comparação direta e na similaridade em relação as amostras de treinamento. Essa similaridade é verificada através da utilização de uma função que calcula a distância, utilizada como uma medida de similaridade, entre as amostras. Assim, a ideia consiste em classificar uma nova amostra baseada nas $k$ amostras mais próximas. 
$\mathrm{Na}$ fase de treinamento, o algoritmo requer pouco esforço computacional, porém para classificação de uma nova amostra, o esforço pode ser alto, uma vez que pode ocorrer a necessidade de se calcular a distância entre todas as amostras de treinamento, que pode ser elevada de acordo com o domínio e quantidade de amostras de treinamento necessária para mapeamento adequado do problema. A figura 14 apresenta graficamente o processo de classificação do algoritmo para valores de $k$ vizinhos igual a 5 .

Figura 14: Classificação utilizando algoritmo kNN com k=5.

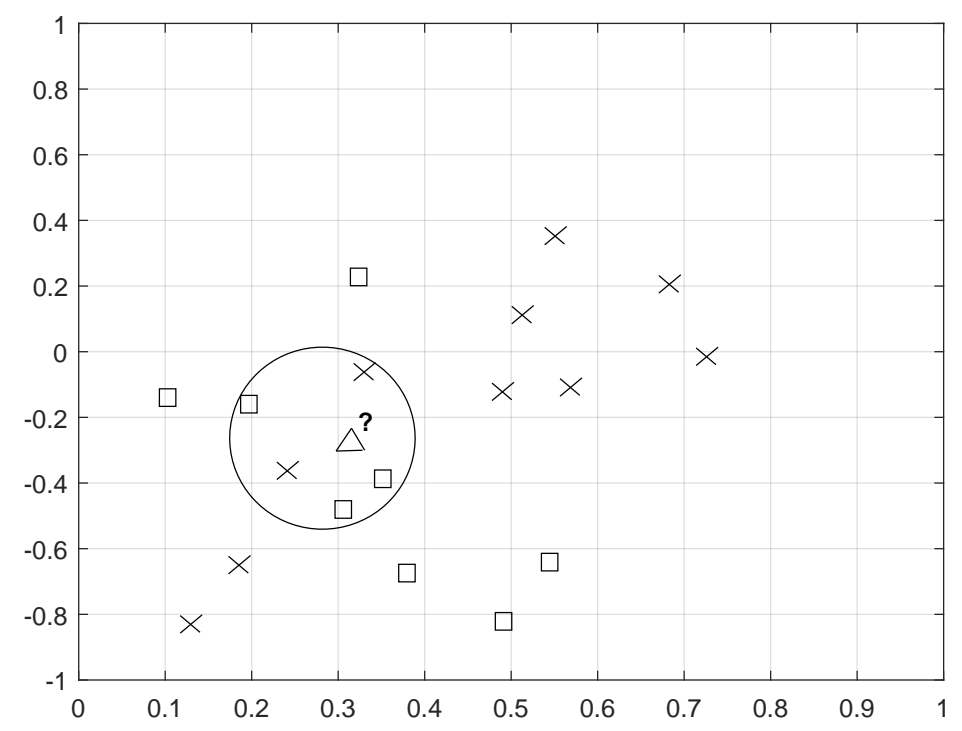

Fonte: Elaborada pelo autor.

Existem diversas medidas de distância, para todos elas, é importante normalizar os valores dos atributos das amostras, para compensar diferenças de unidades. Algumas medidas de distância são:

- Distância Euclidiana: para atributos de valores contínuos, a distância euclidiana é a mais utilizada. Dada pela equação 3.6.

$$
d(x, y)=\sqrt{\sum_{i=1}^{n}\left(x_{i}-y_{i}\right)^{2}}
$$

onde $n$ é a dimensão das amostras.

- Distância de Mahalanobis: trata-se de uma variação da distância Euclidiana, pois considera variações estatísticas das amostras. O cálculo da distância é dado pela equação 3.7 .

$$
d(x, y)=\left[(x-y)^{T} \cdot C^{-1} \cdot(x-y)\right]^{1 / 2}
$$


onde C é uma matriz de covariância.

- Distância Manhattan: também conhecida como "city block", onde a distância entre duas amostras, é a soma das diferenças absolutas do valor de seus atributos. Dado pela equação 3.8 .

$$
d(x, y)=\sum_{i=1}^{n}\left|x_{i}-y_{i}\right|
$$

onde $n$ é a dimensão das amostras.

- Distância de Minkowski: trata-se de uma generalização das distâncias euclidiana e Manhattan. Quando $r=2$, refere-se a distância euclidiana e $r=1$ a distância de Manhattan. Dado pela equação 3.9.

$$
d(x, y)=\left(\sum_{i=1}^{n}\left(x_{i}-y_{i}\right)^{r}\right)^{\frac{1}{r}}
$$

onde $n$ é a dimensão das amostras e $r$ é um parâmetro da equação de distância.

- Distância Levenshtein: utilizado para verificação de similaridade entre cadeias de caracteres. Definido como o número mínimo de operações de edição para transformar uma amostra contendo uma cadeia de caracteres igual a outra amostra dada. As operações de edição devem ser efetuadas e apenas uma cadeia de caracteres.

Em sua operação, o algoritmo kNN calcula a distância, utilizando um tipo dado de medida, entre uma nova amostra de teste e cada amostra de treinamento. Se ajusta o hiper-parâmetro $k$, como sendo a quantidade de vizinhos mais próximos a amostra. Classifica-se a nova amostra com base na classe mais frequente entre os vizinhos mais próximos.

A metodologia proposta, utilizou a medida de distância euclidiana e se utilizou um método de validação cruzada para determinar o valor de $k$ que possui melhor desempenho do problema dado. A literatura deste algoritmo sugere utilizar valor de $k$ ímpar para evitar condições de empates em classificações binárias. Existem algumas variações do algoritmo $\mathrm{kNN}$, como o kNN ponderado, utilizado como forma de reduzir a sensibilidade da escolha do valor do hiper-parâmetro $k$. Assim, cada vizinho selecionado contribui com um peso, podendo ser através da ponderação da influência no valor final de cada vizinho de acordo com sua medida de distância em relação a nova amostra a ser classificada.

O algoritmo ainda pode ser utilizado além de classificações de padrões, para estimar valores de uma função real, ou seja, regressão, através da média entre os vizinhos mais próximos. 


\subsubsection{Redes Neurais Artificiais (RNA)}

As redes neurais artificiais (RNA) são modelos computacionais inspirados no sistema nervoso de seres vivos, que possuem capacidade de aquisição de conhecimento (baseado em informações), e são compostas por um conjunto de unidades de processamento ou neurônios artificiais interligados por um grande número de conexões, que fazem a função comparáveis às conexões sinápticas (SILVA; SPATTI; FLAUZINO, 2010).

Estes sistemas são comumente utilizados para uma vasta gama de tarefas na área de engenharia, como: classificação e reconhecimento de padrões, aproximador universal de função, agrupamento de dados ou clusterização, previsões e mesmo para operações de controle de processos, normalmente com aspectos não-lineares, entre outras.

\section{Principais características}

A estrutura das redes neurais artificiais foi desenvolvida a partir de modelos conhecidos de sistemas nervosos biológicos e do próprio cérebro humano. Os elementos computacionais ou unidades processadoras, denominadas neurônios artificiais, são modelos bem simplificados dos neurônios biológicos (SILVA; SPATTI; FLAUZINO, 2010). O modelo simplificado apresentado por McCulloch e Pitts em 1943 pode ser descrito como um modelo com $n$ entradas (dendritos), representado pelas variáveis $x_{1}, x_{2}, \ldots, x_{n}$ e uma saída (axônio), representado pela variável $y$. A influência de cada entrada na resposta deste unidade de processamento é influenciada por pesos sinápticos, dados por $w_{1}, w_{2}, \ldots, w_{n}$. A Figura 15 apresenta o diagrama deste neurônio artificial.

Figura 15: Neurônio Artificial.

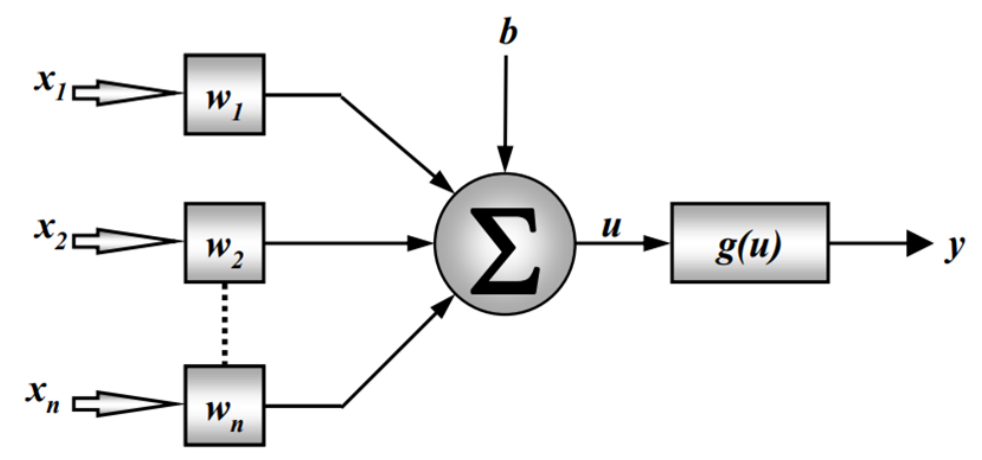

Fonte: Retirado de SILVA, SPATTI e FLAUZINO (2010).

Assim, tem-se que o neurônio artificial é composto por sete elementos essenciais (SILVA; SPATTI; FLAUZINO, 2010):

- Sinais de entrada $(x 1, x 2, \ldots, x n)$ : sinais de entrada advindos de meio externo que representam os valores assumidos pelas variáveis de uma aplicação específica, ou 
seja, são os atributos selecionados dos dados monitorados de um sistema que são normalmente pré-processados;

- Pesos sinápticos $(w 1, w 2, \ldots, w n)$ : são os valores que servirão para ponderar os sinais de entrada, quantificando suas respectivas relevâncias;

- Combinador linear $\left(\sum\right)$ : função de agregar os sinais ponderados de entrada;

- Limiar de ativação (b): é uma variável que especifica o patamar apropriado para que o resultado produzido pelo combinador linear gere valor de disparo na saída do neurônio;

- Potencial de ativação $(u)$ : resultado da diferença do valor produzido entre combinador linear e o limiar de ativação, fazendo com que o neurônio produza um potencial excitatório ou inibitório;

- Função de ativação $(g)$ : limita a saída do neurônio dentro de um intervalo de valores razoáveis;

- Sinal de saída $(y)$ : valor final produzido pelo neurônio.

Desta maneira, as equações 3.10 e 3.11 sintetizam o resultado produzido pelo neurônio artificial proposto por McCulloch e Pitts:

$$
\begin{gathered}
u=\sum_{i=1}^{n} w_{i} \cdot x_{i}-b \\
y=g(u)
\end{gathered}
$$

Existem diversas funções de ativação, que devem ser empregadas de acordo com o problema em questão. Algumas delas são: função degrau, degrau bipolar, função rampa, logística, tangente hiperbólica, gaussiana, linear, entre outras.

\section{Arquiteturas de redes neurais artificiais}

As arquiteturas das RNAs definem a forma como os seus diversos neurônios artificiais estão interligados e no direcionamento das informações entre eles. Adicionalmente existem diversas topologias que podem ser definidas como as diferentes formas de composições estruturais que a RNA pode assumir (SILVA; SPATTI; FLAUZINO, 2010). Uma RNA pode ser dividida em três partes:

- Camada de entrada: responsável pelo recebimento das informações, ou seja, dos atributos normalizados e selecionados previamente. É a camada responsável pela entrada das medições ou sinais advindos do meio externo a partir de amostragens realizadas por experimentos ou simulações; 
- Camadas intermediárias ou ocultas: responsáveis por extrair características associadas ao processo ou sistema a ser inferido. Neste trabalho, se extrai as características dos padrões a serem classificados;

- Camada de saída: responsável pela apresentação dos resultados finais da rede.

As arquiteturas de RNA consideram a disposição dos neurônios, formas de interligação e constituição de suas camadas. Podem ser dividas em:

- Redes Feedforward (camada única): caracteriza-se por ter uma única camada de neurônios de entrada e de saída. O fluxo de informação segue numa única direção, da camada de entrada para a camada de saída. Normalmente utilizadas em classificação de padrões e filtragem linear;

- Redes Feedforward (multicamadas): são constituídas pela presença de uma ou mais camadas escondidas de neurônios. Empregadas na solução de diversos tipos de problemas, como: aproximação de funções, classificação de padrões, identificação de sistemas, controle de processos, etc. Os principais tipos são o Perceptron multicamadas e a Função Base Radial.

- Redes recorrentes ou realimentada: são redes em que os sinais dos neurônios de saída são realimentados como sinais de entrada para outros neurônios. Assim, estas redes têm capacidade de utilizar seu comportamento com relação a padrões anteriormente apresentados, sendo utilizadas por exemplo na previsão de séries temporais, otimização e identificação de sistemas e controle de processo. Os principais tipos são Perceptron com realimentação e redes de Hopfield;

- Redes em estrutura reticulada: consiste na disposição espacial de seus neurônios visando propósito de extração de características. As aplicações são bem diversificadas, como clusterização, otimização de sistemas e grafos. A rede de Kohonen é a principal representante(SILVA; SPATTI; FLAUZINO, 2010).

\section{Perceptron multicamadas}

As redes Perceptron multicamadas (PMC) são tipos de redes mais usadas em problemas envolvendo classificação de padrões ou aproximação de função não lineares (TURCATO, 2015). Este tipo de rede pertence a arquitetura feedforward de multicamadas com treinamento realizado de forma supervisionada. A figura 16 apresenta uma estrutura PMC.

Neste tipo de RNA, as informações são apresentadas na camada de entrada. As camadas escondidas são responsáveis por extrair conhecimento por meio dos pesos sinápticos 
Figura 16: Perceptron multicamadas.

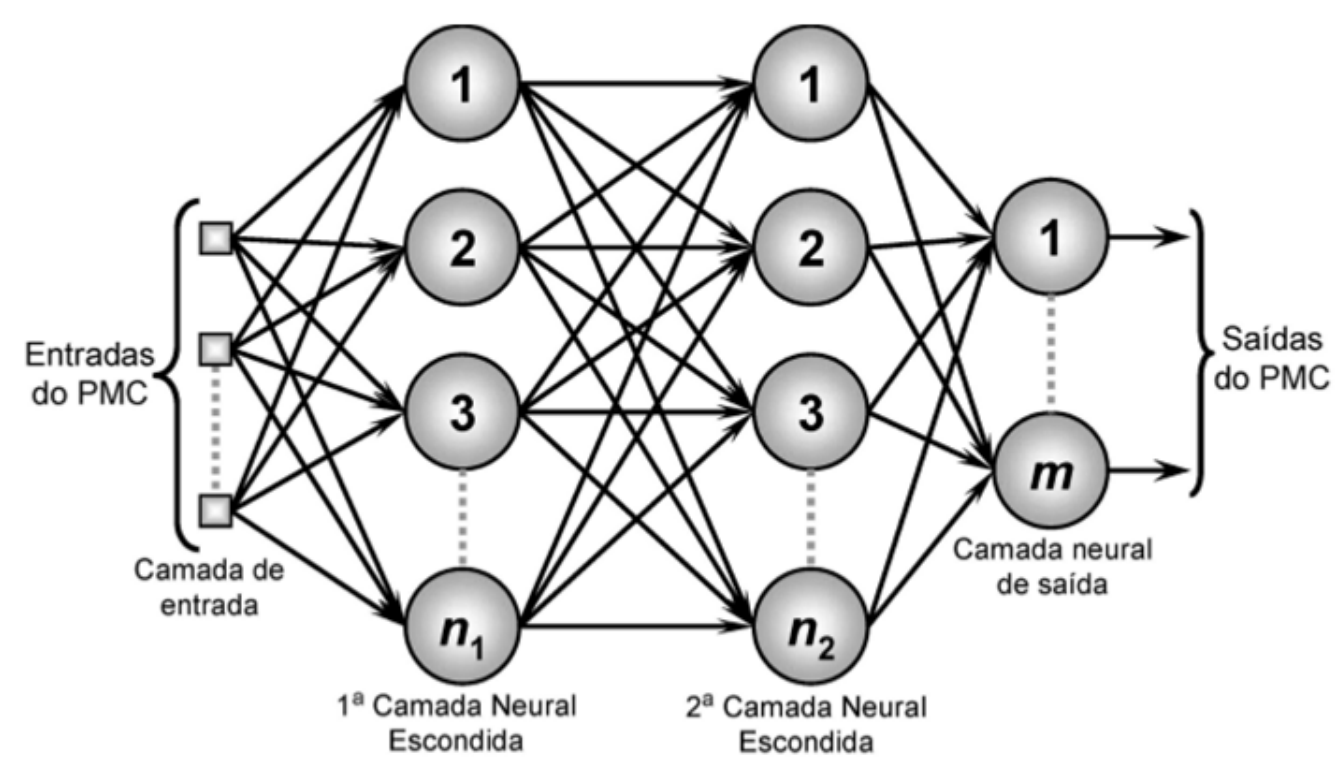

Fonte: Retirado de SILVA, SPATTI e FLAUZINO (2010).

e limiares de ativação de forma a modelar o sistema. Os neurônios da camada de saída, recebem os valores e produzem uma resposta final (SILVA; SPATTI; FLAUZINO, 2010).

O número de camadas escondidas está relacionado a capacidade de aprendizagem. Em aplicações de classificações de padrões, apenas uma camada escondida é capaz de separar conjuntos convexos. Caso os conjuntos a serem separados na classificação sejam não-convexos, um maior número de camadas escondidas se faz necessário.

\section{Processo de treinamento de redes neurais artificiais}

As redes neurais artificiais são capazes de aprender a partir da apresentação de amostras que exprimem o comportamento de um sistema, e a partir deste ponto a rede se torna capaz de produzir uma saída próxima daquela desejada a partir de outras amostras inseridas. O processo de treinamento de uma rede neural consiste da aplicação de passos ordenados para sintonização dos pesos sinápticos e limiares dos neurônios artificiais, tendo como objetivo final a generalização de soluções (SILVA; SPATTI; FLAUZINO, 2010).

No processo de projeto de uma RNA, se divide o conjunto de amostras coletadas no sistema entre amostras de treinamento e teste. O conjunto de treinamento é utilizado no processo de aprendizagem da RNA e com as amostras de teste se verifica seu desempenho, concluindo se houve generalização das soluções que atenda a necessidade do problema. $\mathrm{O}$ treinamento pode ser do tipo supervisionado ou não-supervisionado, conforme apresentado anteriormente.

O processo de treinamento do PMC é realizado com a utilização do algoritmo backpropagation, de forma supervisionada e off-line, ou seja, os ajustes dos pesos sinápticos 
e limiares são efetivados após apresentação de todo o conjunto de treinamento.

O algoritmo é realizado através de duas fases. A fase forward, onde os sinais de entrada são propagados camada-a-camada até gerar a saída, considerando os pesos sinápticos e limiares de ativação atual da rede. Em seguida, executa-se a fase backward, onde a resposta gerada pela fase anterior é comparada com a resposta desejada, resultando em um erro. A partir deste erro, ocorre os ajustes dos pesos sinápticos e limiares de todos os neurônios da rede. Este procedimento é realizado utilizando-se todas as amostras de treinamento da rede.

Diversas técnicas têm sido incorporadas ao algoritmo backpropagation com intuito de reduzir o tempo de convergência, diminuir esforço computacional e mesmo melhorar a acurácia do sistema. Dentre as técnicas utilizadas podem ser destacadas a utilização do termo momentum, método resiliente-propagation e o método Levenberg-Marquardt (Hagan; Menhaj, 1994).

O algoritmo de backpropagation com o termo momentum torna o processo de convergência do treinamento da RNA mais eficiente. Se a solução atual estiver longe da solução final, a variação entre as matrizes de peso entre duas iterações consecutivas será grande e, nesta situação, pode-se aumentar o passo do incremento em direção ao mínimo da função erro. Quando a solução atual estiver bem próxima da solução final, as variações nas matrizes de peso serão pequenas e, consequentemente, a contribuição do termo momentum para a convergência fica reduzida (LIBONI, 2017)

A evolução global do desempenho do algoritmo é verificada através do erro quadrático médio, dado pela equação 3.12 , onde $\mathrm{E}(\mathrm{k})$ representa o erro entre a saída da RNA e o valor desejado da amostra $k$.

$$
E_{M}=\frac{1}{p} \sum_{k=1}^{p} E(k)
$$

onde $p$ é a quantidade de amostras do conjunto a ser avaliado que pode ser treinamento e/ou teste.

Entretanto, esta tese emprega o método de Levenberg-Marquardt, que tem por objetivo reduzir o esforço computacional e tempo no processo de ajuste da RNA, potencializando a eficiência do processo de treinamento. Neste algoritmo as funções de erro quadrático e erro quadrático médio podem ser expressos conjuntamente conforme mostra a equação 3.13, buscando-se assim a minimização da função $V(z)$ em relação a um valor paramétrico $z$.

$$
V=\frac{1}{2 p} \sum_{k=1}^{p} E^{T}(k) \cdot E(k)
$$


Neste processo iterativo, não é mais necessário o calculo da matriz Hessiana (matriz de derivada de segunda ordem), sendo necessário apenas o cálculo da matriz Jacobiana (matriz de derivadas de primeira ordem) de $V(z)$. Por intermédio da implementação destas modificações, verifica-se que o método de Levenberg-Marquardt consegue conduzir o treinamentos de RNA do tipo Perceptron Multicamadas na ordem de 10 a 100 vezes mais rápido em relação ao algoritmo backpropgation convencional (Hagan; Menhaj, 1994). O software MATLAB possui uma toolbox, chamada patternnet que possui este algoritmo implementado.

Para mais informações sobre a aplicação deste algoritmo, sugere-se consulta em Haykin (2009), SILVA, SPATTI e FLAUZINO (2010) e Silva et al. (2016).

\subsubsection{Support Vector Machine (SVM)}

Support Vector Machines (SVM) são algoritmos de aprendizagem de máquinas utilizados para classificação de padrões que vem apresentando melhores resultados em relação a outros métodos de classificação.

O SVM é baseado no princípio da Minimização do Risco Estrutural, o que permite desenvolver máquinas de aprendizado com maior capacidade de generalização e superar problemas de overfitting na classificação dos dados (ALMEIDA, 2002).

\section{Principais características}

Os primeiros trabalhos foram apresentados por Boser, Guyon e Vapnik (1992) e Vapnik (1998), este último com uma definição mais detalhada. O algoritmo tinha como objetivo maximizar a margem entre duas classes de amostras, utilizando um hiperplano de separação, gerado a partir de vetores suporte, os quais seriam os mais importantes para o posicionamento deste hiperplano.

Inicialmente, os algoritmos eram capazes de classificar duas classes com dados linearmente separáveis, chamados de SVM com margem rígida (hard margins). Posteriormente o algoritmo foi sendo aprimorado, e estratégias para classificação de dados não-linearmente separáveis passaram a ser implementadas, como a implementação de erros mínimos de classificação (GUYON, 1999), chamado de SVM com margens flexíveis ou suaves (soft margins). Ademais, foi implementado a utilização do conceito de função kernel, para este tipo de aplicação.

\section{SVM com margens rígidas}

Considerando amostras linearmente separáveis, cada amostra denominada $x(i)$ com $\mathrm{n}$ atributos, sendo $\left(x_{1}, x_{2}, \ldots, x_{n}\right)$, correspondentes as classes $\mathrm{y}$, com y $\{+1,-1\}$, determinase o hiperplano que separa as amostras. Para minimização do erro de generalização, deve-se maximizar a margem $\mathrm{T}$, a distância mínima entre um hiperplano de separação de duas classes e os dados de entrada de cada classe que estejam mais próximas a esse hiperplano 
(BENNETT; CAMPBELL, 2000). A figura 17 apresenta o modo de posicionamento do hiperplano em relação as amostras e a margem $\mathrm{T}$ a ser maximizada.

Figura 17: Hiperplanos de separação de classes (a) Possível hiperplano (b) Hiperplano de separação com margem maximizada.

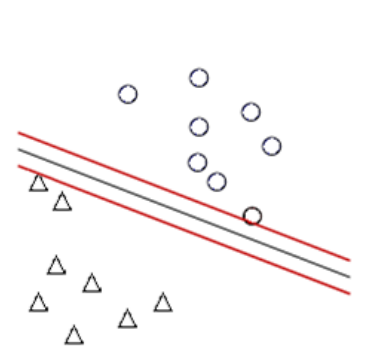

(a)

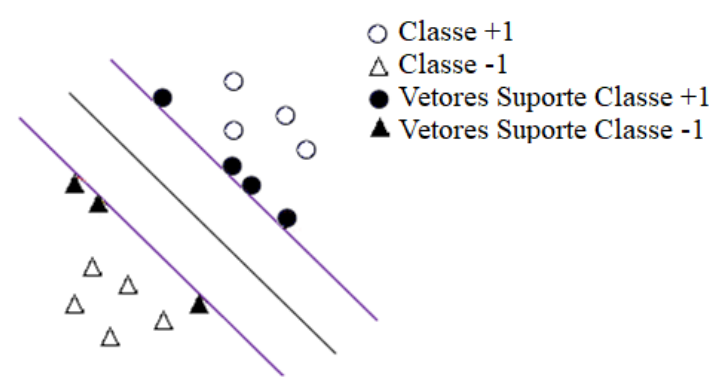

(b)

Fonte: Elaborada pelo autor.

Considerando um hiperplano $\mathrm{H}$, temos que os pontos que pertencem a ele é dado pela equação 3.14, onde b é o vetor de limiar ou bias, e w é o vetor normal ao hiperplano $\mathrm{H}$.

$$
\mathbf{w} \cdot \mathbf{x}+b=0
$$

A equação 3.15 corresponde a distância perpendicular do hiperplano H até a origem.

$$
\frac{|b|}{\|\mathbf{w}\|}
$$

Pode-se definir então uma função empregada na decisão de classificação do tipo sinal, conforme mostra a equação 3.16 .

$$
g(x)=\operatorname{sinal}(\mathbf{w} \cdot \mathbf{x}+b)=\left\{\begin{array}{l}
+1, \text { sew } \cdot \mathbf{x}+b>0 \\
-1, \text { sew } \cdot \mathbf{x}+b<0
\end{array}\right.
$$

Define-se adicionalmente dois hiperplanos canônicos formados por vetores suporte contendo as amostras de cada classe mais próximas do hiperplano de separação H. Os vetores suporte são de suma importância no posicionamento do hiperplano de separação, caso algum vetor suporte seja retirado o hiperplano muda de local. Caso algum vetor que não seja suporte, seja retirado, o hiperplano se mantém. Estes hiperplanos são apresentados na equação 3.17 .

$$
\left\{\begin{array}{l}
\mathbf{w} \cdot \mathbf{x}+b=1 \\
\mathbf{w} \cdot \mathbf{x}+b=-1
\end{array}\right.
$$


A margem total T então necessita ser maximizada. Assim, defini-se a equação 3.18, como a distância mínima entre o hiperplano e as amostras de treinamento.

$$
T=\frac{|b|}{\|\mathbf{w}\|}
$$

A partir destas considerações, verifica-se que a maximização da margem de separação pode ser obtida pela minimização de $\|\mathrm{w}\|$, com as restrições de se manter a separação de amostras corretamente, implicando em um problema de otimização restrita com a função custo dada pela equação 3.19, com restrições dadas pela equação 3.20.

$$
\begin{gathered}
1 / 2\|\mathbf{w}\|^{2}=1 / 2 \mathbf{w}^{T} \mathbf{w} \\
y_{i}\left(\mathbf{w} \cdot x_{i}+b\right) \geq 1
\end{gathered}
$$

Aplicando-se então a teoria dos multiplicadores de Lagrange, podem-se realizar os desenvolvimentos com a finalidade de se encontrar um ótimo para a função objetivo $L(w, b)$ que representa um problema primal de otimização restrita, ou seja, minimizar:

$$
L(w, b)=1 / 2\left(\mathbf{w}^{T} \mathbf{w}\right)-\sum_{i=1}^{n} \alpha_{i}\left(y_{i}\left(\mathbf{w} \cdot x_{i}+b\right)-1\right)
$$

Sujeito a $\sum_{i=1}^{n} \alpha_{i} . y_{i}=0, \operatorname{com} \alpha_{i}>0$.

A solução do problema acima consiste em obter os multiplicadores de Lagrange $\alpha_{i}$, os quais podem ser calculados por meio do método Sequential Quadratic Programming (SQP) e deve atender às condições de otimalidade de Karush-Kuhn-Tucker (KKT).

A partir da solução deste problema de otimização obtém-se a função de decisão do classificador com margem maximizada. A função de decisão pode ser dada pela equação 3.22 .

$$
D(z)=\operatorname{sinal}\left[\sum_{j=1}^{m} \alpha_{i} y_{i}\left(x_{i} . z\right)+b\right]
$$

\section{SVM com margens flexíveis}

As amostras utilizadas no desenvolvimento das SVMs podem conter ruídos, amostras rotuladas incorretamente, outliers que podem comprometer a capacidade de generalização do sistema. O conceito de margens flexíveis ou suaves (soft margins) pode contribuir para reduzir os efeitos destes ruídos. 
Para isso, se insere uma folga $\epsilon_{i} \geq 0$, relaxando restrições impostas pelo problema de otimização primal (LORENA; CARVALHO, 2007). A equação 19 mostra a adaptação.

$$
y_{i}\left(\mathbf{w} \cdot x_{i}+b\right) \geq 1-\epsilon_{i}
$$

Assim, ocorre a suavização das margens do hiperplano H criado pelo algoritmo SVM com margem rígida, de maneira que algumas amostras permaneçam entre os limites impostos pelos vetores de suporte, inclusive a ocorrência de alguns erros de classificação. Desta maneira a função custo é reformulada para minimizar a equação 3.24.

$$
1 / 2 \mathbf{w}^{T} \mathbf{w}+C \sum_{i=1}^{n} \epsilon_{i}
$$

Sujeito a $y_{i}\left(\mathbf{w} \cdot x_{i}+b\right) \geq 1-\epsilon_{i}$, onde $\epsilon_{i}>0$, com $i=1, \ldots n$.

O parâmetro C, denominado de constante de margem suave ou fator de suavização, pode ser visto como uma maneira de controlar o overfitting, ou seja, controla a importância relativa de maximizar a margem a fim de se ajustar os dados de treinamento à "Soft Margin". Quanto menor o fator de suavização, maior quantidade de pontos são ignorados próximos a margem, aumenta assim a margem de folga. Neste caso, o problema de otimização deve maximizar a margem e permitir que alguns vetores estejam dentro da margem, minimizando efeitos de alguns dados extremos no posicionamento do hiperplano (LIBONI, 2017). O problema primal passa a ter dois multiplicadores de Lagrange, $\alpha_{i}$ e $r_{i}$, com a seguinte função objetivo $L(w, b, \alpha, \epsilon)$ :

$$
\left.L(w, b, \alpha, \epsilon)=1 / 2\left(\mathbf{w}^{T} \mathbf{w}\right)+C \sum_{i=1}^{n} \epsilon_{i}-\sum_{i=1}^{n} \alpha_{i}\left(y_{i}\left(\mathbf{w} \cdot x_{i}+b\right)-1+\epsilon_{i}\right)-\sum_{i=1}^{n}\right) r_{i} \epsilon_{i}
$$

Sujeito a $\sum_{i=1}^{n} \alpha_{i} \cdot y_{i}=0$, com $\alpha_{i} \geq 0 e r_{i} \geq 0$.

\section{Utilização de função kernel}

Para problemas não linearmente separáveis utilizando-se SVM de margens rígidas, a representação dos dados deve ser mapeada em um novo espaço de maior dimensão, de maneira que o novo problema passe a ser linearmente separável, com uma dimensão adicional (LIBONI, 2017). Para esta operação utiliza-se funções kernel, que criam uma outra dimensão para as amostras. Existem inúmeras funções kernel que podem ser empregadas, como a função polinomial, Gaussiana, sigmoidal, etc. A tabela 3 apresenta mais detalhes destas funções.

O kernel Gaussiano possui apenas um parâmetro de ajuste. Neste caso, quando $\gamma$ é elevado, a separação dos padrões fica similar a separação sem utilização da função kernel. Para valores pequenos de $\gamma$, o classificador é muito restrito, e não alcança generalização 
Tabela 3: Algumas funções kernel utilizadas em SVM.

\begin{tabular}{ccc}
\hline Kernel & Função & Parâmetros \\
\hline Polinomial & $\left(\delta\left(x_{i} . y_{j}\right)+k\right)^{d}$ & $\delta, k, d$ \\
Gaussiano & $\exp \left(-\gamma\left\|x_{i}-y_{j}\right\|^{2}\right)$ & $\gamma$ \\
Sigmoidal & $\tanh \left(\delta .\left(x_{i} . y_{j}\right)+k\right)$ & $\delta, k$ \\
\hline
\end{tabular}

Fonte: Elaborada pelo autor.

satisfatória. A figura 18 apresenta um exemplo de aplicação de função kernel, com fator de suavização fixo, utilizando banco de dados IRIS disponível no MATLAB.

Figura 18: Interferência do parâmetro $\gamma$ no kernel Gaussiano. Banco de Dados de IRIS do MATLAB.

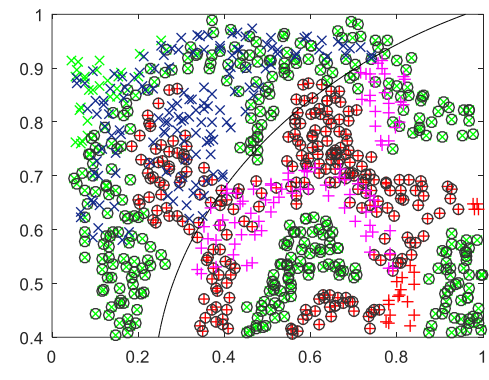

$\gamma=0.01$ Acurácia: $66.38 \%$

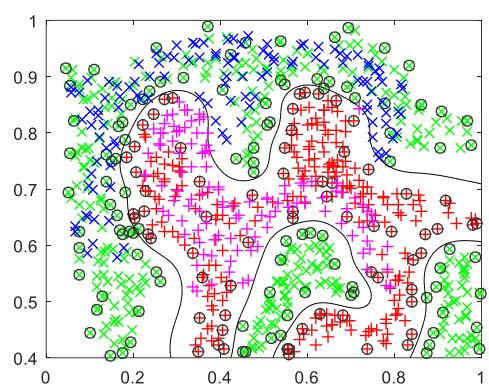

$\gamma=10$ Acurácia: $97.41 \%$

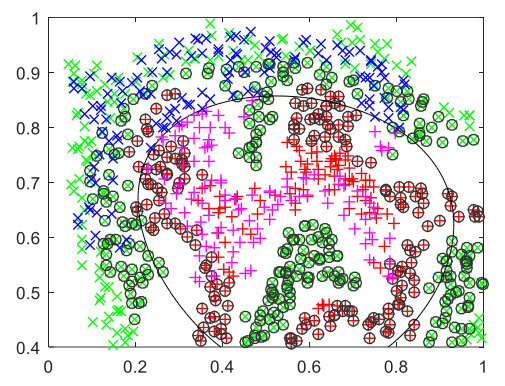

$\gamma=0.1$ Acurácia: $90.95 \%$

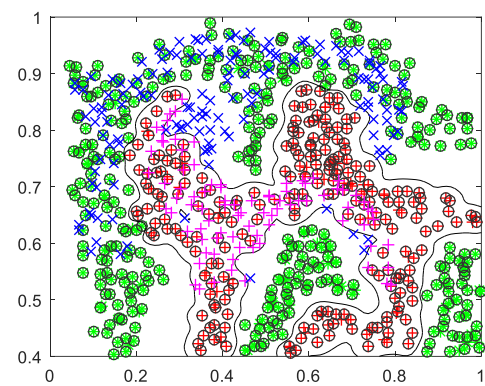

$\gamma=100$ Acurácia: $87.50 \%$

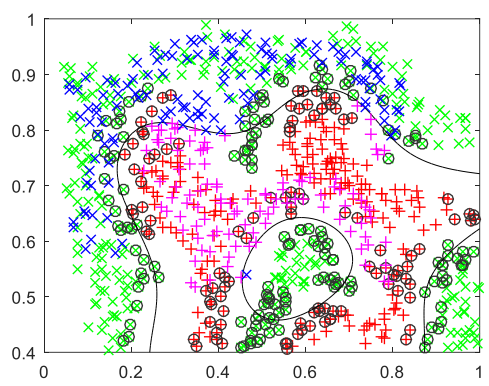

$\gamma=1$ Acurácia: $90.09 \%$
+ Conjunto de treinamento (negativo)

+ Conjunto de teste (negativo)

$\times$ Conjunto de treinamento (positivo)

$\times$ Conjunto de teste (positivo)

$\checkmark$ Vetores Suporte

Fonte: Elaborada pelo autor.

Nesta tese foi utilizado SVM com margens flexíveis e o kernel gaussiano na implementação do classificador. A implementação do algoritmo é realizada a partir da utilização de uma toolbox do software MATLAB denominada fitcsvm.

\subsubsection{One-Class Support Vector Machine (OCSVM)}

Os classificadores apresentados até o momento são ajustados a partir de treinamento supervisionado, ou seja, o ajuste do classificador é realizado a partir de dados de treinamentos que possuem amostras de diversas classes a serem identificadas posteriormente 
utilizando conjunto de teste ou novas amostras. Entretanto, muitas vezes tem-se disponível apenas dados de uma única classe, e assim o objetivo se torna identificar se uma nova amostra é similar ou não as amostras de treinamento, que são conhecido como sistemas para detecção de novidades ou para classificação de uma só classe.

Em aprendizado de máquina, a classificação de uma só classe, tenta identificar objetos de uma classe específica entre todos os objetos, aprendendo principalmente a partir de um conjunto de treinamento contendo apenas os objetos dessa classe (OLIVERI, 2017).

A SVMs de uma só classe ganharam bastante popularidade nas últimas décadas e foi inicialmente proposta por Scholkoft et al. (2001). O algoritmo separa todos os pontos de dados da origem e maximiza-se a distância do hiperplano de separação (LIBONI, 2017). Assim, o classificador OCSVM pode ser entendido como o SVM convencional, que utiliza todos os dados de treinamento de uma única classe, e a origem como o único membro da outra classe. A função de minimização é apresentada na equação 3.26, onde o parâmetro $v$ define a suavidade da função decisão, similar ao parâmetro $C$ para o SVM convencional.

$$
\Phi(\mathbf{w})=\frac{1}{2} \mathbf{w} \cdot \mathbf{w}+\frac{1}{v} \sum_{i=1}^{m} \epsilon_{i}-\rho
$$

Sujeito as restrições $\left(\mathbf{w} . \phi\left(x_{i}\right)\right) \geq \rho-\epsilon_{i}$ e $\epsilon_{i} \geq 0$.

A figura 19, representa a a técnica OCSVM utilizando a abordagem por Schölkpf.

Figura 19: Exemplos de hiperplanos de separação empregando OCSVM.

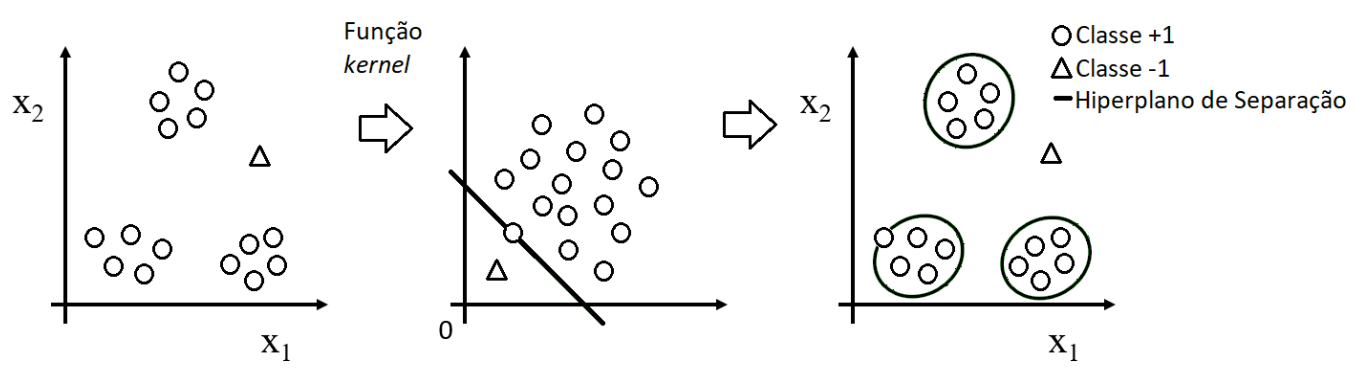

Fonte: Elaborado pelo autor.

Uma outra abordagem de OCSVM foi realizado por Tax e Duin (2004), onde basicamente o hiperplano de separação passa estratégia linear para uma abordagem esférica.

Nesta tese, uma adaptação da metodologia é proposta para aplicação do classificador OCSVM uma vez que o desenvolvimento de sistemas de detecção de anomalias em máquinas acionadas por motores elétricos pode haver grande dificuldade para se coletar amostras anormais, inviabilizando a utilização de classificadores que utilizam treinamento supervisionado. Adicionalmente, espera-se que a máquina opere na maior parte do tempo 
em condições saudáveis de operação, e que a operação em estados faltosos ocorram raramente. Assim, classificadores do tipo one-class são fortemente indicados como é o caso da técnica OCSVM.

\subsection{Validação Cruzada e Otimização de Desempenho}

Os métodos para avaliar o desempenho de um algoritmo de aprendizado de máquinas empregado neste memorial são baseados na validação cruzada. Para os casos dos algoritmo kNN e RNA, investiga-se uma faixa de valores de seus hiper-parâmetros, definindo-os a combinação com apresente melhor desempenho. Para o algoritmo SVM, uma técnica de otimização de seus hiper-parâmetros é utilizada para se obter um melhor desempenho. Em seguida, essas estratégias são apresentadas mais detalhadamente.

\subsubsection{Validação cruzada}

A especificação da topologia de uma RNA e mesmo o valor de $\mathrm{k}$ vizinhos em uma aplicação do algoritmo kNN mais apropriado para o problema é normalmente realizado de forma empírica. No caso de RNA, alguns fatores para se obter o melhor desempenho dependem de características como a complexidade do problema a ser mapeado, a distribuição espacial das amostras, a qualidade do conjunto de treinamento, como presença de outliers e ruídos, entre outras (SILVA; SPATTI; FLAUZINO, 2010).

Uma das técnicas mais utilizadas para seleção de melhores topologias candidatas é a validação cruzada, ou chamada de cross validation (KOHAVI, 1995) (RIPLEY; HJORT, 1996). Seu objetivo é avaliar uma determinada topologia de algoritmo de aprendizado a partir de utilização de parte das amostras coletadas para ajuste dos seus parâmetros internos, denominado conjunto de treinamento, e utilizar amostras que não foram utilizadas para estes ajustes, chamada de amostras do conjunto de teste, para verificação do seu desempenho. Assim, se busca realizar a medição e identificar o melhor desempenho para o mapeamento de um determinado problema.

Um tipo de validação cruzada bastante empregado é o denominado k-partições. Consiste na divisão dos dados em um número de $k$ partições diferentes, utilizando-se $k-1$ partições para treinar o algoritmo e uma única partição para testar. O processo é feito de forma sistemática, e cada partição é composta por amostras selecionadas aleatoriamente. Realiza-se essa repetição por $\mathrm{k}$ vezes e os resultados das $\mathrm{k}$ avaliações de alguns indicadores são ponderados utilizado seus valores como métrica de desempenho da topologia do algoritmo.

Na divisão dos conjuntos e subconjuntos de treinamento e teste é necessário analisar algumas questões importantes. No conjunto de treinamento, recomenda-se que estejam incluídas todas as amostras que possuem valores máximos e mínimos de cada atributo, uma vez que uma amostra de teste com estes valores, poderiam gerar erros significativos 
em uma rede neural tipo PMC, pois estaria tentando generalizar valores que estão fora do domínio de definição de seus atributos de entrada utilizado para o aprendizado. Ademais, deve-se garantir que na fase de operação do algoritmo as novas amostras a ser classificadas estejam com valores de entrada dentro deste domínio de definição.

Na definição da topologia candidata tanto o aumento demasiado de neurônios e quantidade de camadas intermediárias ou ocultas não asseguram uma generalização apropriada para as redes PMC nas amostras de testes e fase de operação do sistema. Geralmente, este tipo de abordagem leva o PMC para a circunstância de memorização excessiva (overfitting). Neste caso, o erro quadrático médio durante a fase de aprendizado tende a ser baixo, porém durante a fase de teste, ele tende a assumir valores elevados (SILVA; SPATTI; FLAUZINO, 2010). Outra característica do uso indiscriminado de neurônios e camadas escondidas é o maior esforço computacional necessário para o cálculo de uma nova amostra.

Um procedimento muito utilizado para evitar condições de overfitting em RNA, é denominado parada antecipada ou early stoping. Esta estratégia consiste em dividir o conjunto de dados em três conjuntos: treinamento, teste e validação. Os conjuntos de teste e validação são apresentados paralelamente durante o processo de aprendizado, porém apenas o primeiro é utilizado para ajuste dos pesos sinápticos. Durante o processo, o erro quadrático médio do conjunto de treinamento e validação devem decair de época em época, porém do momento em que o erro no conjunto de validação começa a aumentar, verificando-se o overfitting, o treinamento é interrompido (LIBONI, 2017).

Um outro aspecto importante em relação a RNA, é a convergência para mínimos locais, durante o processo de aprendizado, uma vez que o erro produzido pelo PMC pode ser não-linear. A tendência de convergência para um determinado ponto de mínimo é condicionada, principalmente, aos valores iniciais de pesos sinápticos, pois a grande maioria dos algoritmos de aprendizagem são baseados em métodos de gradiente descendente. Para evitar esta convergência, um dos procedimentos práticos que pode ser adotado é executar o treinamento de cada topologia diversas vezes, com diferentes matrizes de pesos iniciais gerados aleatoriamente (SILVA; SPATTI; FLAUZINO, 2010).

Neste trabalho, a metodologia proposta não se utilizou esta estratégia de parada antecipada devido a não possuir uma quantidade elevada de amostras disponível. A verificação da melhor topologia e desempenho da RNA implementada utilizou uma técnica baseada na validação cruzada em $k$ partições, e para cada topologia candidata o algoritmo de treinamento executado 5 vezes para evitar convergência inapropriada, como mínimos locais. 


\subsubsection{Otimização de hiper-parâmetros}

Em um problema de otimização deve ser utilizado um critério para comparação de diferentes alternativas de parâmetros aceitáveis e finalmente se concluir com a definição com a melhor alternativa. Este critério é chamado de função objetivo. Geralmente a função objetivo deseja-se minimizar o valor desta função (como no caso de uma função custo) ou maximizar a função, considerando algumas restrições do sistema, uma vez que em problemas reais, os parâmetros de otimização não podem ser escolhidos arbitrariamente. Assim, as restrições do projeto devem ser satisfeitas para se obter o resultado otimizado aceitável.

O software MATLAB possui uma ferramenta de otimização que oferece diferentes algoritmos de otimização para diversos problemas específicos. Destes algoritmos, métodos modernos vem se destacando e se tornando cada vez mais populares.

Neste tese, utiliza-se uma estratégia de otimização dos hiper-parâmetros coeficiente de suavização e função kernel, integrados ao toolbox fitcsvm. O método para encontrar o hiperplano de separação é o Otimização Sequencial Mínima com valores padrão. A estratégia utilizada é baseada em Otimização Bayesiana, que pode ser vista mais detalhadamente em (SNOEK; LAROCHELLE; ADAMS, 2012).

A figura 20 apresenta um exemplo de otimização dos hiper-parâmetros investigados em um algoritmo SVM.

Figura 20: Exemplo otimização de parâmetros utilizando Otimização Bayesiana para hiper-parâmetros de um sistema SVM.

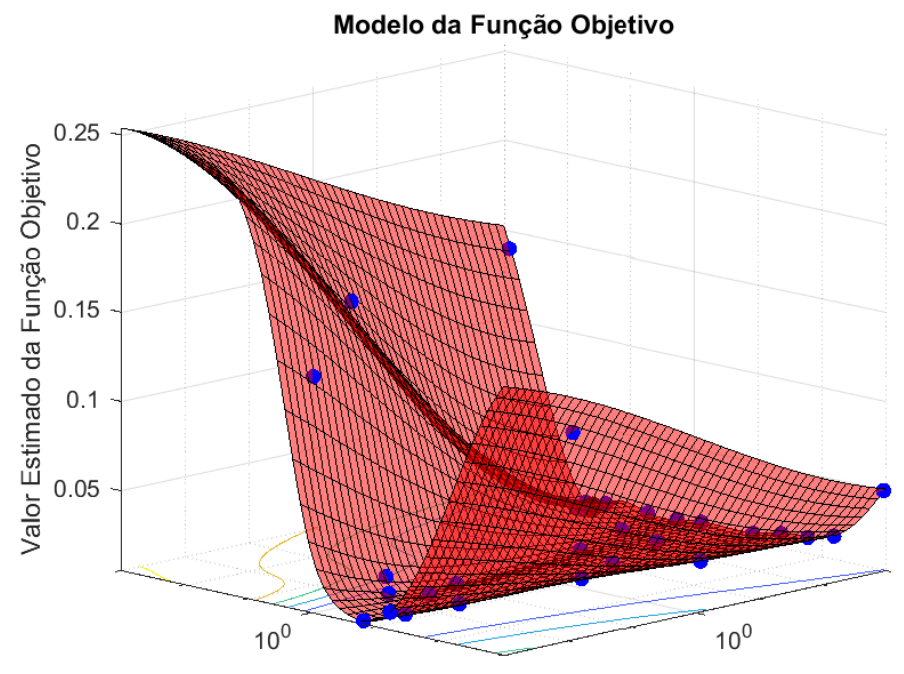

Escala Função Kernel

Coef. de Suavização

Fonte: Elaborada pelo autor. 


\subsection{Curva de Aprendizagem}

Um dos desafios para aplicação de ferramentas de aprendizagem de máquinas é identificar se a quantidade de amostras disponíveis para treinamento dos algoritmos é suficientemente grande para a representação do comportamento de todo o sistema investigado. Trata-se de uma análise importante uma vez que a aquisição de amostras geralmente trata-se de um problema que acarreta altos custos.

As curvas de aprendizagem são uma análise gráfica que indicam o desempenho de um classificador, baseada em seu conjunto de teste, em relação a quantidade de amostras disponibilizadas para o seu treinamento. Um dos indicadores de desempenho que pode ser empregado é a quantidade de amostras etiquetadas incorretamente. A figura 21 apresenta um exemplo de curva de aprendizagem.

Figura 21: Exemplo de curva de aprendizagem.

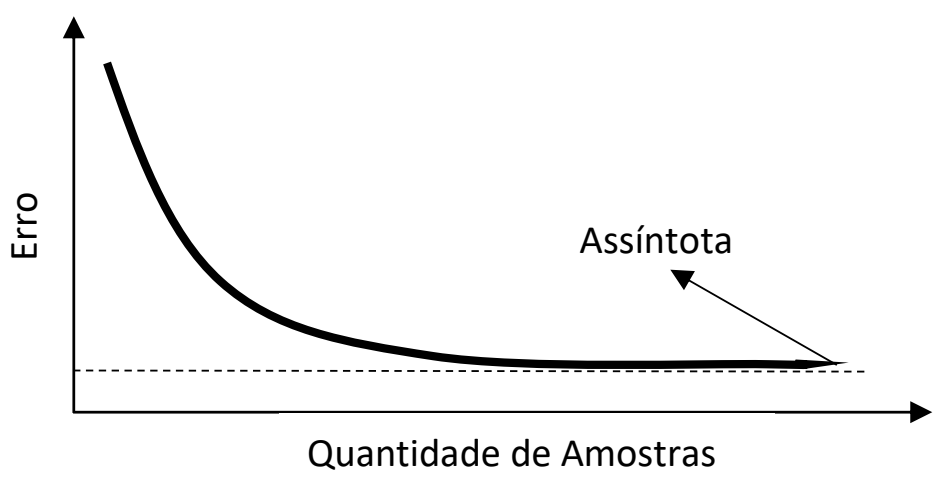

Fonte: Elaborada pelo autor.

Nota-se graficamente pelo exemplo de curva de aprendizagem, que inicialmente utilizando-se poucas amostras, um pequeno aumento em sua quantidade causa grande melhora no desempenho do algoritmo. Entretanto, a partir de certo ponto, o aumento do número de amostras praticamente não impacta no desempenho e o erro de classificação converge, apresentado uma assíntota na curva de aprendizagem.

A curva de aprendizagem pode ser criada, refazendo-se o o treinamento do classificador e testando seu desempenho para diferentes quantidade de amostras, escolhidas aleatoriamente. Inicia-se o processo com uma porcentagem reduzida do universo de amostras disponíveis, e vai se aumentando a quantidade até utilização completa. A análise da curva de aprendizagem mostra que o classificador alcançou todo seu potencial de generalização quando a curva de aprendizagem atingir sua assíntota (LIBONI, 2017). Caso não haja convergência do desempenho, concluí-se que um aumento do número de amostras 
poderia melhorar o desempenho do classificador (WITTEN; FRANCK, 2015). 


\section{CAPÍTULO 4 METODOLOGIA}

Devido a relevância do tema e justificativa apresentada, desenvolveu-se uma metodologia para desenvolvimento de sistemas de diagnósticos para monitoramento e detecção de anomalias e falhas em aplicações que empregam acionamentos de motores elétricos em máquinas rotativas, utilizando-se dados de processo transmitidos em redes de comunicação PROFINET, e que fazem uso do perfil PROFIdrive.

O fluxograma apresentado na figura 22 , mostra os passos que compõe a metodologia, que são explicados detalhadamente nas próximas seções.

Figura 22: Fluxograma da metodologia proposta.

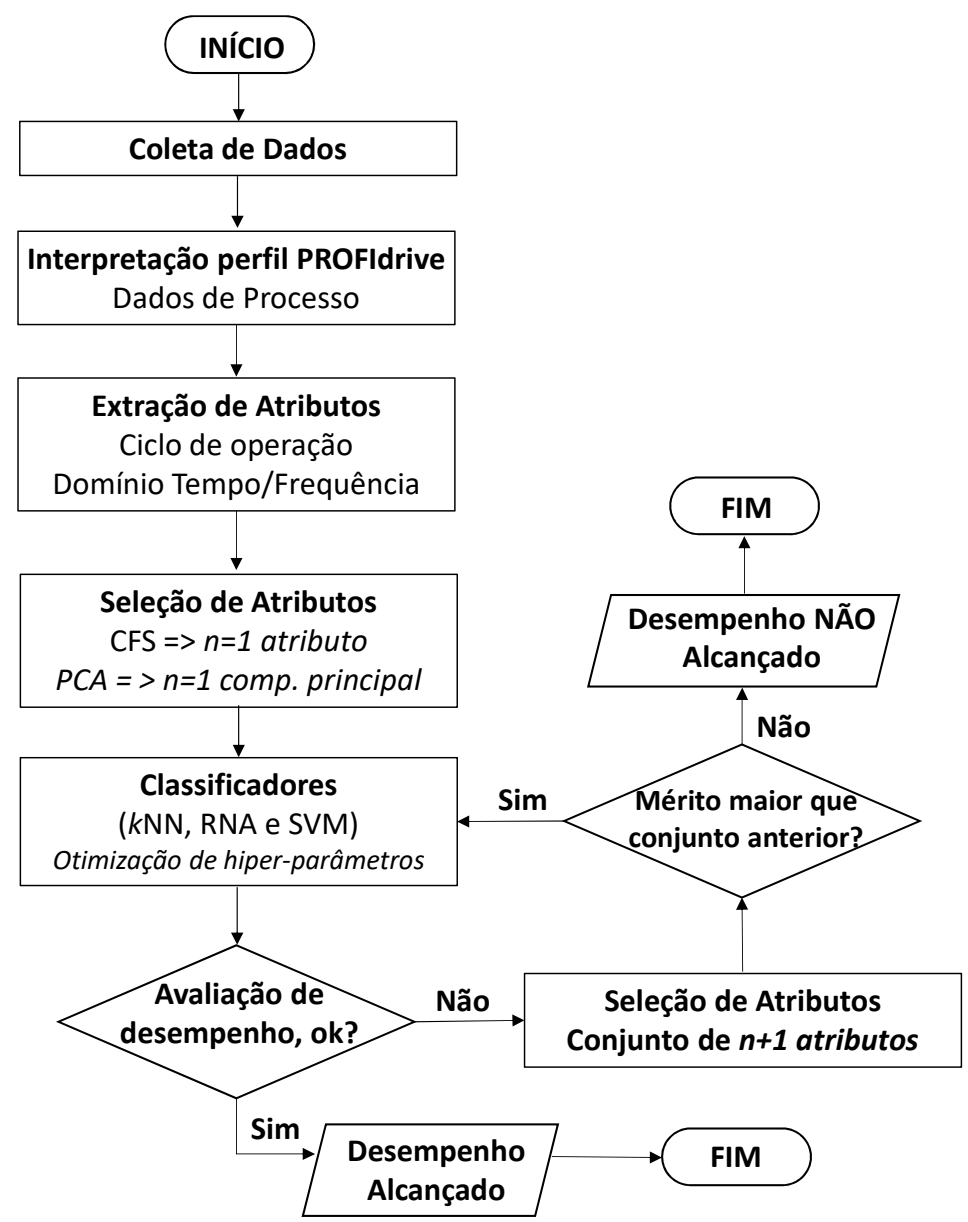

Fonte: Elaborada pelo autor 


\subsection{Coleta de Dados}

A coleta de dados é baseada na captura do tráfego de pacotes transmitidos pela rede PROFINET durante a operação da aplicação de controle de movimento, por meio de um sistema de medição e interpretação de dados de processo dos pacotes do perfil PROFIdrive.

O sistema de medição é composto por uma estação denominada Estação de $D i$ agnóstico, onde um software de análise de rede está instalado, e uma estação de captura dos pacotes de rede conhecida como Ethernet Data Sniffer, que também são utilizados em outros trabalhos acadêmicos, como em Depari et al. (2008) e Sestito et al. (2018).

A figura 23 mostra o esquema utilizado para a etapa de criação da base de dados, onde o sniffer é inserido em um link da rede de comunicação onde tráfega os dados trocados entre o Controlador e os Servo Motores, que são os dispositivos de acionamento elétrico. Um único sniffer é capaz de coletar os dados de todos os Servo Motores da rede de comunicação, para isso basta que a troca de dados como Controlador seja realizada através do link de comunicação de onde o sistema de medição foi instalado.

Figura 23: Esquema de coleta de dados da metodologia proposta

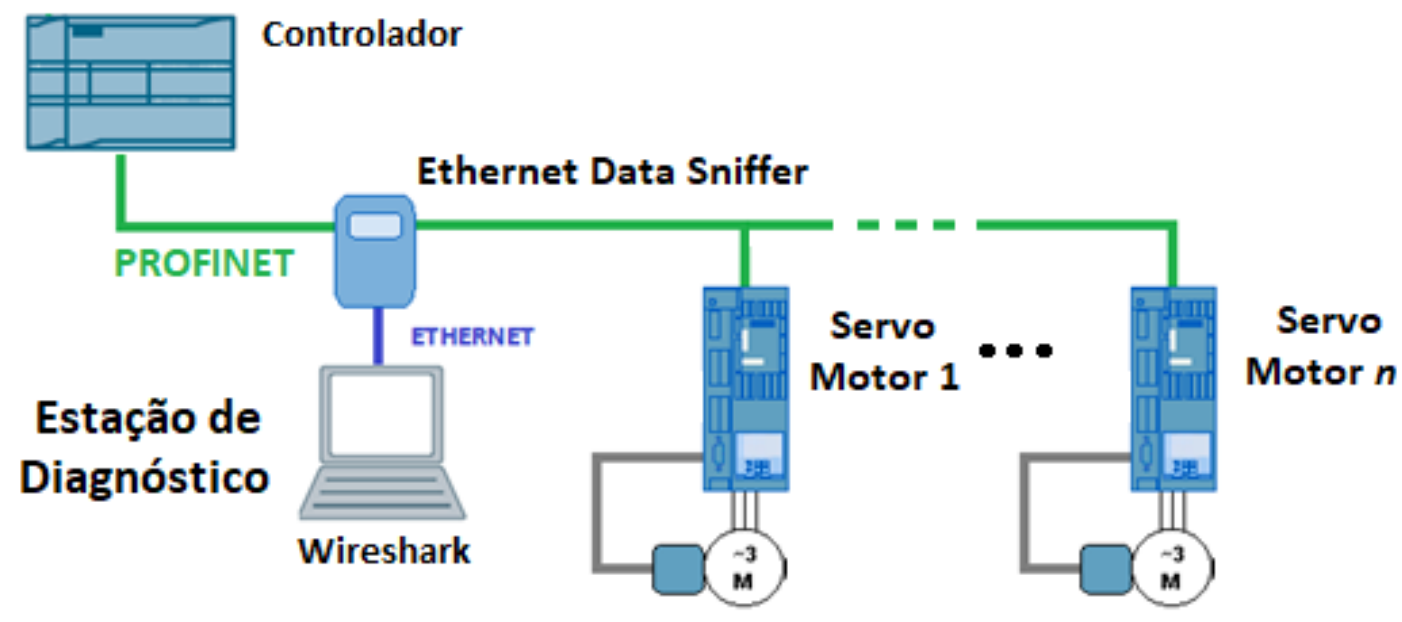

Fonte: Elaborada pelo autor

Neste trabalho, foi analisado apenas um Servo Motor, o sniffer utilizado é o KUNBUS-TAP 2100 da empresa Kunbus. Este equipamento é capaz de coletar os pacotes de dados transmitidos em redes RTE, inserindo uma estampa de tempo. Ele é praticamente transparente aos pacotes que trafegam na rede, não interferindo no seu desempenho, uma vez que insere tempo de atraso na ordem de $1 \mathrm{~ns}$, que pode ser considerado desprezível. A resolução da estampa de tempo inserida é de 10ns. O KUNBUS-TAP coleta os pacotes que trafegam pelas portas X.1 e X.2, conforme mostra esquema da figura 24. Os pacotes 
que chegam na porta X.1, são duplicados e um deles é encaminhado diretamente a porta X.2. Na outra cópia do pacote, é inserido a estampa de tempo e enviado via Ethernet para um software de análise e/ou monitoramento.

A figura 24 adicionalmente mostra duas maneiras possíveis de inserir estampa de tempo em um pacote de dados.

Figura 24: Esquemático do sniffer e inserção de estampa de tempo.

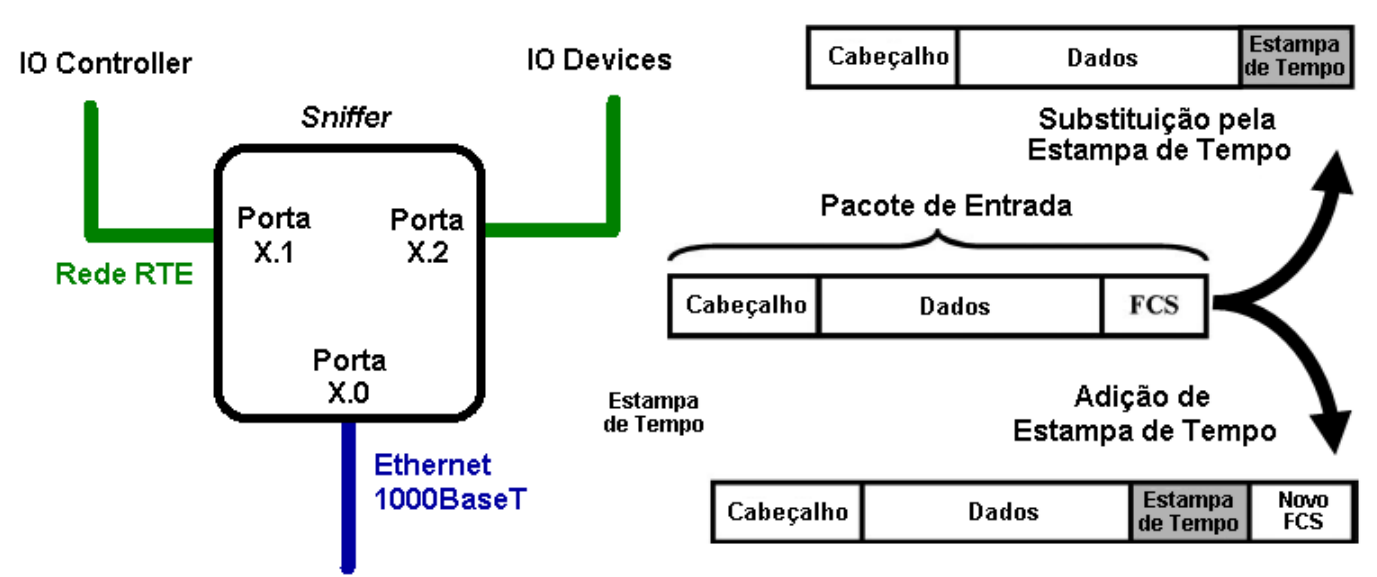

Fonte: Adaptado de Depari et al. (2008)

É importante ressaltar que a coleta de pacotes da rede pode ser feita de diversas formas, como por exemplo utilizando um switch gerenciável com capacidade de espelhamento de porta de comunicação. Mais detalhes acerca deste tema pode ser visto em Dias et al. (2016) e Schafer e Felser (2007).

Grande parte dos trabalhos científicos em redes de automação industrial baseados em Ethernet utilizam o software Wireshark. Este software é um analisador de rede que registra os pacotes Ethernet e decodifica seu conteúdo (YANG; LI, 2014). Ele é certamente a ferramenta de análise mais popular para este tipo de aplicação (MUNZ; CARLE, 2008), e é normalmente instalado em um computador, sem funcionalidades especiais. Trata-se de uma ferramenta de livre distribuição. A figura 25 mostra uma tela de captura de pacotes PROFINET utilizando o software Wireshark versão 1.12.1, que foi instalado na Estação de Diagnóstico.

A tela do software em sua parte superior, apresenta uma lista dos pacotes transmitidos com a informação do dispositivo de origem e destino, o tipo de protocolo utilizado entre outras informações. Adicionalmente, na parte inferior da tela tem-se todos os bytes transmitidos de um pacote específico. Destaca-se o grupo de bytes que envia os dados de processo do protocolo PROFINET, especialmente as informações de palavra de controle e setpoint de velocidade, que é um dos dados de processo interpretados do perfil PROFIdrive utilizados posteriormente para extração de atributos. 
Figura 25: Tela do Wireshark com uma coleta de dados de uma rede PROFINET

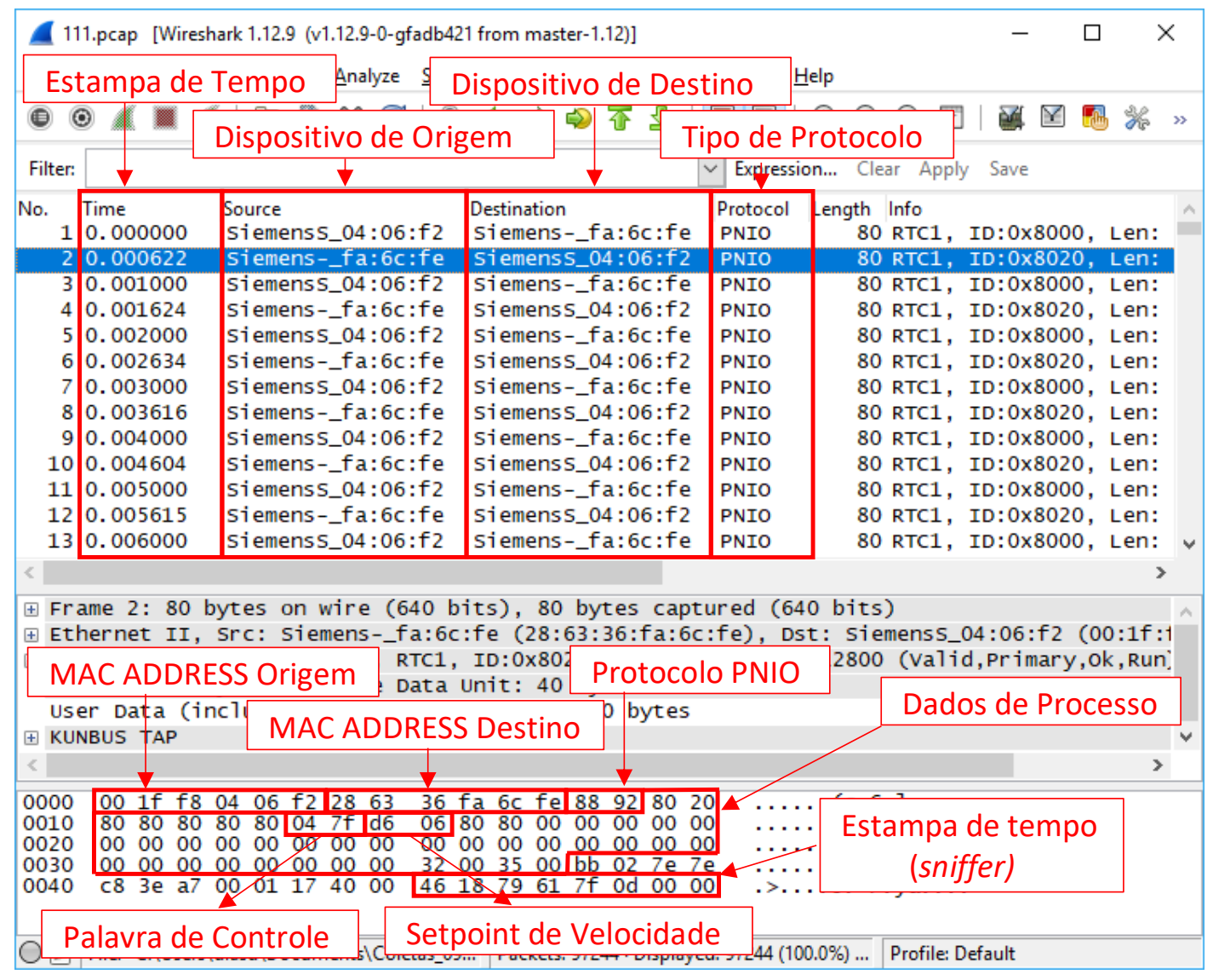

Fonte: Elaborada pelo autor

Existem suplementos do Wireshark que já são capazes de decodificar completamente os pacotes do protocolo PROFINET, desta maneira, recomenda-se utilizar a biblioteca "Plugin tap64 1.12.dll" disponibilizado pelo fabricante do sniffer.

\subsection{Interpretação de dados de processo do perfil PROFIdrive}

O software Wireshark disponibiliza ferramentas de análise estatística, gera arquivos em diversas extensões, sendo as principais *.pcap e *.pcapng. Entretanto, para interpretação dos dados do perfil PROFIdrive, se utilizou o software MATLAB versão R2017a (9.2.0.538062) da empresa MathWorks a partir do desenvolvimento de funções para interpretação das palavras que compõem os dados de processo.

Assim, foi utilizada uma aplicação desenvolvido por Turcato et al. (2018), capaz de transformar o conteúdo dos arquivos * .pcap em arquivos *.mat, para tratamento em ambiente MATLAB. Esta aplicação agrupa os dados dos pacotes em quatro estruturas:

- Estampa de tempo: indica o momento em que o pacote trafegou pelo link de 
comunicação;

- MAC Address do equipamento de origem do pacote: o endereço MAC (Media Access Control), trata-se de um endereço físico associado à interface de comunicação única para cada dispositivo padrão Ethernet. Este campo indica o endereço que partiu a mensagem;

- $M A C$ Address do equipamento de destino do pacote: endereço MAC do dispositivo que recebe o pacote;

- Campo de dados completo dos pacotes: trata-se de todos os bits transmitidos em um pacote de dados, incluindo cabeçalho, endereço de destino, origem, dados de processo e outros campos. A parte inferior da figura 25 apresenta um exemplo do campos de dados de um pacote do perfil PROFIdrive.

A partir deste ponto foi desenvolvido em linguagem MATLAB funções para cada palavra definida no perfil PROFRIdrive que foram necessárias neste trabalho. Ademais, foram criadas funções para cada Telegrama Padrão dos tipos 1, 2 e 3, que basicamente executa a chamada de cada função das palavras que o compõem, conforme apresentado na seção 2.3.2.

A figura 26 apresenta as funções desenvolvidas, que podem ser consultadas no site https://github.com/diasdre/PROFIdrive.

Figura 26: Funções desenvolvidas em MATLAB para interpretação do perfil PROFIdrive

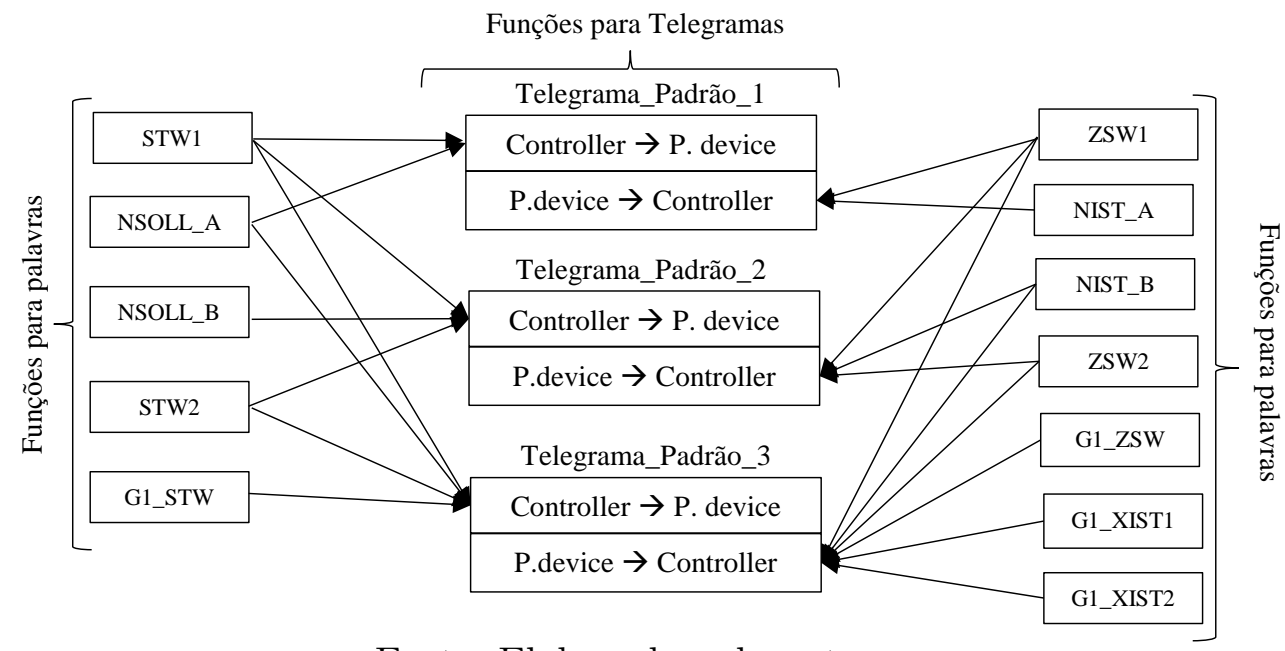

Fonte: Elaborada pelo autor

Cada função para interpretação de Telegramas Padrão exigem o $M A C$ Address do Controlador e Servo Motor. Como o exemplo do Telegrama padrão 3, tem o modelo de função Telegrama_Padrao_3(MAC_ADDRESS_Controller, MAC_ADDRESS_Device). 
Assim, o envio de pacotes do Controller para o $P$. Devive, utilizam as funções de interpretação de palavras $S T W 1, N S O L L \_B$ (interpreta o valor do setpoint de velocidade), $S T W 2$ e $G 1 \_S T W$. Para pacotes do $P$. device para o Controller, empregam-se as funções $Z S W 1, N I S T \_A$ (velocidade atual do motor), ZSW2, G1_XIST1 (valor correspondente a posição atual do motor) e G1_XIST2.

A figura 27 apresenta o pseudo código para interpretação do Telegrama Padrão 3.

Figura 27: Funções desenvolvidas em MATLAB para interpretação do perfil PROFIdrive

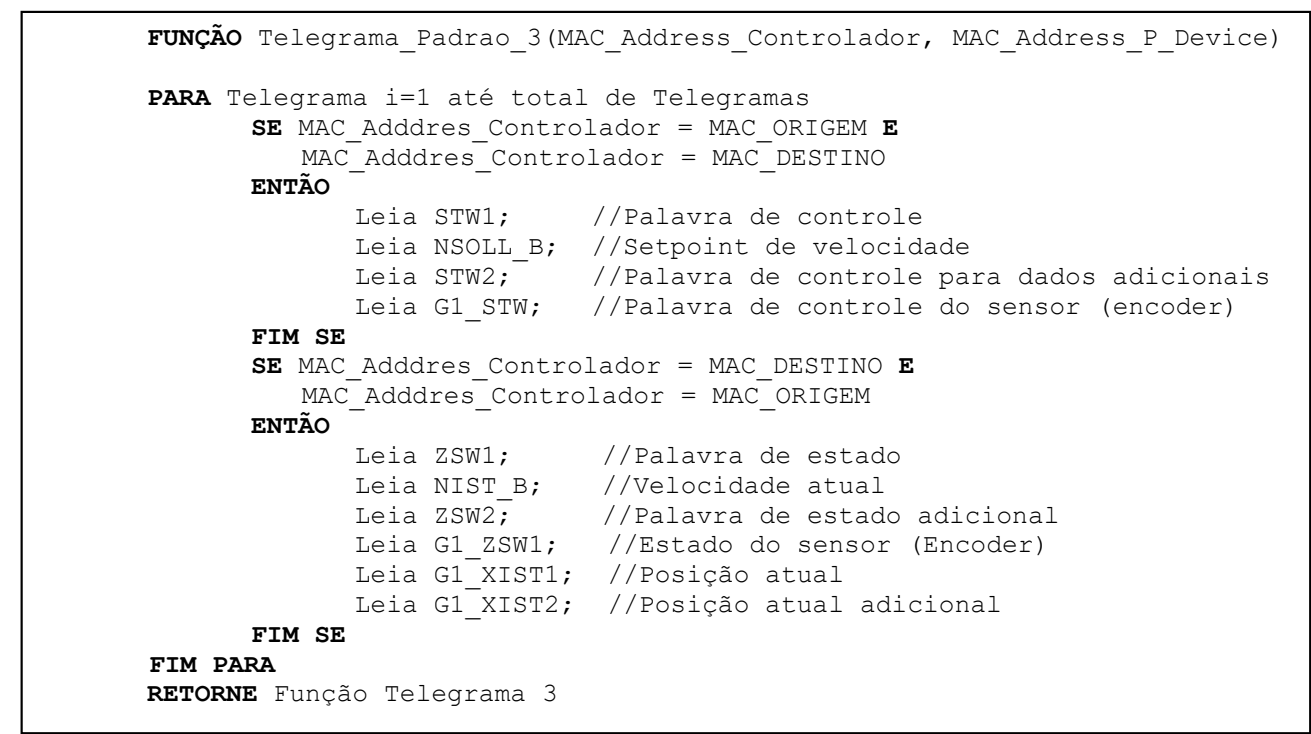

Fonte: Elaborada pelo autor

A partir da execução da função correspondente ao Telegrama Padrão, são gerados vetores das variáveis de processo no workspace do software MATLAB. A Figura 28 apresenta um exemplo dos dados de processo de uma aplicação de acionamento de motores.

Nota-se que no exemplo, a coleta durou em torno de 30 segundos. Por se tratar do Telegrama Padrão 3 na Classe de Aplicação 4, a rede disponibiliza três sinais ou dados de processo. O primeiro é a posição atual do motor, visto no gráfico superior, que está sendo controlada via interpolação central no CLP, que envia setpoint de velocidade para o drive, visto no gráfico inferior. Adicionalmente, tem-se a informação da velocidade atual do drive.

Tanto o setpoint de velocidade quanto a velocidade atual do motor tratam de informação em porcentagem em relação a velocidade nominal que é parametrizada no Servo Motor, podendo ser de $-200 \%$ a $+200 \%$. Portanto, verifica-se que o valor absoluto desta variável não é possível de ser identificada diretamente nos telegramas padrões. Algo similar ocorre em relação a posição atual do motor, que se trata de um número sem 
Figura 28: Exemplo de dados de processo coletada empregando funções desenvolvidas em coletas com perfil PROFIdrive
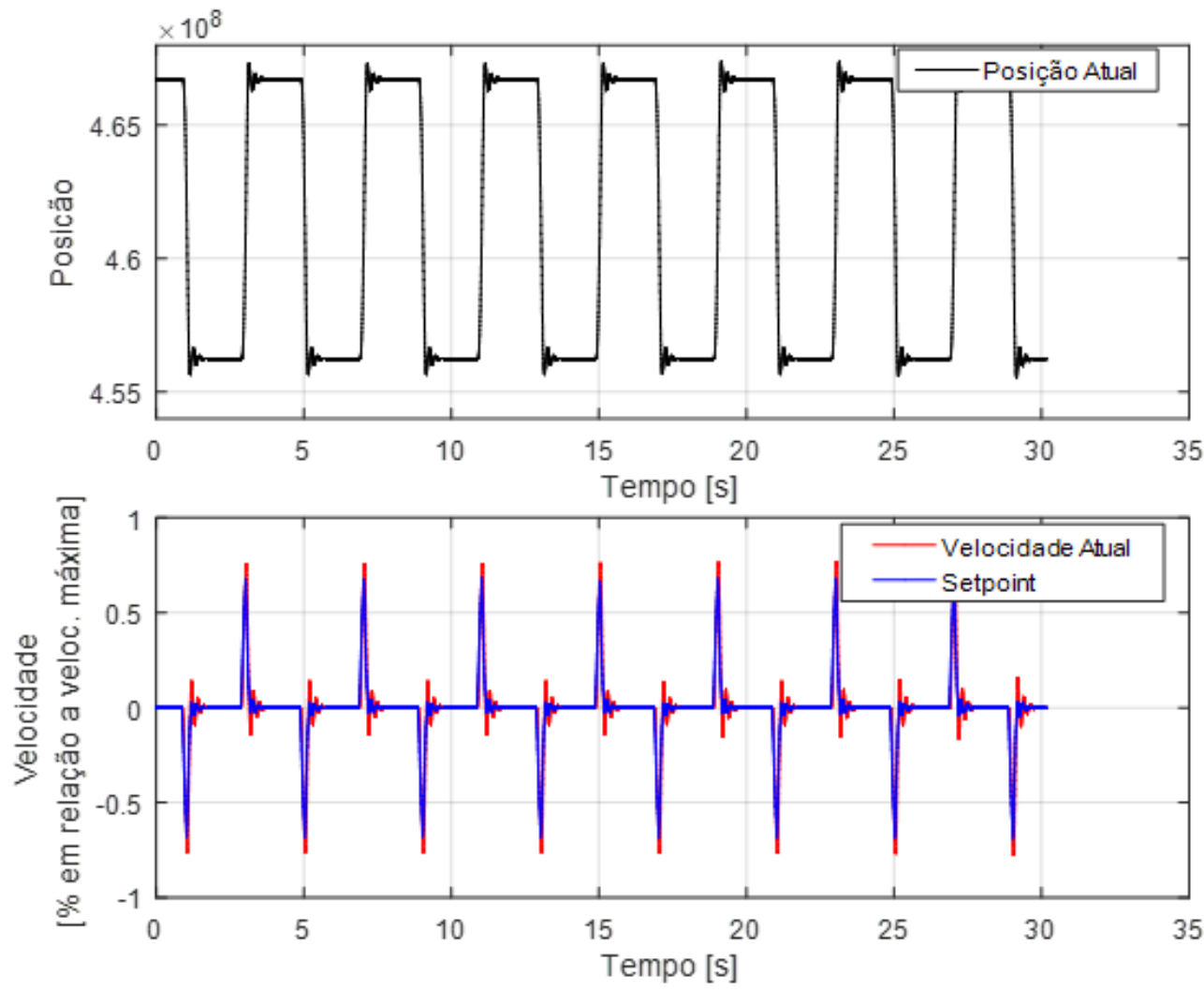

Fonte: Elaborada pelo autor

unidade de medida determinada, a qual está previamente parametrizada no Controlador.

Além destes sinais, o sinal do erro referente ao controle de velocidade do sistema de controle de todo o conjunto eletromecânico é utilizado. Ele é definido como a diferença entre o valor do setpoint de velocidade e velocidade atual entre dois pacotes de rede subsequentes no controle de um motor.

\subsection{Extração de Atributos}

A extração de atributos cria o banco de dados para treinamento e teste do sistema de diagnóstico baseado em ferramentas de aprendizagem de máquinas. Ele é realizado de maneira offline neste trabalho.

Cada amostra é composta por $N$ elementos $\left(x_{i}\right)$, que correspondem aos pacotes do perfil PROFIdrive transmitidos na rede de comunicação durante um ciclo completo de operação da máquina no processo produtivo. Assim, é importante ressaltar que a metodologia proposta se aplica somente para operações cíclicas, característico em indústrias de manufatura. 
O tratamento do sinal e identificação do ciclo de operação da máquina é realizado a partir de um algoritmo também em ambiente MATLAB.

Devido a necessidade de cálculo dos valores das componentes harmônicas dos sinais investigados, que será descrito mais detalhadamente adiante, é realizado tratamento do sinal, deslocando o sinal interpretado, fazendo com que sua média seja nula, uma vez que será aplicada Fast Fourier Transform (FFT), e desta maneira o sinal não possua um nível de sinal contínuo elevado.

A figura 29-a apresenta uma amostra do sinal de posição, criado a partir da identificação do ciclo de operação da máquina dos sinais utilizados na extração de atributos, e 29-b do mesmo sinal ajustado para aplicação da FFT.

Figura 29: Exemplos de sinal de posição utilizado para extração de características. a) Identificação do ciclo de operação b) Tratamento do sinal.

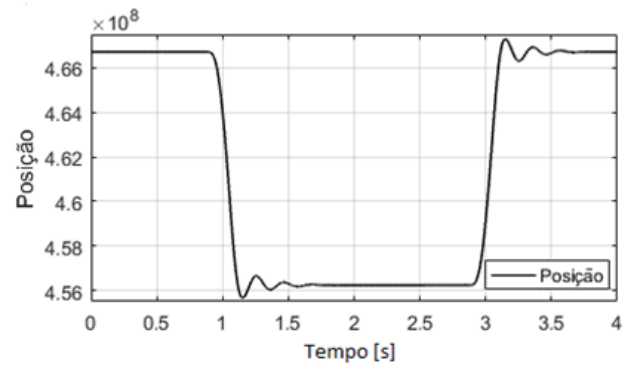

(a)

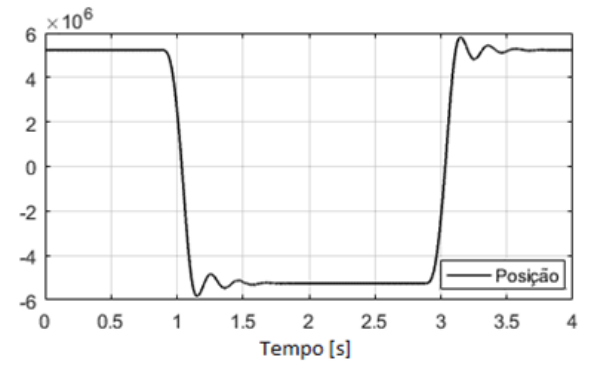

(b)

Fonte: Elaborada pelo autor

A definição dos atributos extraídos foram inspirados em trabalhos correlatos sobre manutenção preditiva e condition monitoring em aplicação de eixos rotativos e em Borges et al. (2016) que emprega uma vasta gama de atributos para detecção de distúrbios em sistemas elétricos de potência.

A tabela 4 apresenta a lista de atributos extraídos para cada um dos quatro sinais investigados: setpoint de velocidade, velocidade atual, erro do sistema de controle de velocidade e posição atual de cada amostra, resultando em um total de até 102 atributos.

Adicionalmente é indicado os autores que utilizaram tais atributos em seus trabalhos. Atributos $A 41$ e $A 42$ são sugeridos como novos atributos a serem investigados por este trabalho, aplicados somente ao sinal do erro do controle de velocidade, baseado em conclusões de Dias, Sestito e Brandao (2017), que o tempo de ciclo da rede de comunicação industrial poderia influenciar no desempenho do sistema de controle, o que pode implicar diretamente no comportamento deste sinal. 
Tabela 4: Lista de atributos extraídos das amostras

\begin{tabular}{|c|c|c|c|}
\hline Atributo & Descrição & Equação & Autores \\
\hline \multirow{2}{*}{ A01-A04 } & \multirow{2}{*}{ Desvio Padrão } & \multirow{2}{*}{$F_{1}$} & (PRIETO et al., 2013) \\
\hline & & & (BORGES et al., 2016) \\
\hline \multirow{3}{*}{ A05-A08 } & \multirow{3}{*}{ Maior Valor Absoluto } & \multirow{3}{*}{$F_{2}$} & (PRIETO et al., 2013) \\
\hline & & & (PATIL et al., 2010) \\
\hline & & & (BORGES et al., 2016) \\
\hline \multirow{2}{*}{ A09-A12 } & Variação entre maior & \multirow[b]{2}{*}{$F_{3}$} & (TAHIR et al., 2016) \\
\hline & e menor valor & & (BORGES et al., 2016) \\
\hline A13-A16 & Entropia & $F_{4}$ & (BORGES et al., 2016) \\
\hline $\mathrm{A} 17-\mathrm{A} 20$ & Entropia de Shannon & $F_{5}$ & (BORGES et al., 2016) \\
\hline \multirow{2}{*}{ A21-A32 } & Entropia & \multirow[t]{2}{*}{ ApEn } & (SAMPAIO; NICOLETTI, 2016) \\
\hline & Aproximada $(p=2,3,4)$ & & \\
\hline \multirow{6}{*}{ A33-A36 } & \multirow{6}{*}{ Kurtosis } & \multirow{6}{*}{$F_{6}$} & (PRIETO et al., 2013) \\
\hline & & & (FOURNIER et al., 2015) \\
\hline & & & (PATIL et al., 2010) \\
\hline & & & (DWI et al., 2015) \\
\hline & & & (TAHIR et al., 2016) \\
\hline & & & (BORGES et al., 2016) \\
\hline \multirow{5}{*}{ A37-A40 } & \multirow{5}{*}{ Valor Quadrático Médio } & \multirow{5}{*}{$F_{7}$} & (PRIETO et al., 2013) \\
\hline & & & (AMIR; GUL; KHAN, 2016) \\
\hline & & & (TAHIR et al., 2016) \\
\hline & & & (PATIL et al., 2010) \\
\hline & & & (BORGES et al., 2016) \\
\hline $\mathrm{A} 41^{*}$ & Integral do Erro Absoluto & $F_{8}$ & - \\
\hline $\mathrm{A} 42^{*}$ & Integral do Erro Quadrático & $F_{9}$ & - \\
\hline \multirow{4}{*}{$\mathrm{A} 43-\mathrm{A} 102$} & \multirow{4}{*}{$\begin{array}{l}\text { Magnitude das quinze } \\
\text { k-harmônicas ímpares }\end{array}$} & \multirow{4}{*}{$F_{10} k$} & (PANDARAKONE et al., 2017) \\
\hline & & & (TAHIR et al., 2016) \\
\hline & & & (MARTINEZ-MORALES et al., 2010) \\
\hline & & & (BORGES et al., 2016) \\
\hline
\end{tabular}

Fonte: Elaborada pelo autor.

As características dos sinais investigadas estão no domínio do tempo e no domínio da frequência. Os atributos de A01 à A40 são no domínio do tempo, utilizam parâmetros como desvio padrão, máximo valor absoluto, diferença entre maior e menor valor, valor de diferentes tipos de entropia e kurtosis dos sinais das variáveis do sistema. O atributo ApEn trata-se de um algoritmo definido em Sampaio e Nicoletti (2016). Os atributos A41 e A42 são relacionados a indicadores de desempenho de sistema de controle, como dito anteriormente. Estes atributos também são trabalhados no domínio do tempo.

Já os atributos de A43 à A102 são baseados na aplicação da FFT, convertendo o sinal de cada variável física do domínio do tempo para o domínio da frequência. A justificativa para utilização desta transformada é devido a características dos sinais investigados serem periódicos. Adicionalmente se ressalta que este tipo de transformada requer pouco esforço computacional. Foram utilizadas como atributos, as 15 primeiras componentes harmônicas ímpares de cada sinal. 
As equações para cada atributo são apresentadas em seguida.

$$
\begin{gathered}
F_{1}=\sqrt{\frac{\sum_{i=1}^{N}\left(x_{i}-m e ́ d i a\left(x_{i}\right)\right)^{2}}{N-1}} \\
F_{2}=\max \left|x_{i}\right| \\
F_{3}=\max \left(x_{i}\right)-\min \left(x_{i}\right) \\
F_{4}=\frac{\sum_{i=1}^{N} \log \left(x_{i}^{2}\right)}{N-1} \\
F_{5}=-\frac{\sum_{i=1}^{N} x_{i}^{2} * \log \left(x_{i}^{2}\right)}{N-1} \\
F_{6}=\frac{\frac{1}{N} \sum_{i=1}^{N}\left(x_{i}-m e ́ d i a\left(x_{i}\right)\right)^{4}}{\left[\frac{1}{N} \sum_{i=1}^{N}\left(x_{i}-m e ́ d i a\left(x_{i}\right)\right)^{2}\right]^{2}} \\
F_{10} k=\sum_{i=1}^{N} x_{i} * e^{\frac{-2 \pi i}{(N-1)} k n} \\
F_{7}=\frac{\sum_{i=1}^{N} x_{i}^{2}}{N} \\
F_{8}=\frac{\sum_{i=1}^{N}\left|x_{i}\right|}{N} \\
F_{i} \mid
\end{gathered}
$$

As características ou atributos obtidos compõem um vetor de informação que descreve cada amostra. Todos os atributos são normalizados no intervalo de $[0,1]$, de acordo com a equação 4.11 .

$$
A_{n k}^{i}=\frac{A_{k}^{i}-\min \left(A^{i}\right)}{\max \left(A^{i}\right)-\min \left(A^{i}\right)}
$$

onde:

$A_{n k}^{i}$ é o valor normalizado do $i$-éssimo atributo da $k$-éssima amostra;

$A_{k}^{i}$ é o valor do i-éssimo atributo da $k$-éssima amostra e

$A^{i}$ são os valores de todo o vetor de amostras do $i$-éssimo atributo. 


\subsection{Seleção de Atributos}

Devido ao grande número de atributos, que pode implicar em alto esforço computacional e overfitting, é recomendado a redução da dimensão de atributos para posterior aplicação como entrada em um sistema de inferência para reconhecimento de padrões. Dois métodos são investigados, o CFS e PCA.

Inicialmente um atributo é selecionado pelo CFS, conforme apresentado na seção 3.2.1, e uma única componente principal é calculada pelo PCA, conforme apresentado na seção 3.2.2, resultado em um único atributo que caracteriza cada amostra coletada.

Ajusta-se os classificadores para reconhecimento de padrão e caso o desempenho seja satisfatório para algum dos algoritmos investigados, verificado pela estratégia de validação cruzada, a metodologia retorna com o sistema de diagnóstico ajustado para o melhor desempenho.

Caso o desempenho não tenha sido alcançado, a metodologia recomenda a seleção de um novo conjunto de atributos com uma característica adicional, sendo dois atributos selecionados pelo CFS e duas componentes principais, que são utilizados novamente nos classificadores. Este processo é repetido até que o desempenho requerido seja alcançado ou a condição de valor do mérito do novo conjunto ser maior que o anterior não seja mais satisfeita.

A figura 30 apresenta um esquemático das ferramentas utilizadas para reduzir dimensionalidade do problema.

Figura 30: Metodologia proposta apresentada graficamente.

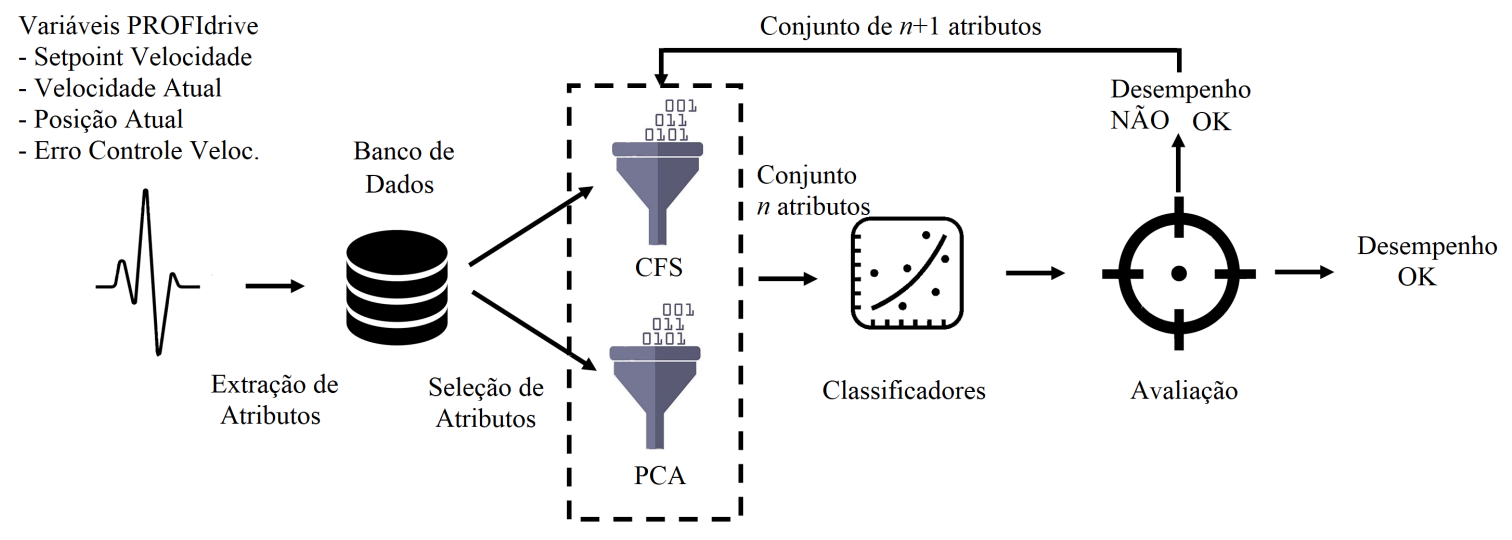

Fonte: Elaborada pelo autor

Assim, a metodologia busca com a etapa de redução de atributos, utilizar como entradas nos classificadores dados que contenham menos informações redundantes, melhorando a capacidade de generalização e assimilação do comportamento do sistema monitorado. 


\subsection{Classificadores}

Os sistema de inferência objetivam classificar o status da aplicação de acionamento de motor como normal (sendo operação saudável do motor) ou anormal (sendo operação em condição faltosa ou não planejada), baseando-se nos atributos selecionados previamente. Trata-se de um problema de reconhecimento de padrões. São investigadas nesta metodologia, os classificadores do tipo kNN, RNA e SVM.

A ferramenta kNN trata-se de um método tradicional de classificação de padrão, empregando a distância Euclidiana, uma vez que é a utilizada em sua maioria em problemas de atributos com valores contínuos. Realiza-se a classificação com base na classe mais frequente entre $k$ vizinhos mais próximos. Utiliza-se um toolbox do MATLAB denominado fitcknn e predict para este classificador.

Para RNA, foi utilizado um classificador baseado em uma rede neural tipo PMC com algoritmo de treinamento do tipo supervisionado chamado "Levenberg-Marquardt Backpropagation". Este algoritmo executa o ajuste dos pesos sinápticos da RNA mais rapidamente que os outros algoritmos de treinamento, e pode ser empregado em problemas de classificação de padrões.

Alguns parâmetros importantes deste algoritmo para treinamento da RNA são:

- Erro quadrático médio (EQM): dado pela equação 3.12 representa o erro entre a saída da RNA e o valor desejado para cada amostra. Neste caso é avaliado somente os conjuntos de treinamentos das $k$-partições.

- Gradiente mínimo de desempenho: valor mínimo do gradiente do indicador de desempenho empregado, para que o processo de aprendizado pare.

- Número máximo de épocas: máxima quantidade de épocas utilizada na fase de treinamento para ajuste dos pesos sinápticos.

O algoritmo foi parametrizado com função de desempenho o indicador erro quadrático médio, e gradiente mínimo de desempenho de $10^{-6}$, que determinam o efeito das variações dos ajustes dos pesos sinápticos. O processo de treinamento da rede proposta finaliza quando o gradiente de desempenho, ou seja, o erro quadrático médio, fica com gradiente abaixo de $1.10^{-6}$ ou atinge-se número máximo de épocas para o treinamento, que foi parametrizado para 1000 épocas.

As funções de ativação utilizadas são a Tangente Sigmoidal Hiperbólica para camadas ocultas intermediárias e Soft Max para a camada de saída. São investigadas configurações de redes neurais com duas camadas escondidas $k 1$ e $k 2$, uma vez que segundo SILVA, SPATTI e FLAUZINO (2010) é possível se classificar qualquer problema de 
reconhecimento de padrões utilizando duas camadas escondidas. Utiliza-se um toolbox do MATLAB denominado patternnet para este classificador.

O ajuste dos hiper-parâmetros para os classificadores kNN e RNA utiliza uma estratégia de validação cruzada conhecida como $k$-partições. No caso, o universo de amostras foi dividido em 5 partições (5-fold). A composição de cada partição é feita com seleção de amostras escolhidas aleatoriamente, mas que mantém a mesma proporção de dados de cada classe, ou seja, as partições são compostas por amostras balanceadas.

Assim, cinco conjuntos de treinamento são montados, cada um contendo quatro das cinco partições (80\% das amostras) e 5 conjuntos de testes, utilizando a partição remanescente de cada caso (20\% das amostras).

O conjunto de treinamento é utilizado para ajustar o classificador que, após ajustado, utiliza o conjunto de teste, que viabiliza a verificação de seu desempenho. Na estratégia sugerida, esta tarefa é repetida para as 5 situações diferentes de conjuntos de treinamento e teste.

No caso do algoritmo kNN, o ajuste do hiperparâmetro k-vizinhos é realizado investigando k no intervalo entre $[1,20]$.

Para a RNA, foram investigadas configurações entre 1 a 20 neurônios em duas camadas escondidas, sendo que cada caso é executado 5 vezes, para evitar mínimos locais devido a inicialização dos pesos sinápticos iniciais.

Para a ferramenta SVM foi utilizado margens flexíveis com fator de suavização (hiper-parâmetro $C$ ) e função kernel do tipo gaussiana (hiperparâmetro $\gamma$ ), uma vez que foi considerado que os conjuntos de classe não seriam linearmente separáveis.

A configuração dos hiperparâmetros da SVM é investigado automaticamente por uma estratégia de otimização, conforme mostra 3.4.2 para os hiper-parâmetros $\gamma$ da função kernel gaussiana e coeficiente de suavização $C$, ambos são investigados entre valores de 0.001 e 1000.

A figura 31 apresenta o esquemático da metodologia de maneira simplificada com apresentação das ferramentas de aprendizagem de máquina empregadas.

A tabela 5 apresenta os hiper-parâmetros e faixa de valores que foram indicados nesta metodologia para investigação, para cada classificador.

\subsection{Avaliação de Desempenho e Validação}

Para a avaliação dos resultados do sistema diagnóstico gerado a partir desta metodologia alguns indicadores de desempenho foram empregados, e para a validação dos resultados e verificação da capacidade de generalização do sistema foi utilizada a estratégia de validação cruzada para $k$-partições, conforme descrito anteriormente. 
Figura 31: Metodologia proposta apresentada graficamente.

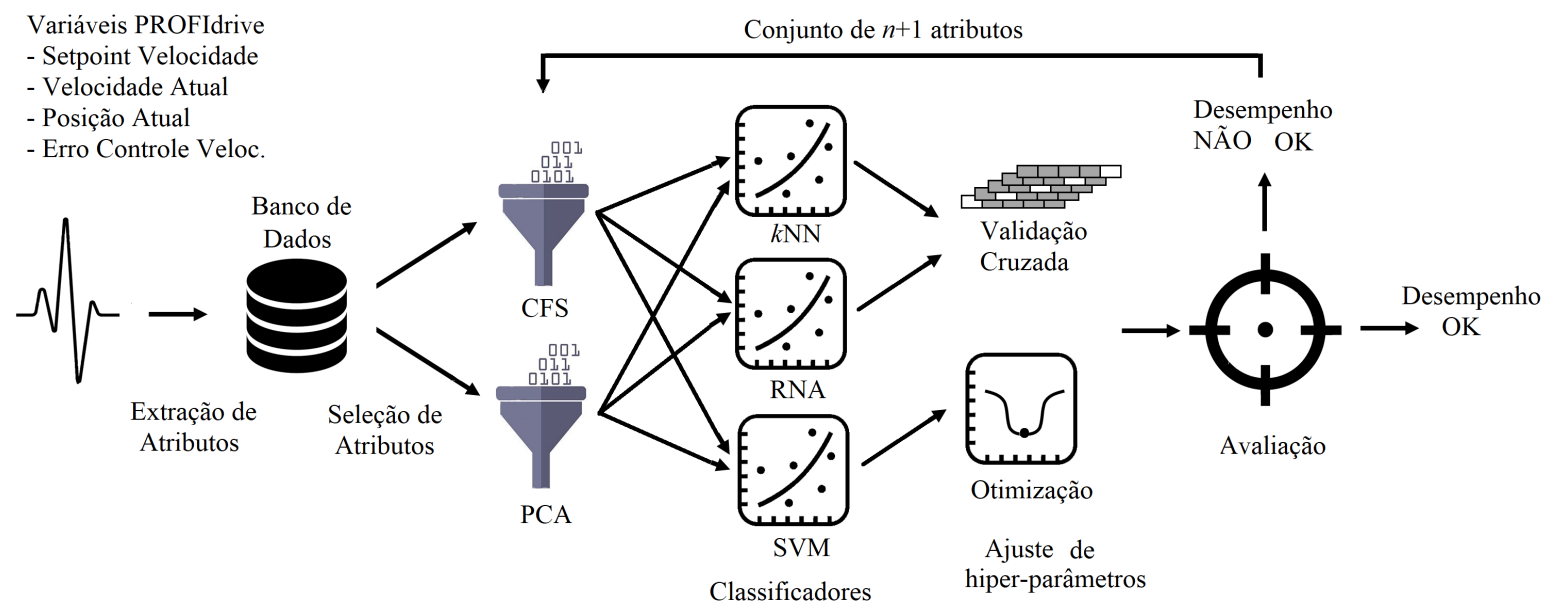

Fonte: Elaborada pelo autor

Tabela 5: Lista de hiper-parâmetros a serem ajustados para o classificador correspondente

\begin{tabular}{ccccc}
\hline Classificador & Qtd. & Hiper-Parâmetros & Descrição & Faixa \\
\hline kNN & 1 & $k$ & Número de vizinhos & {$[1,20]$} \\
RNA & 2 & $k_{1}, k_{2}$ & Núm. de Neurônios & {$[1,20]$} \\
\multirow{2}{*}{ SVM } & 2 & $C, \gamma$ & nas Camadas Escondidas & Fator de Suavização \\
& & & Função Kernel & {$[0.001,1000]$} \\
\hline
\end{tabular}

Fonte: Elaborada pelo autor.

Em um sistema de detecção de anomalias, existem quatro possibilidades de resultados para as amostras do conjunto de teste, conforme apresentado por (BHUYAN; BHATTACHARYYA; KALITA, 2014). Quando uma amostra anômala é classificada como anômala é contado como Verdadeiro Positivo (VP), e se for classificada como condição normal, é contabilizada como Falso Negativo (FN). Por outro lado, se uma amostra normal for classificada também como normal, é chamada de Verdadeiro Negativo (VN), e se for classificada como anormal, resulta em Falso Positivo (FP).

A partir da definição destes eventos, a avaliação dos classificadores investigados emprega os seguintes indicadores desempenho:

- Acurácia: trata-se da proporção de amostras classificadas corretamente pelo total de amostras classificadas, para a estratégia (5-fold) será calculada a média e desvio padrão;

$$
\text { Acurácia }=\frac{V P+V N}{V P+V N+F P+F N}
$$


- Erro: proporção de amostras classificadas incorretamente pelo total de amostras classificadas;

- Razão de Falsos Positivos (RFP): proporção de amostras classificados como anormais, porém genuinamente normais;

$$
R F P=\frac{F P}{F P+V N}
$$

- Razão de Falsos Negativos (RFN): proporção de amostras classificadas como normais, porém genuinamente anormais e

$$
R F N=\frac{F N}{V P+F N}
$$

- Tempo de processamento: tempo necessário para execução de uma classificação. Neste trabalho considerando o tempo para classificação de todos os conjuntos de teste.

Além destes indicadores, outros indicadores são utilizados na literatura sobre classificadores binários: a Especificidade e a Sensibilidade.

Segundo (BHUYAN; BHATTACHARYYA; KALITA, 2014), a sensibilidade é a proporção de instâncias anômalas classificadas corretamente sobre o número total de instâncias anômalas presentes nos dados de teste. A especificidade, também conhecida como a Razão de Verdadeiros Negativos (RVN) é a proporção de instâncias normais classificadas corretamente sobre o número total de instâncias normais presentes nos dados de teste.

$$
\text { Especificidade }=\frac{V N}{V N+F P}
$$

Assim, a Sensibilidade é definida como prioritária quando o sistema deve ser protegido a todo custo, e a Especificidade tem mais prioridade quando a eficiência é a principal preocupação. Para o caso do sistema de diagnóstico proposto, onde busca-se identificar anomalias no sistema eletromecânico, que pode até mesmo ocorrer por meio de um processo de degradação gradual, preocupa-se mais com o indicador especificidade. Desta maneira, dá-se preferência por não indicar uma falha que possa estar ocorrendo no sistema, em detrimento a indicar uma falha que não esteja ocorrendo no sistema, o que poderia reduzir a disponibilidade do processo industrial. Assim, objetiva-se redução do número de Falsos Positivos. 
Ademais, outro importante indicador é a Precisão, definida pela razão de amostras classificadas corretamente como anômala-las, sobre o total de amostras classificadas como anômalas, conforme mostra a equação 4.16 .

$$
\text { Precisão }=\frac{V P}{V P+F P}
$$

A análise do melhor classificador se baseia nos indicadores apresentados. Inicialmente é verificado o valor médio e desvio padrão da acurácia, porém outros indicadores são analisados como RFP, Especificidade, Precisão e tempo de execução para classificação de uma nova amostra.

Assim, verifica-se o classificador com melhor desempenho e se obteve resultados satisfatórios. O cálculo dos indicadores de desempenho é realizada considerando apenas os conjuntos de teste na estratégia de validação cruzada. O sistema de diagnóstico resultante é composto pela definição dos atributos selecionados, juntamente com o classificador a ser empregado, com hiper-parâmetros ajustados de acordo com os dados coletados para seu treinamento.

A estratégia de Curva de Aprendizagem pode ser utilizada para validação no que tange a quantidade de amostras utilizadas no treinamento.

\subsection{Adaptação da Metodologia para a Estratégia de Detecção de No- vidades}

Para casos em que a coleta de dados da máquina operando em condição de operação anormal é muito custosa, inviabilizando a utilização de classificadores que utilizam treinamento supervisionado, esta tese sugere uma adaptação da metodologia proposta para que apenas dados de processo em condição de operação normal dos acionamentos de motores sejam necessários no desenvolvimento do sistema de diagnóstico. A adaptação ocorre na etapa de Seleção de Atributos e Classificadores.

Na etapa Seleção de Atributos, é investigada a utilização de todos os atributos ou utilização do conjunto de atributos indicados a partir de conclusões retiradas de máquinas similares onde foi possível a coleta de dados em condições normais e anormais.

Na etapa de Classificadores é utilizado um algoritmo para detecção de uma só classe ou detecção de novidades. Nesta tese, investiga-se a ferramenta OCSVM, utilizando fator de suavização igual a 1 e função kernell gaussiana.

A figura 32 apresenta a adaptação da metodologia de forma esquemática.

A próxima seção apresenta os cenários que servirão para validação da metodologia e sua adaptação para detecção de novidades sugeridas por esta tese. 
Figura 32: Adaptação da metodologia proposta apresentada graficamente.

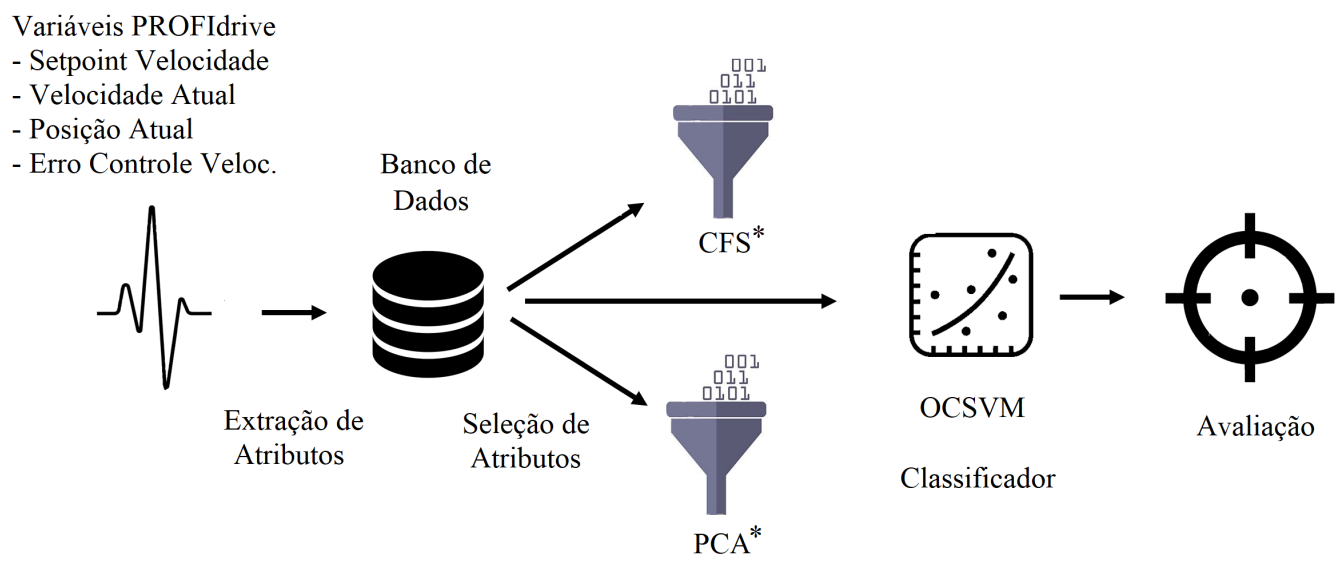

Fonte: Elaborada pelo autor 



\section{CAPÍTULO 5 EXPERIMENTOS E ESTUDOS DE CASO}

Neste capítulo é descrita toda a estrutura responsável pela coleta de dados experimentais dos cenários das aplicações de controle de movimento para o desenvolvimento do trabalho de identificação de anomalias.

\subsection{Bancada Experimental}

A bancada experimental recria equipamentos utilizados para controle de motores elétricos amplamente utilizada em máquinas e processos industriais, interligados por uma rede PROFINET. Ela é composta basicamente pelos seguintes equipamentos:

- Controlador Lógico Programável (CLP): utilizado para propósitos de controle e criação dos setpoints do processo industrial. Dentro da rede PROFINET, perfil PROFIdrive faz a função do IO Controller, denominado Controlador. O software de programação do CLP, utilizado para implementação das redes dos experimentos foi o TIA Portal V14 SP1 da fabricante SIEMENS.

- Drive: responsável pelo acionamento elétrico do motor a partir da referência do CLP. Executa o controle baseado em dados do Encoder, enviando informação sobre posição e velocidade atual do motor. O software de programação foi o Drive ES STARTER V4.5.1.0 da empresa SIEMENS.

- Encoder: instalado no eixo do motor, é responsável pela medição da posição e rotação. Trata-se de um encoder absoluto multivoltas, com 512 pulsos por revolução.

- Motor: responsável pela transferência de energia para a carga a ser acionada. Foi utilizado um motor síncrono de imãs permanentes, rotação nominal de 6000RPM, torque nominal de $0.6 \mathrm{NM}$ e corrente nominal de $1.4 \mathrm{~A}$.

- Cargas*: foram empregadas diversos tipos de cargas a serem apresentadas no decorrer deste capítulo. Alguns cenários utilizam discos mecânicos instalados no eixo do motor, e o outros um redutor mecânico de velocidade acoplador por um acoplador flexível.

- Sistema de medição: responsável pela coleta de dados de processo da rede PROFINET. 
Tabela 6: Lista de equipamentos.

\begin{tabular}{cccc}
\hline Item & Dispositivo & Descrição & Referência \\
\hline 1 & Controller & PLC S71200 CPU1214C & 6ES7214-1AG40-0XB0 \\
2 & Drive & S110 CU305PN & 6SL3210-1SB14-0UA0 \\
3 & Servo Motor & Motor Síncrono & 1FK7022-5AK71-1LG0 \\
4 & Encoder & Multivoltas, 512pulsos/rev & - \\
5 & Sniffer & Analisador de Rede & KUNBUS-TAP 2100 \\
\hline
\end{tabular}

Fonte: Elaborada pelo autor.

A tabela 6 apresenta a lista de dispositivos empregados na bancada experimental utilizada.

Adicionalmente, se utiliza uma estrutura mecânica para fixação dos equipamentos que compõem todo o sistema eletromecânico da bancada. A figura 33 ilustra a composição da bancada experimental utilizada para aquisição dos dados.

Figura 33: Esquema geral da estrutura da bancada experimental.

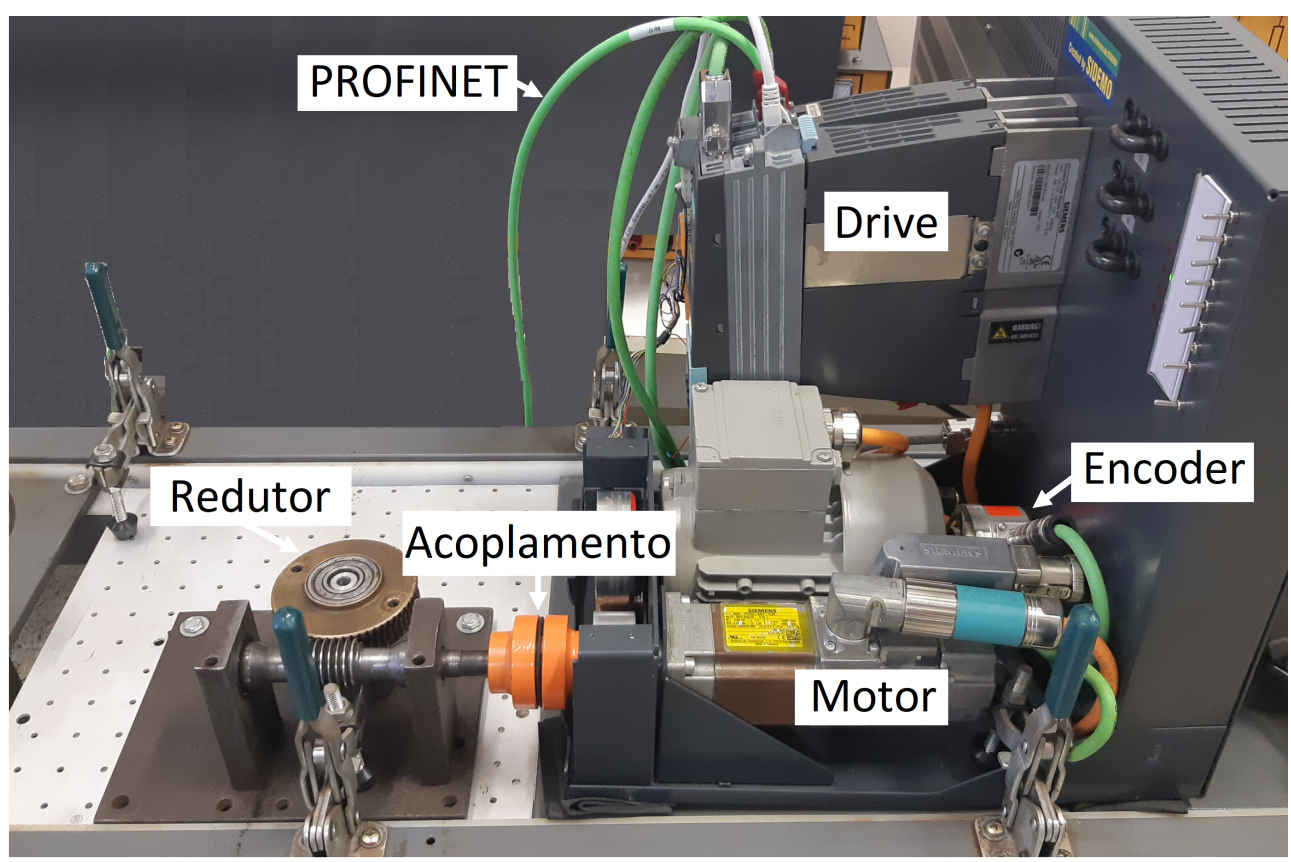

Fonte: Elaborada pelo autor

Cenários foram produzidos em laboratório para validar a metodologia proposta. Eles foram desenvolvidos para representar as mais comuns aplicações em indústria de manufatura: controle de velocidade e posição de motores elétricos, que requerem comunicação em tempo real com valores restritos, executando operações cíclicas, ou seja os setpoints para operação das máquinas utilizados são periódicos.

Para o controle de posição propõem-se a Classe de Aplicação 4 de acordo com 
Figura 34: Esquemático da aplicação para controle de posição do motor.

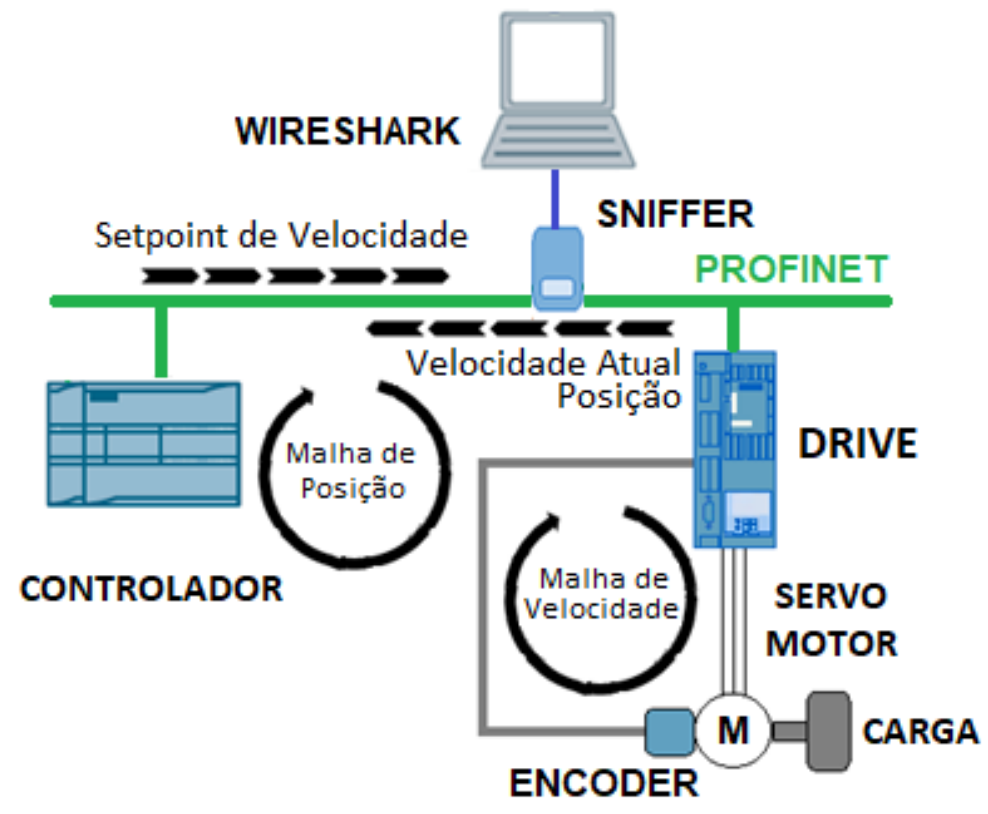

Fonte: Elaborada pelo autor

o perfil PROFIdrive, utilizando o Telegrama Padrão 3. Como mostrado na figura 34, a malha de controle de posição é processado no Controlador que calcula e envia o setpoint de velocidade para o Drive. Este retorna os valores de velocidade atual e posição. A troca destes dados de processo é realizada através da rede PROFINET, via comunicação em tempo real cíclica. O setpoint de posição empregado na aplicação é criado no Controlador sendo do tipo degrau, gerado ciclicamente com um período fixo e amplitude de 10 revoluções do motor (3600 graus). O controle de velocidade é processado internamente no Drive.

As aplicações com controle de velocidade são baseadas na Classe de Aplicação 1 e Telegrama Padrão 1. Neste trabalho, o Controlador utiliza setpoint de velocidade tipo senoidal com período fixo. O setpoint é enviado até o Drive via rede de comunicação industrial, que internamente executa o controle de velocidade e envia como retorno o valor da velocidade atual do motor ao Controlador. Ressalta-se, que pela utilização do Telegrama Padrão 1, o sinal de posição do motor não é disponibilizado na rede nesta Classe de Aplicação.

Todos os cenários utilizados deste trabalho utilizam sinais de referência para controle cíclico de máquinas elétricas com período fixo de 4 segundos nas aplicações.

\subsection{Cenários para os Estudos de Caso}

Alguns cenários são investigados para treinamento e validação do sistema de diagnóstico proposto, identificando algumas falhas que normalmente ocorrem durante a 
operação de máquinas em processos industriais. A descrição dos cenários pode ser listado como:

Cenário 1 - Aumento excessivo da inércia da carga: cargas mecânicas acionadas por motores elétricos podem sofrer mudanças com o tempo ou mesmo ser alteradas para execução de outros tarefas, influenciando aspectos do desempenho do sistema de controle, causando perda de eficiência uma vez que o controle em malha fechada normalmente é ajustado de acordo com a carga a ser acionada entre outros aspectos. Kral, Pirker e Pascoli (2007) destaca o impacto da inércia nos efeitos de falhas em rotores, e demonstra que o valor total da inércia possui grande impacto nas assinaturas de falhas. Para este trabalho, cargas com momento de inércia de acordo com a tabela 7 foram utilizadas, sendo consideradas anormais a inércia definida como "Alta", praticamente duas vezes o valor da inércia da carga denominada "Média", que assim como as demais, são consideradas como condições normais de operação. Estas variações de valores investigados denominadas como normais é importante uma vez que proporciona ao sistema de diagnóstico aceitar pequenas variações de inércia, que podem ser consideradas como aceitáveis.

Tabela 7: Descrição das Inércia utilizadas no experimento.

\begin{tabular}{cccc}
\hline $\begin{array}{c}\text { Inércia } \\
\text { Descrição }\end{array}$ & Material & $\begin{array}{c}\text { Momento de Inércia } \\
\text { Adicional }\left[\mathrm{kg} \mathrm{cm}^{2}\right]\end{array}$ & $\begin{array}{c}\text { Momento de Inércia } \\
\text { Total }\left[\mathrm{kgcm}^{2}\right]\end{array}$ \\
\hline Eixo & Alumínio & - & 0.280 \\
Baixa & Alumínio & 0.485 & 0.765 \\
Média & Aço carbno & 0.269 & 1.034 \\
Alta & Aço Carbono & 0.979 & 2.013 \\
\hline
\end{tabular}

Fonte: Elaborada pelo autor.

A figura 35 apresenta algumas peças utilizadas como inércias para coletas de dados e sua fixação no eixo do motor.

Alguns exemplos de máquinas deste tipo são mesa alimentadoras, que podem sofrer alteração do tipo de peças e mesmo de sua base; e máquinas tipo empacotadoras e embaladora que comumente são utilizadas para diversos tipos de pacotes e peças e suas configurações são trocados frequentemente, devendo ser reparametrizadas corretamente. Em geral máquinas que possuem alta dinâmica, com ciclos que envolvam acelerações e desacelerações frequentes. É importante ressaltar que alguns tipos de máquinas o aumento excessivo de inércia é natural do processo de fabricação, como o caso de bobinador e desbobinador e de alguns manipuladores robóticos, que em momentos estão transportando cargas e em outros não.

Cenário 2 - Desacoplamento da carga: o eixo de motores de indução são geralmente acoplados a carga acionada por um sistema do tipo polia e correia, engrenagem ou acoplamentos. Problemas mecânicos podem implicar em desacoplamento da carga, que podem causar danos ao processo produtivo e longas paradas não programadas se não forem 
Figura 35: Inércias utilizadas no cenário (a) Alguns tipos de inércia (b) Fixação no eixo do motor.

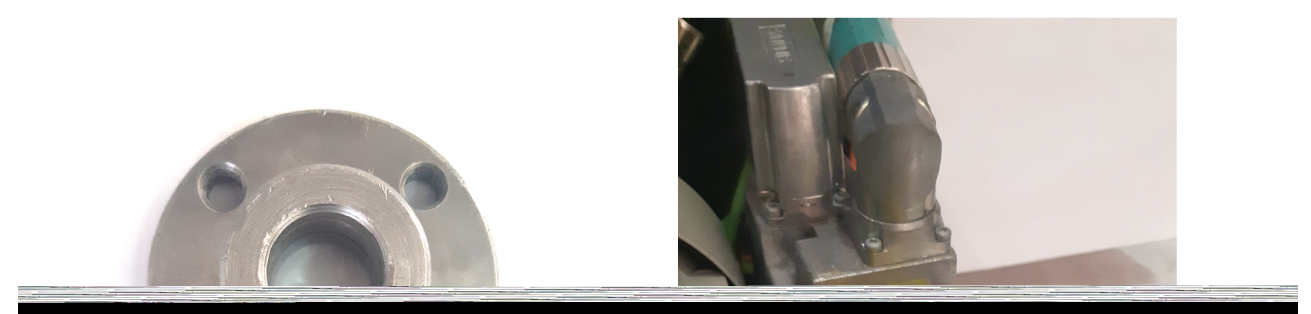

Fonte: Elaborada pelo autor

alertadas em curto espaço de tempo. Neste cenário o eixo do motor é acoplado em um redutor do tipo coroa e rosca sem fim, com redução de 1:60. Utiliza-se um acoplamento flexível ou elástico do tipo mandíbula, para transmissão do torque. Considera-se operação normal do sistema o correto acoplamento permitindo a transmissão de torque do motor para a carga acionada, condição anormal como a impossibilidade de transmissão devido ao desacoplamento, fazendo com que o motor gire praticamente em condição similar à sem carga ou conjugado resistente.

A figura 36 mostra o acoplamento modelo GR050 do fabricante Mademil utilizado neste cenário. A montagem do acoplamento foi realizada de acordo com instruções do fabricante.

Este tipo de falha pode ser aplicado em máquinas em geral que utilizem algum dos sistemas supracitados para transmissão de torque à máquina.

Cenário 3- Desbalanceamento mecânico: Desbalanceamento e desalinhamento são as falhas mecânicas que mais ocorrem em máquinas. Desbalanceamento é definido como distribuição desigual de massa em torno do eixo central do rotor (TAHIR et al., 2016).

A figura 37 apresenta uma carga mecânica na forma de disco, desbalanceada por 
Figura 36: Acoplamento flexível utilizado para transmissão de torque entre eixo do motor e redutor.
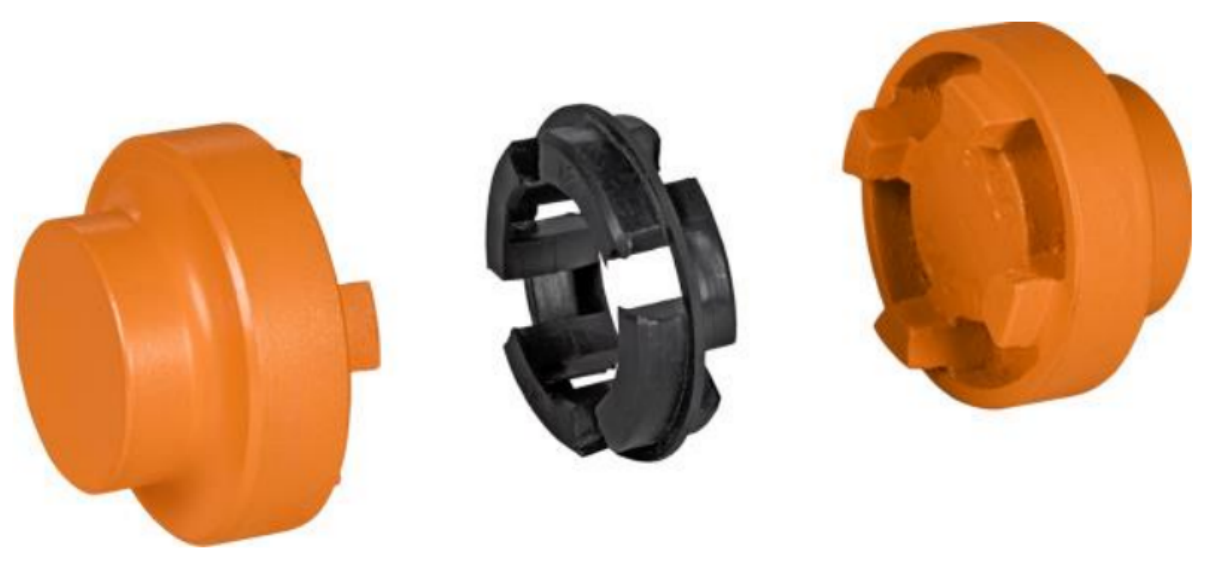

Fonte: Elaborada pelo autor

meio da inserção de uma massa $m$ a uma distância $R$ do centro de rotação, que gira uma velocidade de rotação $\omega$. É possível se medir o desbalanceamento pelo produto entre massa $m$ e distância $R$.

Figura 37: Desbalanceamento em cargas rotativas (a) Representação esquemática da carga desbalanceada (b) Foto do disco utilizado para gerar níveis de desbalanceamento.

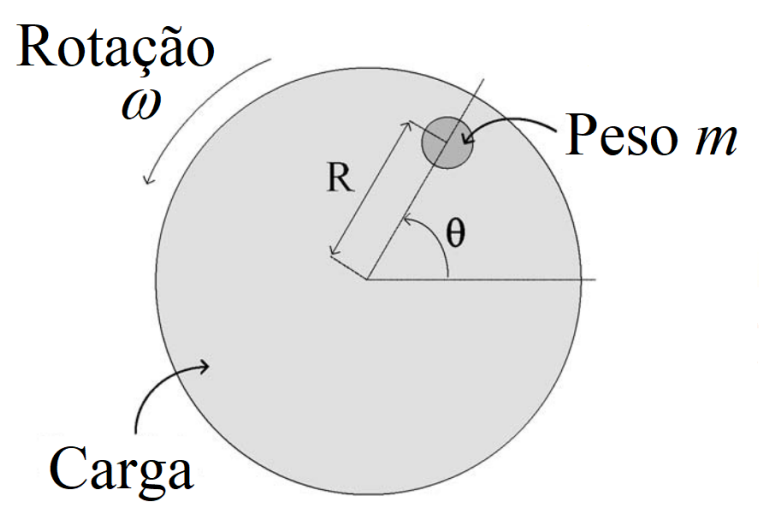

(a)

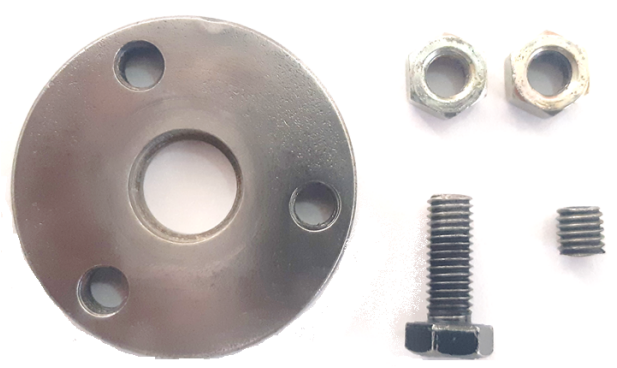

(b)

Fonte: Elaborada pelo autor

Para este cenário, um disco cilíndrico foi instalado no eixo do motor, possuindo $55 \mathrm{~mm}$ de diâmetro, $7 \mathrm{~mm}$ de espessura e $110 \mathrm{~g}$ de peso. Para introduzir diferentes níveis de desbalanceamento mecânico no sistema, massas $m$ de acordo com a tabela 8 , são fixadas a uma distância de $R=20 \mathrm{~mm}$ do centro do disco, através de roscas padrão M8, que também foram usinadas no disco. Itens identificados como "Nenhum"e "Pouco"são considerados 
Tabela 8: Massas utilizadas para desbalanceamento da carga.

\begin{tabular}{ccc}
\hline $\begin{array}{c}\text { Descrição do } \\
\text { Desbalanceamento }\end{array}$ & $\begin{array}{c}\text { Peso } \\
{[\mathrm{g}]}\end{array}$ & $\begin{array}{c}\text { Desbalanceamento Total } \\
{[\mathbf{m m} \cdot \mathrm{g}]}\end{array}$ \\
\hline Nenhum & 0 & 0 \\
Pouco & 2.25 & 45 \\
Médio & 21.30 & 246 \\
Grande & 28.65 & 533 \\
\hline
\end{tabular}

Fonte: Elaborada pelo autor.

condições de operação saudáveis, ou seja, desbalanceamentos aceitáveis, enquanto os itens "Médio"e "Grande"criam condições faltosas.

A figura 38 apresenta um esquemático do motor, disco e massas a serem inseridas para criação deste cenário.

Figura 38: Tipos de desalinhamento e indicação de valores.

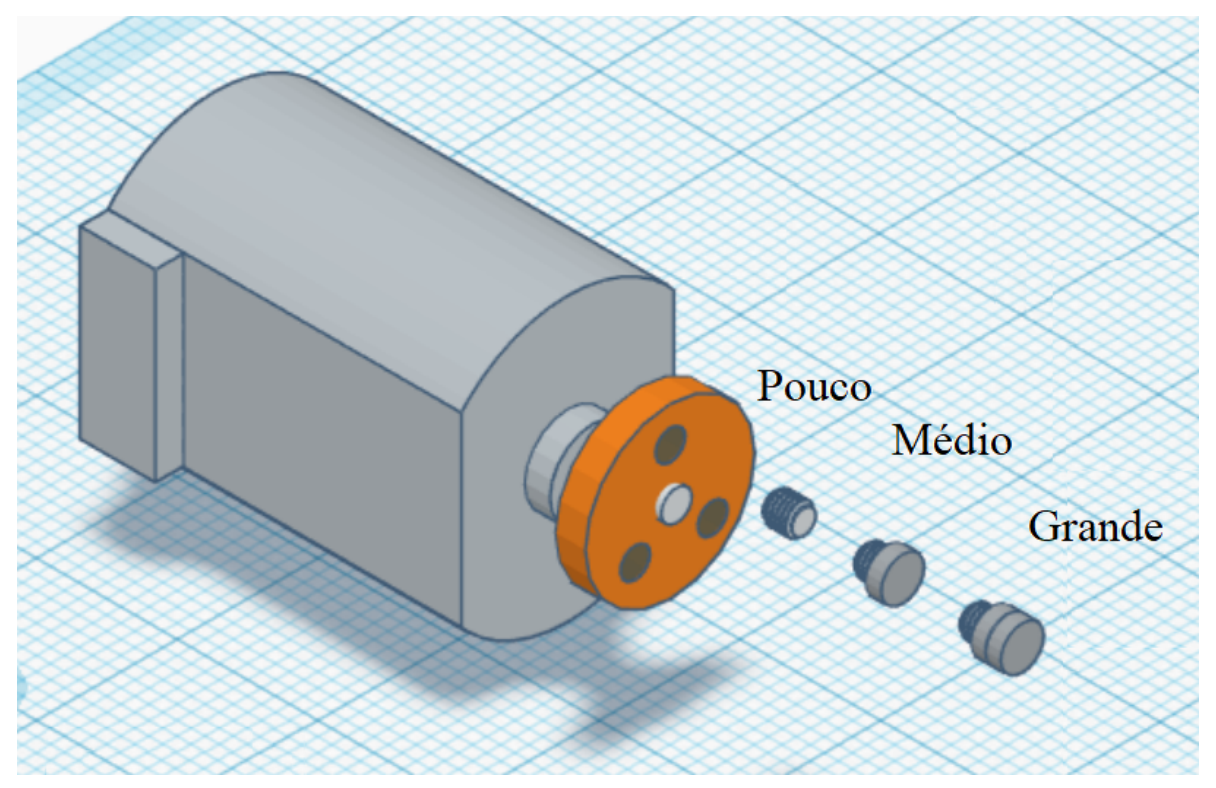

Fonte: Elaborada pelo autor

Cenário 4 - Desalinhamento: ocorre quando o eixo do motor e o eixo da carga não estão acoplados de maneira perfeitamente colinear. A falha de desalinhamento pode ser classificada como angular e paralelo ou linear. Este trabalho investiga ambos os tipos. Da mesma maneira como no Cenário 2, um redutor é acoplado ao eixo do motor por meio de um acoplamento flexível axial. A condição de operação normal é quando a instalação da carga é realizada de acordo com especificação do fabricante obtendo-se alinhamento aceitável entre os eixos do motor e carga. A figura 39 mostra os tipos de desalinhamento. Como condições faltosas, a condição de operação de desalinhamento angular emprega valor de $\alpha$ sendo 1 grau, e para desalinhamento paralelo, utiliza $d$ de $0.8 \mathrm{~mm}$.

A figura 40 apresenta um esquemático deste cenário apresentando algumas medidas 
Figura 39: Tipos de desalinhamento e indicação de valores.

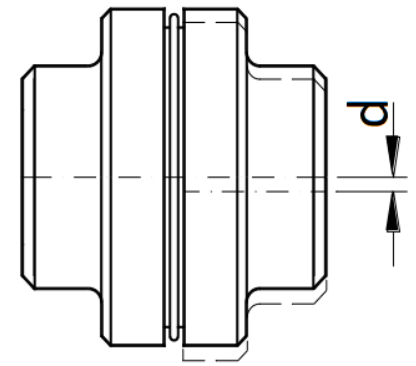

Parallel misaligment

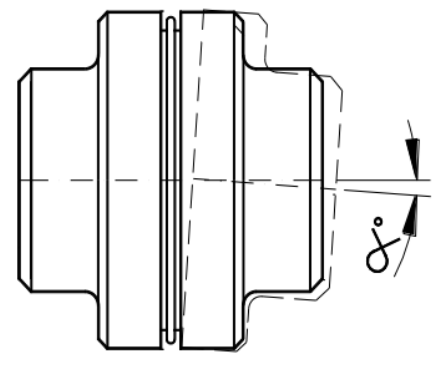

Angular misaligment

Fonte: Elaborada pelo autor

importantes entre motor e redutor mecânico, que foram necessárias para gerar os níveis de desalinhamento que serão investigados.

Figura 40: Tipos de desalinhamento e indicação de valores.
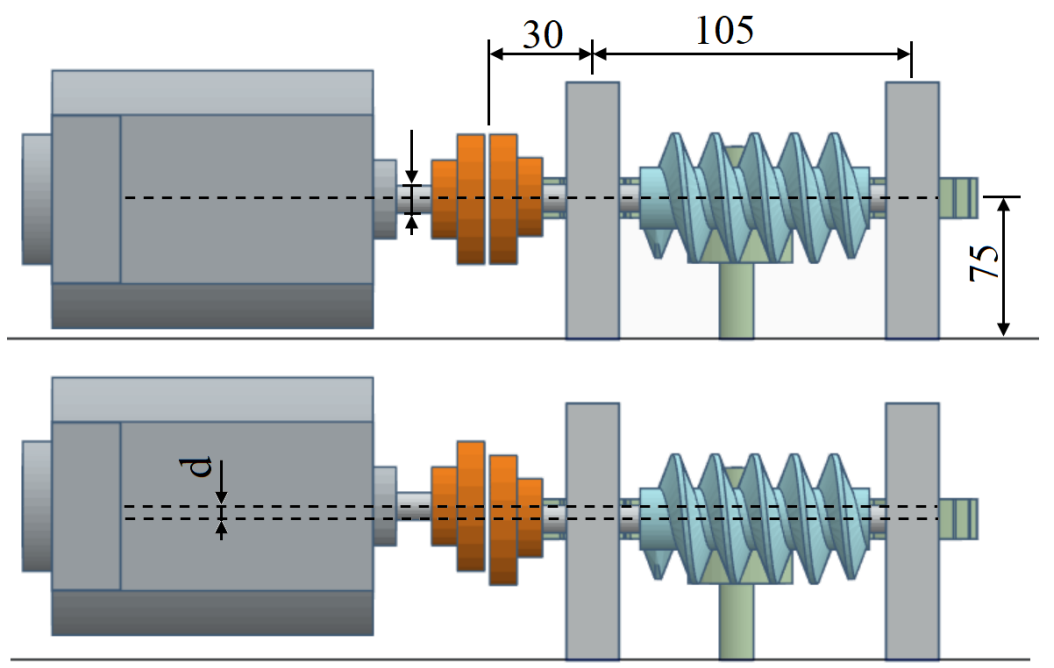

b)

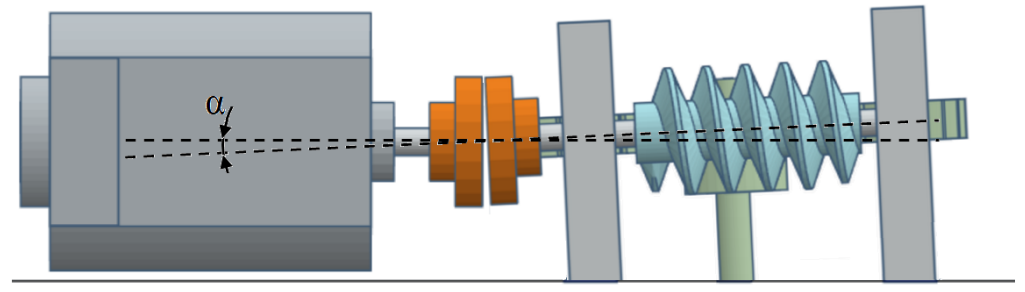

c)

Fonte: Elaborada pelo autor

A investigação desenvolvida neste tese foi limitada aplicando-se estratégias de controle conforme Classe de Aplicação 4 para o primeiro e segundo cenário, e Classe de Aplicação 1 para terceiro e quarto cenário.

Com propósito de buscar uma análise mais adequada dos cenários e representar 
de uma maneira mais ampla o sistema eletromecânico conforme aplicações reais, a coleta de dados foi desenvolvida para diferentes parâmetros de operação da máquina. Tanto em relação a aspectos da rede quanto para aspectos de controle de movimento, que representem possíveis alterações de parâmetros feitas por operadores e mesmo para ajuste de eficiência no processo produtivo.

Os parâmetros variados neste trabalho foram:

- Tempo de Ciclo da rede: o tempo para a atualização dos dados de processo entre IO Controller e IO Device.

- Velocidade Máxima: Velocidade máxima de rotação que é habilitada para o controle de posição ou o setpoint de velocidade máximo enviado pelo controlador.

- Aceleração Máxima: aceleração máxima de rotação que é habilitada para o controle. A nomenclatura tempo da rampa de aceleração e desaceleração também pode ser utilizado.

Esta abordagem garante maior robustez para o sistema de diagnóstico uma vez que poderá diagnosticar anomalias na máquina acionada mesmo com diferentes parametrizações da aplicação. A tabela 9 mostras as condições empregadas para cada cenário proposto. A aceleração máxima é configurada sempre com o dobro do valor da velocidade máxima ou amplitude do setpoint senoidal empregado na Classe de Aplicação 1.

Tabela 9: Variações de parâmetros investigados.

\begin{tabular}{ccccc}
\hline & Cenário 1 & Cenário 2 & Cenário 3 & Cenário 4 \\
\hline $\begin{array}{c}\text { Tempo de Ciclo } \\
{[\mathrm{ms}]}\end{array}$ & $1,2,4,8,16$ & $1,2,4,8,16$ & $1,2,4,8,16$ & $1,2,4,8,16$ \\
\hline Veloc. Máxima & 6000,4500, & 4500,3750, & 4500,3750, & 5250,4500, \\
{$[$ rpm $]$} & 3000,1500 & 3000,2250, & 3000,2250, & 3750,3000, \\
& & 1500,750 & 1500 & 2250,1500 \\
\hline Aceler. Máxima & 12000,9000, & 9000,7500, & 9000,7500, & 10500,9000, \\
{$\left[\right.$ rev/min $\left.{ }^{2}\right]$} & 6000,3000 & 6000,4500, & 6000,4500, & 7500,6000, \\
& & 3000,1500 & 3000 & 4500,3000 \\
\hline
\end{tabular}

Fonte: Elaborada pelo autor.

Finalmente, com a descrição da bancada experimental e cenários propostos para investigação, a metodologia é aplicada. Os resultados são apresentados na próximo capítulo. 



\section{CAPÍTULO 6 RESULTADOS E DISCUSSÃO}

Neste capítulo são apresentados os resultados obtidos pela aplicação da metodologia proposta no capítulo 4 para identificação de anomalias em aplicações de acionamentos de motores elétricos causadas por problemas na carga ou mesmo por variações de todo o conjunto eletromecânico. Para organização das informações, os resultados são apresentadas em seções conforme cenários apresentados. Como regra geral, espera-se alcançar valores de acurácia elevadas por volta de $99 \%$ ou similares a literatura correlata, definindo-se o sistema de diagnóstico que emprega o melhor algoritmo de seleção de atributos e classificador de padrões. Busca-se adicionalmente baixo valores para RFP, especificidade, Precisão e tempo de execução.

\subsection{Aumento excessivo da inércia da carga}

Analisa-se a identificação de anomalia causada pela condição da máquina operando com inércia instalada no eixo do motor com valores muito superiores do que foi inicialmente planejado, ou seja a variação do processo consiste no diagnóstico de alta inércia sendo acionado pelo motor elétrico em um sistema de controle de posição, Classe de Aplicação 4, utilizando Telegrama Padrão 3 do perfil PROFIdrive. Utilizou-se o servo motor acionando cargas com três diferentes valores inércia, conforme tabela 7 , sendo duas delas consideradas normais (itens 1 e 2) e outra classificada como condição de inércia anormal (item 3).

\section{Etapa Coleta de Dados}

No passo da metodologia denominado Coleta de Dados, coloca-se a máquina em operação de acordo com as condições especificadas, aciona-se o sistema de medição (via sniffer e software Wireshark descrito anteriormente). Os dados de processo da rede PROFINET são coletados por um determinado período de tempo, neste caso foi coletado em torno de 30 segundos para cada condição "normal"e "anormal"investigada. O sinal de setpoint de posição foi criado no Controlador, com 4 segundos de período, alterando em amplitude de 10 voltas do motor no sentido horário, seguida de 10 voltas no sentido anti-horário.

É importante ressaltar, que no caso de uma máquina ou sistema que empregue rede PROFINET com um IO-Controller como função de controlador do acionamento e diversos IO-Devices com função de drives de acionamentos, um único sniffer é requerido, sem necessidade de instalação de sensores dedicados instalados na máquina para verificação de seu status de operação. 


\section{Etapa Interpretação Perfil PROFIdrive}

No próximo passo, Interpretação perfil PROFIdrive, aplica-se as funções apresentadas na figura 26 de acordo com a classe de aplicação e telegrama empregados. Interpreta-se para todo o conjunto de pacotes de rede, os dados de processo transmitidos entre dispositivos da aplicação. No caso deste cenário, obtém-se os valores de sinal de setpoint de velocidade enviado do controlador para o drive e velocidade e posição atual enviado do drive para o controlador. O sinal do erro do controle de velocidade também é criado.

\section{Etapa Extração de Atributos}

Na próxima etapa, Extração de Atributos, aplica-se o algoritmo desenvolvido para identificação automática do ciclo de operação da máquina. A partir do resultado obtido, é possível separar a coleta de dados em diversas amostras, cada uma representando um ciclo de operação da máquina. O algoritmo para identificação do ciclo da máquina atingiu excelentes resultados, uma vez que foi capaz de definir com precisão o tempo de ciclo e por consequência a quantidades de pacotes a ser analisada de cada condição de operação do acionamento da máquina. A tabela 10 apresenta os valores da diferença entre o tempo de ciclo real e o verificado pelo algoritmo em milissegundos.

Tabela 10: Resultados do algoritmo para identificação do ciclo de operação. Diferença entre tempo de ciclo real e resultante do algoritmo em milissegundos.

\begin{tabular}{ccccc}
\hline & \multicolumn{4}{c}{ Veloc. Máxima [RPM] } \\
Tde $[\mathbf{m s}]$ & 6000 & 4500 & 3000 & 1500 \\
\hline 1 & -0.37 & 0.22 & 0.48 & -0.23 \\
2 & -0.27 & -0.18 & -0.48 & 0.55 \\
4 & 0.22 & -1.58 & -1.65 & 1.82 \\
8 & -0.60 & -0.56 & -0.18 & -3.99 \\
16 & -0.18 & -0.18 & -0.18 & -3.38 \\
\hline
\end{tabular}

Fonte: Elaborada pelo autor.

Nota-se que os piores resultados são para os sistemas com dinâmica mais lenta, onde os extremos dos valores de velocidade e posicionamento são mais suaves. O resultado com maior diferença obtido foi de $-3.99 \mathrm{~ms}$ para tempo de ciclo de rede configurado em $8 \mathrm{~ms}$ e velocidade máxima configurada para aplicação de 1500RPM. Verifica-se que o módulo do valor da diferença ficou inferior a metade do valor do tempo de ciclo configurada, ou seja inferior a $4 m s$, o que resultou na utilização da quantidade exata de pacotes para cada amostra considerada, conforme mostra a tabela 11. Estes resultados foram similares as demais condições investigadas.

No total, 560 amostras foram consideradas para este cenário, sendo metade delas em condição normal de operação e metade em condição anormal, ou seja, trata-se de um universo de amostras balanceado. Adicionalmente, estas amostras foram coletadas com diferentes parametrizações que representam possíveis alterações realizadas pelos operadores 
Tabela 11: Quantidade média de pacotes utilizada por amostra de acordo com tempo de ciclo parametrizado após identificação do ciclo de operação da máquina.

\begin{tabular}{cc}
\hline Tde [ms] & Qtd. de Amostras \\
\hline 1 & 4000 \\
2 & 2000 \\
4 & 1000 \\
8 & 500 \\
16 & 250 \\
\hline
\end{tabular}

Fonte: Elaborada pelo autor.

de máquina em questão, conforme indicado na tabela 9. Foram empregadas 7 amostras para cada condição normal e 14 amostras para a condição anormal, assim tornando possível se obter um conjunto de dados balanceado. A coleta de várias amostras por condição se faz necessário para dar maior robustez aos resultados de identificação do ciclo de operação da máquina e classificadores empregados pelo sistema de diagnóstico.

A figura 41 apresenta um exemplo de amostras na condição de operação de aplicações saudáveis (baixa e média inércia) e anormal (alta inércia) para os sinais investigados. Os sinais foram plotados de maneira que o eixo das ordenadas se refere ao valor dos dados de processo coletado na rede. Para a medição de velocidade e erro, representa a porcentagem da velocidade angular em relação a velocidade nominal configurada no drive do eixo do motor, e a posição representa um valor diretamente proporcional a posição angular do eixo, porém a unidade de medida específica depende da resolução do encoder e configurações do acionamento implementadas no controlador, que não são transmitidas pela rede PROFINET. Assim, considera-se os sinais como sendo adimensionais.

Na comparação apresentada, verifica-se o comportamento dos sinais para uma única condição de tempo de ciclo (4 milissegundos), velocidade máxima (6000RPM) e aceleração máxima (12000 rev/ $\mathrm{min}^{2}$ ). Nota-se que é possível identificar visualmente diferenças dos sinais dos dados de processo, especialmente o sinal do erro no controle de velocidade.

Ressalta-se também que a coleta de dados para a aplicação no decorrer da metodologia não exige que as amostras estejam sincronizadas, ou seja, cada amostra pode ser aquisitada em momentos diferentes do ciclo de operação da máquina, o que adicionalmente oferece maior flexibilidade na utilização do sistema de detecção de falhas proposto.

Em geral, verifica-se que as amostras geradas a partir dos dados de processo oferecidos pela rede de comunicação para identificação da aplicação de controle de movimento como saudável ou faltoso, possui as seguintes características:

- são relacionados apenas a velocidade e posição angular do eixo do motor, sem unidades de medida específicas, não são disponibilizadas informações de vibração, temperatura, corrente elétrica entre outros utilizando-se telegramas padrões; 
Figura 41: Exemplos de amostras coletadas na rede PROFINET para condição de inércia normal e anormal.
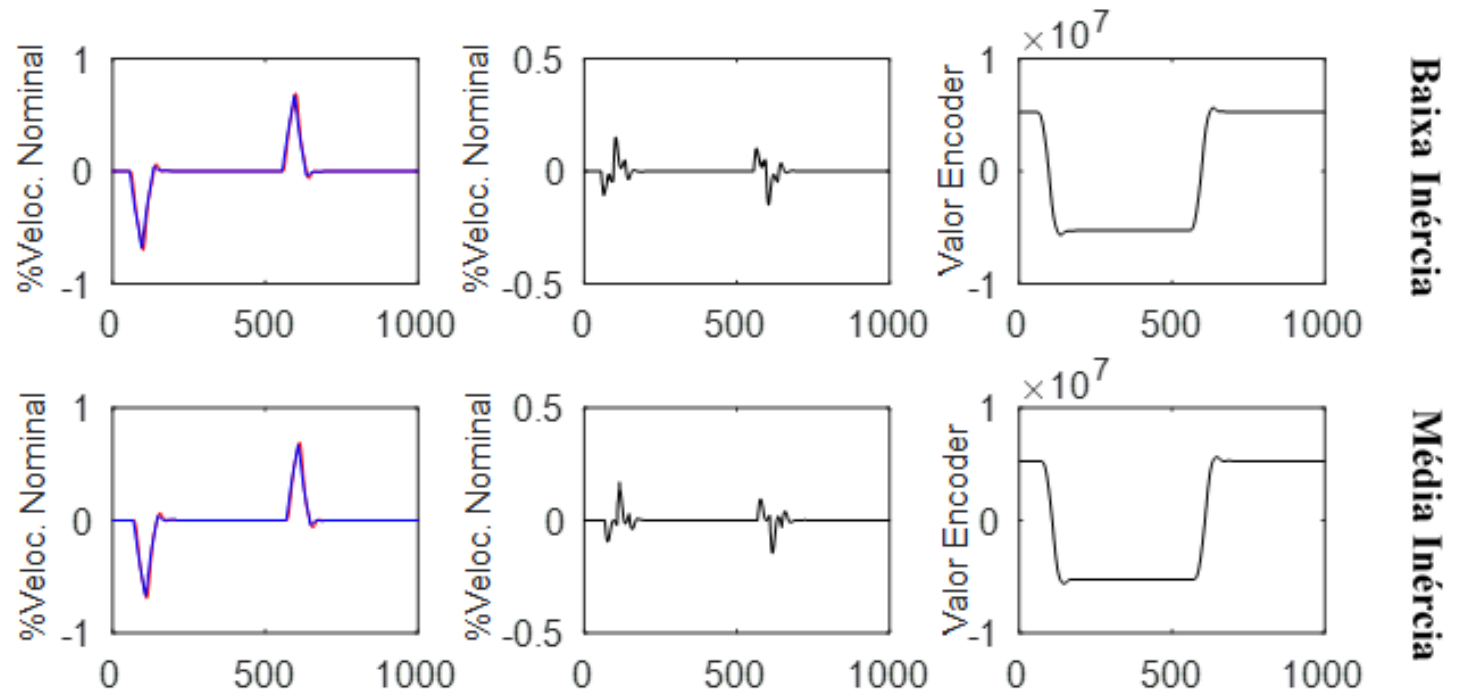

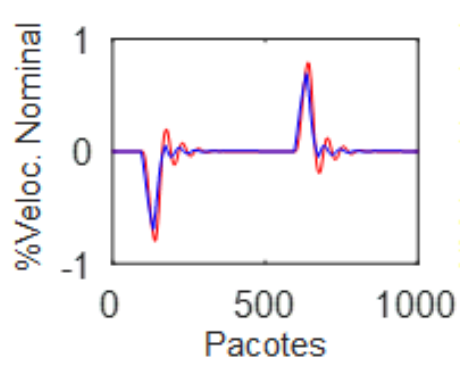

Velocidade Atual (\%) Setpoint de Velocidade $(\%)$

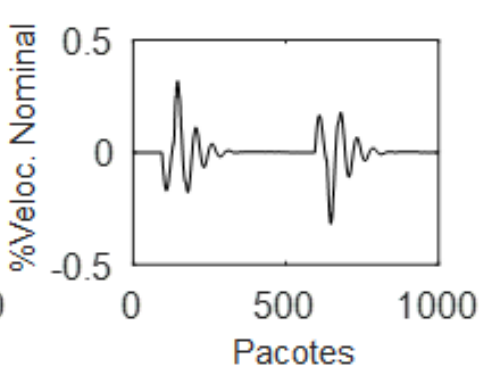

Erro (\%Veloc.

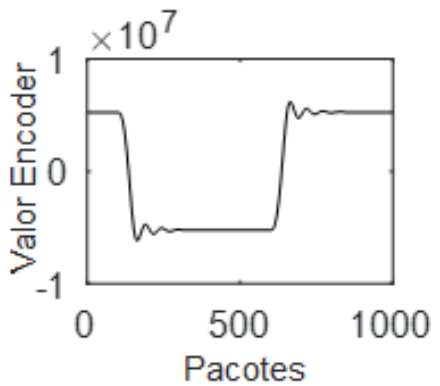

$\frac{2}{\frac{2}{3}}$

Fonte: Elaborada pelo autor

- pode ser compostas por quantidades diferentes de pontos, caso o tempo de ciclo da rede seja configurado em diversos valores, ou seja, a taxa de amostragem de cada sinal pode variar;

Ainda na etapa de Extração de Atributos, características de cada sinal são extraídas de acordo como apresentado na tabela 4, a partir do desenvolvimento de um algoritmo em MATLAB, criando-se uma banco de dados contendo para cada amostra, um vetor com diversas características. No casso da Classe de Aplicação 4 para controle de posição, 102 atributos são extraídos de cada amostra.

\section{Etapa Seleção de Atributos e Classificadores utilizando CFS}

Como a quantidade de atributos extraídos é muito grande, no passo Seleção de Atributos, aplicam-se os métodos de seleção de atributos tipo CFS e PCA. Para o CFS, inicialmente seleciona-se um único atributo, que na aplicação estudada resultou no atributo 
A99, $23^{a}$ harmônica do sinal do erro de velocidade, possuindo correlação com a classe e mérito de 0.629 .

Finalmente, a etapa Classificadores é realizado, aplicando-se os classificadores propostos pela metodologia, chegando-se aos resultados da tabela 12 .

Tabela 12: Resultados para falha de aumento de inércia utilizando CFS a partir de um único atributo.

\begin{tabular}{|c|c|c|c|c|c|c|c|}
\hline $\begin{array}{l}\text { Núm. } \\
\text { Entradas }\end{array}$ & $\begin{array}{l}\text { Método } \\
\text { Seleção }\end{array}$ & Classif. & $\begin{array}{c}\text { Hiper- } \\
\text { parâmetros }\end{array}$ & $\begin{array}{l}\text { Acurácia (\%) } \\
\text { Média(Desv.) }\end{array}$ & FPR & FNR & $\begin{array}{c}\text { Tempo } \\
{[\mathrm{ms}]}\end{array}$ \\
\hline \multirow{3}{*}{1} & \multirow{3}{*}{ CFS } & kNN & $\mathrm{k}=9$ & $88.8(1.5)$ & 14.6 & 7.9 & 1.59 \\
\hline & & RNA & $\begin{array}{l}1^{a} \text { cam. }=7 \\
2^{a} \text { cam. }=2\end{array}$ & $89.8(1.9)$ & 14.3 & 6.1 & 8.41 \\
\hline & & SVM & $\begin{array}{l}\gamma=120.93 \\
\mathrm{C}=996.26\end{array}$ & $88.6(2.4)$ & 15.4 & 7.5 & 0.91 \\
\hline
\end{tabular}

Fonte: Elaborada pelo autor.

Os resultados apresentados se referem aos melhores desempenho para cada classificador de acordo com o ajuste dos hiper-parâmetros de cada algoritmo. É considerado inicialmente o maior valor de acurácia, e em casos onde a acurácia é igual em mais de uma configuração do classificador, os menores valores de RFP, Especificidade, Precisão e menor tempo de execução são considerados. Nesta análise inicial, verifica-se que o melhor resultado para acurácia foi de $89.8 \%$.

Como o desempenho esperado não é atendido, o algoritmo seleciona um novo conjunto com um atributo adicional, como na etapa Seleção de Atributos. Desta vez, resulta-se nos atributos A16, que é a entropia do sinal do erro de velocidade, e manteve-se o atributo A99. O atributo adicional possui correlação com a classe de 0.615 , e correlação mútua de 0.052 , alcançando valor do mérito de 0.857 , que é maior quando comparado ao valor do conjunto anterior. Verifica-se que neste caso, obteve-se atributos com alta correlação com a classe e baixa correlação mútua, provendo informações relevantes para o classificador. Aplicando-se novamente a etapa de Classificadores, obtém-se os resultados da tabela 13 .

Tabela 13: Resultados para aumento de inércia utilizando CFS a partir de dois atributos.

\begin{tabular}{cccccccc}
\hline $\begin{array}{c}\text { Núm. } \\
\text { Entradas }\end{array}$ & $\begin{array}{c}\text { Método } \\
\text { Seleção }\end{array}$ & Classif. & $\begin{array}{c}\text { Hiper- } \\
\text { parâmetros }\end{array}$ & $\begin{array}{c}\text { Acurácia (\%) } \\
\text { Média(Desv.) }\end{array}$ & RFP & RFN & $\begin{array}{c}\text { Tempo } \\
{[\mathbf{m s}]}\end{array}$ \\
\hline \multirow{2}{*}{$\mathrm{kNN}$} & $\mathrm{n}=1$ & $100.0(0.0)$ & 0.0 & 0.0 & 1.04 \\
2 & $\mathrm{CFS}$ & $\mathrm{RNA}$ & $\begin{array}{c}1^{a} c a m .=4 \\
2^{a} \text { cam. }=2 \\
\gamma=31.81 \\
\mathrm{C}=6.27\end{array}$ & $100.0(0.0)$ & 0.0 & 0.0 & 8.97 \\
& $\mathrm{SVM}$ & $100.0(0.0)$ & 0.0 & 0.0 & 0.79 \\
\hline
\end{tabular}

Fonte: Elaborada pelo autor. 
Verifica-se que utilizando conjunto de dois atributos todos classificadores obtiveram acurácia de 100\%, ou seja o desempenho esperado é atendido, sendo possível identificar anomalia em todas as amostras coletadas, validadas pelo método de $k$-fold.

A figura 42 apresenta a distribuição das amostras deste cenário a partir dos atributos selecionados. Nota-se que é possível visualizar o quão esparsas e de que forma estão localizadas as amostras a serem classificadas, dando subsídios para a definição do classificador empregado.

Figura 42: Distribuição das amostras no cenário 1 em função dos atributos selecionados por CFS.

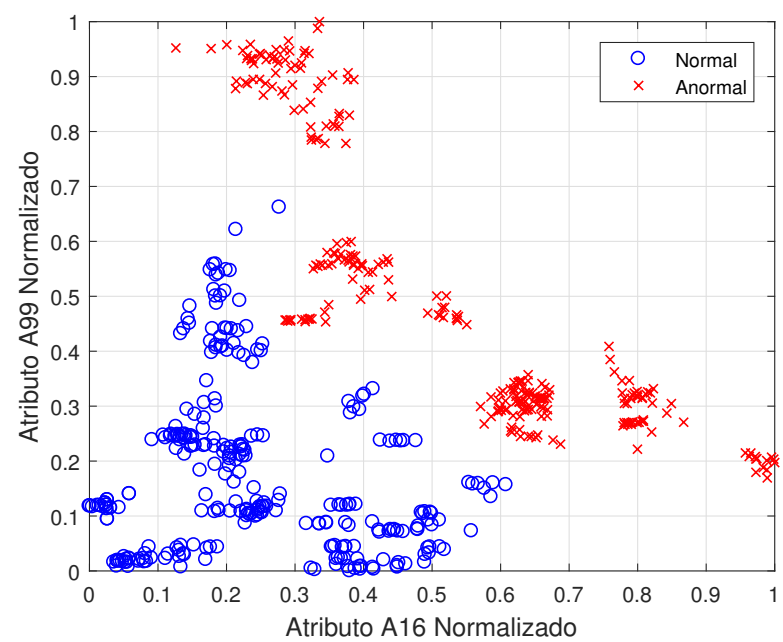

Fonte: Elaborada pelo autor

\section{Etapa Seleção de Atributos e Classificadores utilizando PCA}

Aplicando-se a seleção de atributos com o algoritmo PCA, inicialmente utiliza-se apenas uma componentes principal e aplica-se os classificadores. A partir da análise do desempenho obtido, conforme apresentado na tabela 14, verifica-se que novamente a eficácia não foi satisfeita. Assim, é adicionado ao conjunto de entradas a segunda componente principal, e novamente os classificadores sugeridos são aplicados.

Verifica-se que utilizando a seleção de atributos por PCA, também foi possível obter bons resultados, principalmente com o classificador do tipo kNN, que obteve acurácia de 98.6\%. Porém, comparando apenas o método de seleção de atributos, constata-se que os melhores resultados foi utilizando o algoritmo CFS.

A figura 43 apresenta a distribuição das amostras plotando-se duas componentes principais.

Nota-se que diferentemente da distribuição por CFS, no PCA visualmente não houve uma clara separação entre classes, o que pode ser ratificado comparando os resultados dos classificadores utilizando ambos algoritmos de redução de atributos. Os classificadores que 
Tabela 14: Resultados para falha de aumento de inércia utilizando PCA.

\begin{tabular}{|c|c|c|c|c|c|c|c|}
\hline $\begin{array}{l}\text { Núm. } \\
\text { Entradas }\end{array}$ & $\begin{array}{l}\text { Método } \\
\text { Seleção }\end{array}$ & Classif. & $\begin{array}{c}\text { Hiper- } \\
\text { parâmetros }\end{array}$ & $\begin{array}{l}\text { Acurácia (\%) } \\
\text { Média(Desv.) }\end{array}$ & FPR & FNR & $\begin{array}{c}\text { Tempo } \\
{[\mathrm{ms}]}\end{array}$ \\
\hline \multirow{3}{*}{1} & \multirow{3}{*}{ PCA } & $\mathrm{kNN}$ & $n=2$ & $88.2 .0(1.7)$ & 5.7 & 17.9 & 1.13 \\
\hline & & RNA & $\begin{array}{l}1^{a} \text { cam. }=19 \\
2^{a} \text { cam. }=13\end{array}$ & $87.3(6.3)$ & 12.9 & 12.5 & 9.91 \\
\hline & & SVM & $\begin{array}{c}\gamma=106.61 \\
\mathrm{C}=5.27\end{array}$ & $88.0(1.9)$ & 16.1 & 7.9 & 1.33 \\
\hline \multirow{3}{*}{2} & \multirow{3}{*}{ PCA } & $\mathrm{kNN}$ & $\mathrm{n}=1$ & $98.6(1.2)$ & 2.1 & 0.7 & 1.21 \\
\hline & & RNA & $\begin{array}{l}1^{a} \text { cam. }=17 \\
2^{a} \text { cam. }=10\end{array}$ & $96.8(2.7)$ & 5.4 & 1.1 & 11.40 \\
\hline & & SVM & $\begin{array}{c}\gamma=22.99 \\
\mathrm{C}=74.01\end{array}$ & $97.3(1.8)$ & 4.3 & 1.1 & 0.94 \\
\hline
\end{tabular}

Fonte: Elaborada pelo autor.

Figura 43: Distribuição das amostras no cenário 1 em função de duas componentes principais.

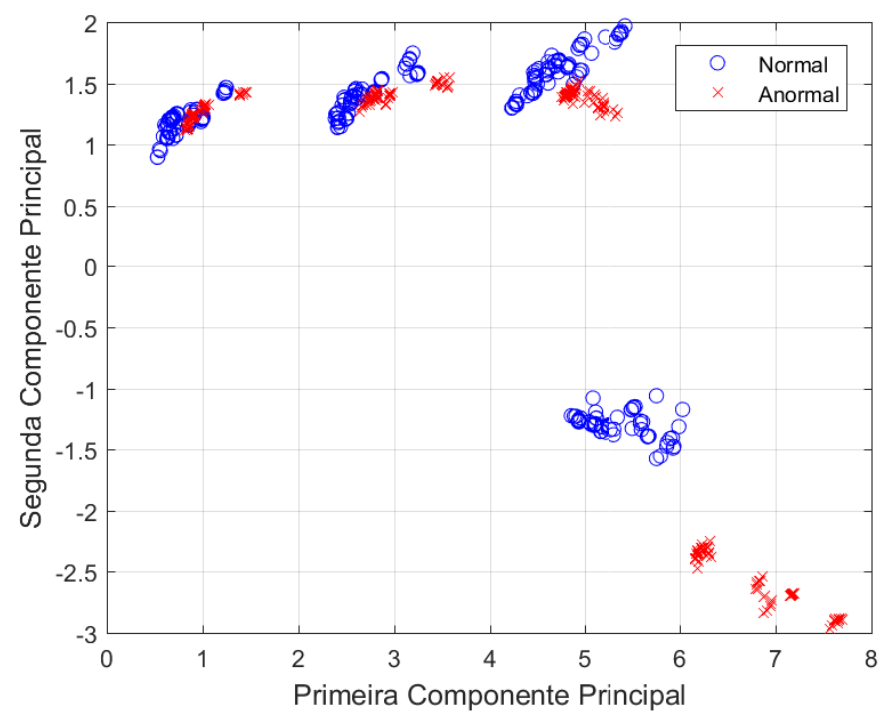

Fonte: Elaborada pelo autor 
utilizaram seleção de atributos por CFS atingiram acurácia com 2.44 pontos percentuais superior.

\section{Avaliação de Desempenho do Sistema de Diagnóstico}

Dentre todas as configurações de ferramentas de aprendizagem de máquinas investigadas, destaca-se a utilização de um conjunto de dois atributos selecionados por CFS, com destaque para o algoritmo SVM, que além de alcançar 100\% de acurácia, obteve menor valor de tempo de execução para classificação de amostras. Este fato pode ser importante uma vez que esta ferramenta pode ser implementada em trabalhos futuros em sistemas embarcados para obter-se respostas online, onde o tempo de execução se torna um indicador importante.

A figura 44 apresenta as margens de classificação do algoritmo SVM após treinamento, utilizando-se validação cruzada. Todos as amostras coletadas são representadas na figura.

Figura 44: Separação de classes utilizando SVM pela metodologia proposta.

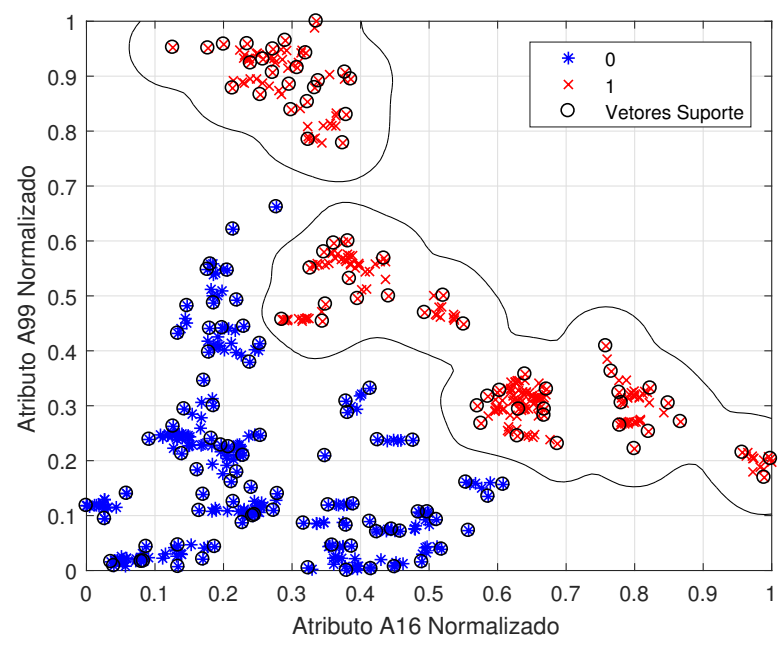

Fonte: Elaborada pelo autor

Neste cenário, ambos os atributos selecionados pelo CFS para identificação da falha são relacionados ao sinal do erro no controle de velocidade. A figura 45, apresenta alguns exemplos de amostras coletadas. Plota-se amostras de condição saudável e faltosa, para as diferentes condições de operação do ponto de vista do controle de acionamento e tempo de ciclo da rede.

Nota-se pela figura que não se trata de uma análise trivial a identificação do sistema faltoso, uma vez que quando a quantidade de pacotes e tempo de amostragem podem ser muito diferentes para cada amostra coletada, com valores entre 250 à 4000 pontos. Adicionalmente observa-se a grande variabilidade da amplitude do erro, que vai da ordem de $2 \%$ a $20 \%$. Ressalta-se que essa grande diferença de parametrizações é comumente 
Figura 45: Sinal do erro no controle de velocidade da aplicação de algumas amostras coletadas.

Vmáx=6000RPM
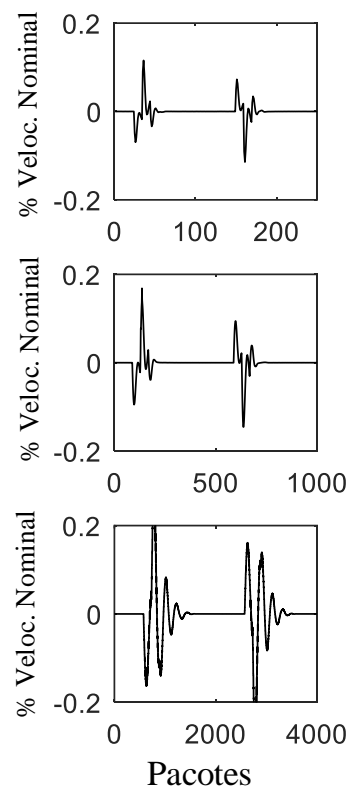

Pacotes
Vmáx=4500RPM
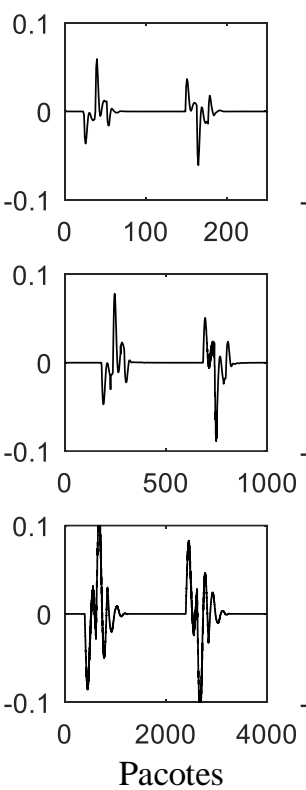

Pacotes
Vmáx=3000RPM
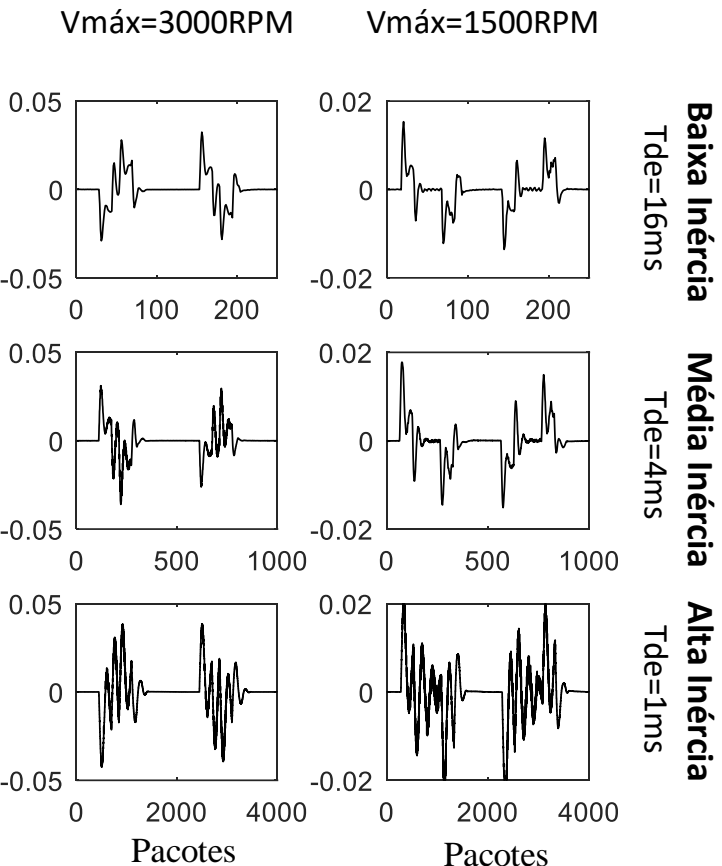

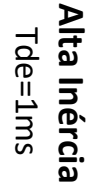

Fonte: Elaborada pelo autor

utilizada para buscar melhora da eficiência do processo ou mesmo alterações de ferramentas ou tarefas.

Comparando os resultados obtidos com trabalhos correlatos, Bansal, Evans e Jones (2005), que utilizou a assinatura de movimento e corrente elétrica para classificação de inércia de cargas em eixos de motores usando abordagem com redes neurais artificiais, teve um acurácia geral de classificação de $97.59 \%$.

\section{Discussão sobre dispersão de amostras por CFS e PCA}

Uma investigação mais aprofundada sobre a distribuição das amostras utilizando-se ambos métodos de seleção a partir das parametrizações do ponto de vista da aplicação de controle de movimento foi implementada conforme mostra a figura 46. Nesta análise as amostras são plotadas no gráfico indicando além do status de normal e anormal, a parametrização de velocidade e aceleração máxima configurada a qual foi submetida.

Verifica-se pelo gráfico que a redução de atributos por PCA, agrupou de forma bastante adequada as diferentes condição da aplicação de controle de movimento, concentrando as amostras em quatro grupos bem definidos visualmente, equivalentes as quatro condições de parametrizações implementadas. Assim, o emprego de PCA para casos em que deseja-se detecção de anomalias para diversas condições de operação, produz resultados menos eficazes que quando comparados a seleção de atributos por CFS, que obteve 
Figura 46: Distribuição das amostras no cenário 1 utilizando CFS e PCA com indicação das condições de operação.
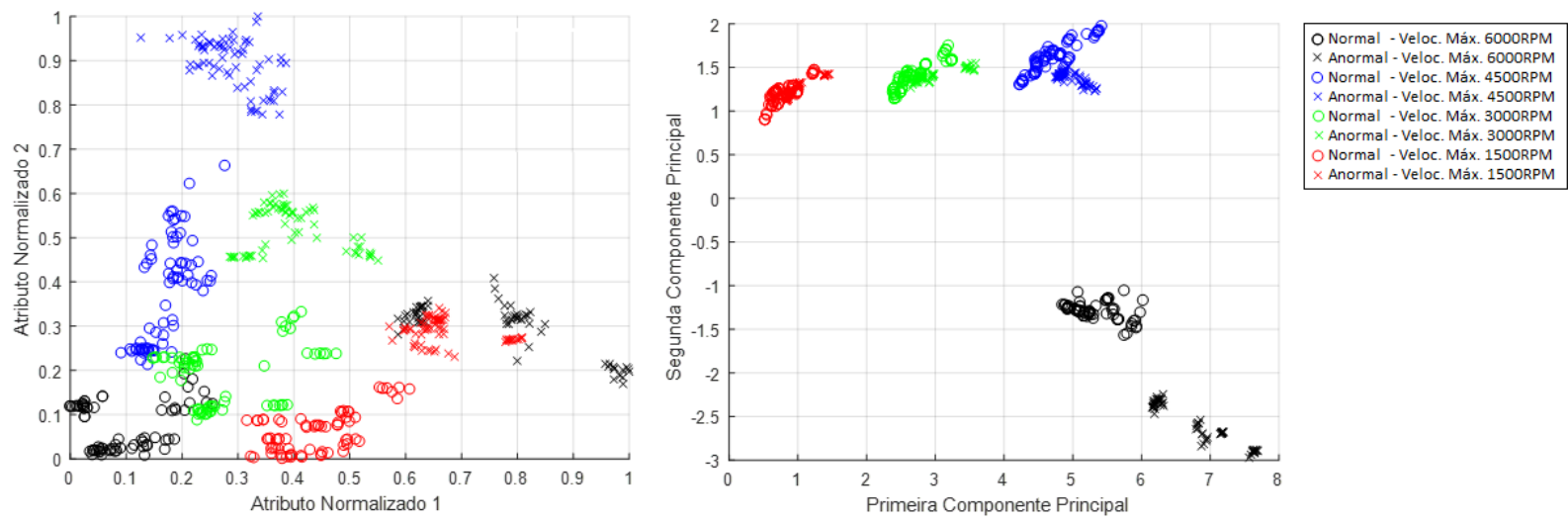

Fonte: Elaborada pelo autor

distribuição de amostras mais favorável para aplicação dos classificadores, no sentido de dispersão entre amostras em condições normais e anormais.

\section{Discussão sobre desempenho considerando menor faixa de parametriza-} ções

Uma outra análise pode ser feita quando se reduz a faixa de parametrizações relacionadas a aplicações de acionamentos de máquinas no desenvolvimento do sistema de diagnóstico. A tabela 15 apresenta os resultados para o classificador SVM utilizando seleção de atributos por CFS, analisando o desempenho da metodologia quando se utiliza os dados de cada condição de parametrização separadamente.

Tabela 15: Resultados para falha de aumento de inércia utilizando condições de operação separadamente.

\begin{tabular}{cccccc}
\hline $\begin{array}{c}\text { Velocidade } \\
\text { Máx. }[R P M]\end{array}$ & $\left.\begin{array}{c}\text { Aceleração } \\
\text { Máx. }[\text { rev/min }\end{array}\right]$ & $\begin{array}{c}\text { Núm. } \\
\text { Atributos }\end{array}$ & Atributos & Mérito & $\begin{array}{c}\text { Acurácia (\%) } \\
\text { Média(Desv.) }\end{array}$ \\
\hline 6000 & 12000 & 1 & A98 & 0.981 & $100.0(0.0)$ \\
4500 & 9000 & 1 & A95 & 0.978 & $100.0(0.0)$ \\
3000 & 6000 & 1 & A99 & 0.941 & $100.0(0.0)$ \\
1500 & 3000 & 1 & A99 & 0.952 & $100.0(0.0)$ \\
\hline
\end{tabular}

Fonte: Elaborada pelo autor.

Nota-se que para todos os casos, apenas um atributo foi suficiente para alcançar 100\% de acurácia do sistema de diagnóstico, indicando que quanto menor a faixa de condições de parametrização do ponto de vista do acionamento, melhor tende a ser o desempenho do sistema de detecção de anomalia. Assim, sugere-se que para aplicações da metodologia proposta em outros cenários e aplicações, o usuário deve restringir de maneira adequada as condições de operação da máquina para se obter melhores resultados 
do sistema de diagnóstico desenvolvido. Em contrapartida, a redução destas condições, torna o sistema não-aplicável em condições para a qual não foi treinado.

\section{Análise da quantidade de dados para validação dos resultados}

Uma análise para verificar se a quantidade de amostras coletadas, que foram empregadas no ajuste dos classificadores foi suficiente para representar o comportamento das condições de operação da máquina foi realizada. Para isso traçou-se a curva de aprendizado, conforme apresentado na seção 3.5, onde o treinamento e teste do sistema de diagnóstico da metodologia proposta foi realizada considerando quantidades inferiores de amostras, escolhidas aleatoriamente. Nesta análise, apenas o método de seleção de atributos CFS e classificador SVM, que obteve melhor desempenho foi utilizado. A figura 47 apresenta os resultados.

Figura 47: Curva de aprendizado do cenário 1.

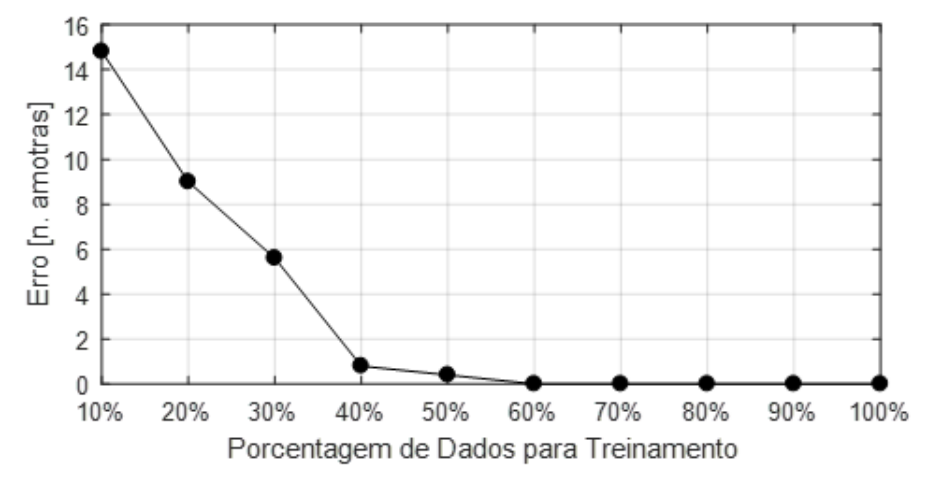

Fonte: Elaborada pelo autor

Nota-se que a curva de aprendizado atinge assíntota quando o conjunto de dados utilizado fica próximo aos $40 \%$ e $50 \%$ do total de dados disponíveis, neste cenário, 560 amostras. Assim, verifica-se que não era necessário uma maior disponibilidade ou coleta de dados para ajuste do sistema de diagnóstico, que foi capaz de aprender o comportamento do sistema nas condições estudadas.

\section{Análise de desempenho sem redução de atributos}

Uma análise para investigação sobre a eficiência da redução de atributos foi desenvolvida. Os classificadores foram empregados utilizando todo o conjunto de atributos extraídos dos dados coletados. Os resultados são apresentados na tabela 16.

Verifica-se que a utilização de todo o conjunto de atributos extraídos resulta em acurácia de $100 \%$ em todos os classificadores, assim como foi alcançado com conjunto de apenas dois atributos. Entretanto, a utilização de grande quantidade de atributos causou um aumento significativo no tempo de execução do classificador, o que pode ser um indicador crítico em aplicações de tempo real em um sistema embarcado, onde o recursos 
Tabela 16: Resultados para falha de aumento de inércia empregando todos atributos extraídos.

\begin{tabular}{|c|c|c|c|c|c|c|}
\hline $\begin{array}{c}\text { Núm. } \\
\text { Entradas }\end{array}$ & Classif. & $\begin{array}{c}\text { Hiper- } \\
\text { parâmetros }\end{array}$ & $\begin{array}{l}\text { Acurácia (\%) } \\
\text { Média(Desv.) }\end{array}$ & FPR & FNR & $\begin{array}{c}\text { Tempo } \\
{[\mathrm{ms}]}\end{array}$ \\
\hline \multirow{3}{*}{102} & $\mathrm{kNN}$ & $\mathrm{n}=6$ & $100.0(0.0)$ & 0.0 & 0.0 & 3.58 \\
\hline & RNA & $\begin{array}{l}1^{a} \text { cam. }=1 \\
2^{a} \text { cam. }=1\end{array}$ & $100.0(0.0)$ & 0.0 & 0.0 & 19.97 \\
\hline & SVM & $\begin{array}{l}\gamma=3.21 \\
\mathrm{C}=19.56\end{array}$ & $100.0(0.0)$ & 0.0 & 0.0 & 1.75 \\
\hline
\end{tabular}

Fonte: Elaborada pelo autor.

computacionais podem ser escassos.

Assim, a aplicação da metodologia proposta até o momento se mostrou bastante eficaz, e acredita-se que possa ser aplicada em diversas máquinas que podem apresentar anomalias ao haver uma grande alteração da inércia da carga. Algumas máquinas potenciais para utilização são mesas giratórias, empacotadora tipo flowpack horizontal e vertical, manipuladores robóticos, entre outras.

\section{Adaptação da metodologia para detecção de novidades}

A aplicação da metodologia investigada, exige a coleta de dados da máquina operando em condições anômalas, o que muitas vezes pode não ser possível ou muito custoso. Fabricantes de máquinas seriadas por exemplo, tem maior probabilidade de ter capacidade de desenvolver um sistema de diagnóstico para manutenção preditiva de suas máquinas com a metodologia proposta, criando condições de anomalias no ambiente fabril, justificado por um grande volume de máquinas semelhantes produzidas.

Em contrapartida, a coleta deste tipo de dados pode ser um problema em alguns ambientes, como por exemplo em usuários finais de máquinas empregadas em seus processos produtivos e mesmo por fabricantes de máquinas especiais. Nestes casos, a aplicação da metodologia se torna inviável devido a necessidade de colocar a máquina em uma condição de falha, o que pode ser impraticável tanto no que tange a inserção de uma falha no acionamento de motor ou carga, como devido a necessidade de parada da máquina para esta coleta de dados.

Desta maneira, esta tese sugere uma adaptação da metodologia para desenvolvimento do sistema de diagnóstico baseado em um algoritmo de detecção de novidades, onde apenas dados de máquinas na condição de operação saudável é necessário.

Investiga-se a utilização do conjunto de dois atributos selecionados por CFS e de duas componentes principais exigidas para obtenção de bons resultados na metodologia original. Adicionalmente, verifica-se o desempenho empregando todo o universos de atributos extraídos. O classificador de novidades utilizado neste trabalho foi o OCSVM, conforme 
descrito na seção 3.3.4. A validação dos resultados novamente é feita por meio de estratégia baseada em validação cruzada $k$-fold. Neste caso, todo o conjunto de amostras (condição de operação normal e anormal) é dividido em 5 partições, porém o treinamento é realizado apenas com amostras de condição normal a partir de 4 das 5 partições, e finalmente a partição remanescente é utilizada para teste, esta sim incluindo tanto amostras de condição saudável e anormal. Esta estratégia é realizada para as 5 combinações possíveis de conjunto de treinamento e teste. Os mesmos indicadores de desempenho são empregados para verificação e comparação dos resultados.

Os resultados dos classificadores para o Cenário 1, são apresentados na tabela 17.

Tabela 17: Resultados para falha de aumento de inércia utilizando detecção de novidades.

\begin{tabular}{cccccc}
\hline $\begin{array}{c}\text { Núm. } \\
\text { Entradas }\end{array}$ & $\begin{array}{c}\text { Método } \\
\text { Seleção }\end{array}$ & $\begin{array}{c}\text { Acurácia (\%) } \\
\text { Média(Desv.) }\end{array}$ & RFP & RFN & $\begin{array}{c}\text { Tempo } \\
{[\mathbf{m s}]}\end{array}$ \\
\hline \multirow{2}{*}{2} & CFS & $98.4(1.6)$ & 0.4 & 2.9 & 1.5 \\
& PCA & $73.9(2.5)$ & 1.4 & 50.7 & 1.09 \\
\hline 102 & - & $66.8(3.1)$ & 66.4 & 0.0 & 3.35 \\
\hline
\end{tabular}

Fonte: Elaborada pelo autor.

Novamente a redução de atributos por PCA obteve resultados inferiores quando comparados ao CFS, com acurácia de apenas 73.9\%, no entanto destaca-se o baixo valor para RFP (1.4\%), que resulta em indicadores Especificidade de 98.6\% e Precisão de $97.2 \%$, que são próximos aos obtidos por CFS, porém ainda inferiores.

Verifica-se que o algoritmo OCSVM para detecção de novidades atinge valores satisfatórios de acurácia utilizando-se os atributos selecionados por CFS, que chega a 98.4\%, e adicionalmente devido ao baixo valor de RFP (0.4\%), gera valores de Especificidade e Precisão de $99.6 \%$, o que indica que o sistema de diagnóstico faz indicação de falha com menor probabilidade de erro em relação a indicação de operação saudável, que obteve RFN de $2.9 \%$.

Apesar do resultado obtido ser inferior quando comparado ao SVM convencional, com treinamento utilizando dados tanto de amostras normais como com falha, considera-se satisfatório a utilização do OCSVM para este tipo de falha no cenário e nas condições investigadas.

Adicionalmente, verifica-se que neste cenário, a utilização de todos os atributos extraídos para aplicação em detecção de novidades obteve resultados muito inferiores, com acurácia de apenas $66.8 \%$ e alto RFP (66.4\%). Isso se deve a questões de distribuição das amostras coletadas, influenciadas pela grande quantidade de atributos redundantes e que não contribuam para a classificação de falhas, comprometendo assim o desempenho do classificador. Assim, para outras aplicações, não se recomenda a utilização de todo o universo de atributos, sendo recomendado a utilização de atributos correlacionados com a 
falha, como por exemplo os utilizados nesta tese para este cenário.

\section{Análise do sistema frente a dados de outras falhas}

Uma última análise dos dados neste cenário, investiga-se a capacidade do sistema de detecção ser capaz de identificar especificamente a falha de aumento de inércia, em relação a outras possíveis falhas. No caso, a falha a ser investigada é o desbalanceamento, que possui características similares a aplicação de alta inércia proposta.

Para isto, coleta-se dados da carga na condição de Média Inércia conforme apresentado na tabela 7 , incluindo desbalanceamento denominado Médio conforme mostra a tabela 8, para diversas condições de operação conforme mostra a tabela 9 para o Cenário 1. Foram testadas 200 amostras nestas condições de operação, ou seja, alterando tempo de ciclo da rede, velocidade máxima e aceleração máxima da aplicação de controle de movimento.

Os dados coletados, são testados pelos classificadores tanto pela metodologia proposta inicialmente, como pela metodologia adaptada para detecção de novidades. Espera-se neste caso, que o classificador não identifique falhas, uma vez que o sistema possui inércia em condições consideradas normais de operação, porém com a presença da falha de desbalanceamento.

Os resultados são apresentado conforme mostra a tabela 18.

Tabela 18: Resultados para identificação de falha de aumento excessivo de inércia frente a dados de desbalanceamento.

\begin{tabular}{cccccc}
\hline Tipo & $\begin{array}{c}\text { Núm. Amostras } \\
\text { Testadas }\end{array}$ & $\begin{array}{c}\text { Núm. } \\
\text { Entradas }\end{array}$ & $\begin{array}{c}\text { Método } \\
\text { Seleção }\end{array}$ & Classificador & Erro (\%) \\
\hline Desbalanceamento & 200 & 2 & CFS & SVM & 0.0 \\
& & 2 & OCSVM & 30.0 \\
\hline
\end{tabular}

Fonte: Elaborada pelo autor.

Nota-se que a taxa de erro do classificador é zero empregando a metodologia com SVM, convencional, ou seja, neste caso o sistema de diagnóstico proposto foi capaz de detectar a anomalia, e adicionalmente, identificar a falha específica de aumento de inércia em relação a dados de falha de desbalanceamento.

Entretanto, a estratégia para detecção de novidade atingiu erro relativamente alto, no valor de $30.0 \%$, não sendo possível concluir que o sistema foi capaz de identificar exclusivamente a falha do qual foi proposto.

As próximas seções apresentam de maneira mais direta e resumida os resultados 
obtidos para os demais cenários investigados nesta tese.

\subsection{Desacoplamento de carga}

Conforme apresentado no capítulo 5, o cenário 2 é constituído pelo servo motor acionando um redutor do tipo coroa e rosca sem fim, acoplados por um acoplamento flexível.

Para este cenário foi empregado Classe de Aplicação 4, por meio do Telegrama Padrão 3, para posicionamento de motor com interpolação no controlador. As condições de operação saudável são definidas como o eixo do motor acoplado ao redutor e a condição anormal definida como eixo desacoplado ou livre. As diferentes parametrizações utilizadas para rede de comunicação e acionamento estão de acordo com a tabela 9.

Foram coletadas por volta de 40 segundos de cada condição, que resultou num total de 10 amostras para cada parametrização, resultando em um universo de 600 amostras balanceadas.

A tabela 19 apresenta dos resultados observados.

Tabela 19: Resultados para falha de desacoplamento.

\begin{tabular}{|c|c|c|c|c|c|c|c|}
\hline $\begin{array}{c}\text { Núm. } \\
\text { Entradas }\end{array}$ & $\begin{array}{l}\text { Método } \\
\text { Seleção }\end{array}$ & Classif. & $\begin{array}{c}\text { Hiper- } \\
\text { parâmetros }\end{array}$ & $\begin{array}{l}\text { Acurácia (\%) } \\
\text { Média(Desv.) }\end{array}$ & RFP & RFN & $\begin{array}{c}\text { Tempo } \\
{[\mathrm{ms}]}\end{array}$ \\
\hline \multirow{3}{*}{1} & \multirow{3}{*}{ CFS } & $\mathrm{kNN}$ & $\mathrm{n}=1$ & $92.3(0.7)$ & 7.7 & 7.7 & 1.65 \\
\hline & & RNA & $\begin{array}{l}1^{a} \text { cam. }=5 \\
2^{a} \text { cam. }=5\end{array}$ & $91.9(3.3)$ & 5.3 & 10.8 & 8.92 \\
\hline & & SVM & $\begin{array}{l}\gamma=998 \\
\mathrm{C}=4.03\end{array}$ & $92.2(3.8)$ & 5.0 & 10.7 & 1.21 \\
\hline \multirow{3}{*}{1} & \multirow{3}{*}{ PCA } & $\mathrm{kNN}$ & $\mathrm{n}=1$ & $88.7(3.6)$ & 12.0 & 10.7 & 2.27 \\
\hline & & RNA & $\begin{array}{l}1^{a} \text { cam } .=16 \\
2^{a} \text { cam. }=19\end{array}$ & $83.7(3.3)$ & 17.7 & 15.0 & 8.74 \\
\hline & & SVM & $\begin{array}{c}\gamma=1858 \\
\mathrm{C}=898.03\end{array}$ & $87.8(3.0)$ & 14.7 & 9.7 & 1.00 \\
\hline \multirow{3}{*}{2} & \multirow{3}{*}{ CFS } & $\mathrm{kNN}$ & $\mathrm{n}=1$ & $99.2(1.0)$ & 1.0 & 0.7 & 1.15 \\
\hline & & RNA & $\begin{array}{c}1^{a} \text { cam. }=3 \\
2^{a} \text { cam. }=18\end{array}$ & $98.6(1.7)$ & 2.3 & 0.4 & 8.60 \\
\hline & & SVM & $\begin{array}{l}\gamma=55.38 \\
C=152.16\end{array}$ & $99.5(0.7)$ & 0.7 & 0.3 & 0.81 \\
\hline \multirow{3}{*}{2} & \multirow{3}{*}{ PCA } & $\mathrm{kNN}$ & $\mathrm{n}=1$ & $98.2(1.6)$ & 1.3 & 2.3 & 1.58 \\
\hline & & RNA & $\begin{array}{l}1^{a} \text { cam. }=18 \\
2^{a} \text { cam. }=16\end{array}$ & $98.3(5.0)$ & 2.1 & 1.3 & 9.17 \\
\hline & & SVM & $\begin{array}{l}\gamma=10.24 \\
\mathrm{C}=134.40\end{array}$ & $98.5(0.9)$ & 1.3 & 1.7 & 0.99 \\
\hline
\end{tabular}

Fonte: Elaborada pelo autor.

O sistema de diagnóstico obteve resultados satisfatórios utilizando conjunto de dois atributos para o CFS ou duas componentes principais. No caso do CFS os atributos 
selecionados foram $9^{a}$ e $21^{a}$ harmônica do sinal do erro do controle de velocidade, com mérito de 0.754 .

O melhor desempenho foi verificado utilizando os atributos selecionados pelo CFS em conjunto com o classificador SVM, ajustado pelos hiper-parâmetros $\gamma=55.38$ para a função kernell e $C=152.16$ para fator de suavização, uma vez que obteve-se o maior valor de acurácia médio. Ademais, o SVM obteve menor tempo de execução.

É importante destacar que em alguns sistemas de mercado, utilizam a informação da corrente elétrica que passa pelo motor para identificação da existência de uma falha de desacoplamento. Basicamente com valor de corrente baixa, há indicação de redução do torque no eixo do motor, havendo assim a indicação de desacoplamento da carga. Ou seja, a relação do desacoplamento, se faz a partir da corrente elétrica que está diretamente ligada ao torque fornecido pelo eixo do motor. Porém, esta estratégia não pode ser utilizada, uma vez que os Telegrama Padrão do perfil PROFIdrive em sua configuração original, não disponibilizam a informação da corrente elétrica. Mesmo assim, verificou-se que apenas com a utilização do sinal do erro de velocidade, o qual deriva os dois atributos selecionados por CFS, foi possível alcançar altos índices de acurácia pelo sistema de diagnóstico.

Uma análise utilizando o classificador de novidades foi realizada. Os resultados são apresentados na tabela 20 .

Tabela 20: Resultados para falha de desacoplamento utilizando detecção de novidades.

\begin{tabular}{cccccc}
\hline $\begin{array}{c}\text { Núm. } \\
\text { Entradas }\end{array}$ & $\begin{array}{c}\text { Método } \\
\text { Seleção }\end{array}$ & $\begin{array}{c}\text { Acurácia (\%) } \\
\text { Média(Desv.) }\end{array}$ & RFP & RFN & $\begin{array}{c}\text { Tempo } \\
{[\mathbf{m s}]}\end{array}$ \\
\hline \multirow{2}{*}{2} & CFS & $83.2(1.5)$ & 0.7 & 33.0 & 1.02 \\
& PCA & $86.7(5.0)$ & 1.3 & 25.3 & 0.98 \\
\hline 102 & - & $68.7(10.1)$ & 62.7 & 0.0 & 2.94 \\
\hline
\end{tabular}

Fonte: Elaborada pelo autor.

Analisando o valor de acurácia, verifica-se que não foi possível definir para este tipo de falha o melhor algoritmo para redução de atributos empregado no classificador para detecção de novidades, uma vez que o PCA apesar de ter obtido 86.7\% de acurácia, atingiu um desvio padrão bastante elevado, chegando a 5.0\%, enquanto o sistema utilizando CFS obteve $83.2 \%$ de acurácia média e $1.5 \%$ para seu desvio padrão. Considerando na análise o valor de RFP, verifica-se que os atributos selecionados por CFS obtiveram melhor desempenho, com RFP de apenas $0.7 \%$, sendo assim considerados como atributos mais indicados para utilização.

Fazendo uma comparação com relação ao classificador convencional, que havia obtido valor de $99.3 \%$ de acurácia, o sistema de detecção de novidades obteve valores relativamente baixos. Porém, ao analisar os indicadores RFP, Especificidade e Precisão, com valores de $0.7 \%, 99.3 \%$ e $99.0 \%$ respectivamente, verifica-se que são similares ao 
classificador convencional, sendo assim considerados como resultados satisfatórios para sua aplicação.

Os resultados obtidos considerando todo o universo de atributos não atingem boa acurácia, com o agravamento do alto índice de RFP, que chega a $22.4 \%$, ou seja o classificador tem grande probabilidade de indicar um estado de máquina com defeito, mesmo que a máquina esteja operando em condições adequadas, o que induziria uma parada de máquina para averiguar possíveis falhas que não existam. Adicionalmente, a utilização de grande quantidade de atributos, contribui para aumento do tempo de execução do classificador.

Assim, os resultados obtidos com a falha de desacoplamento verifica-se que o sistema de detecção de novidades atinge bom desempenho utilizando redução de atributos utilizando algoritmo CFS em conjunto com o classificador OCSVM.

Os sistemas de diagnóstico com os melhores desempenhos neste cenário, sendo o SVM para a metodologia inicial, e OCSVM para a metodologia de detecção de novidades, foram testados em outros condições de falha com o objetivo de verificar se o sistema identifica especificamente a falha de desacoplamento.

Para este fim, dados do processo foram coletados operando em condições de carga com desalinhamento angular e paralelo. O desalinhamento angular e paralelo inserido no sistema foram os mesmos inseridos para o Cenário 4, descrito no capítulo 5. Foram consideradas as condições de configuração conforme apresenta a tabela 9. No total, 300 amostras de cada falha foram empregadas na análise.

A tabela 21 apresenta os resultados.

Tabela 21: Resultados para identificação de falha de desacoplamento frente a dados de desalinhamento.

\begin{tabular}{cccccc}
\hline Tipo & $\begin{array}{c}\text { Núm. Amostras } \\
\text { Testadas }\end{array}$ & $\begin{array}{c}\text { Núm. } \\
\text { Entradas }\end{array}$ & $\begin{array}{c}\text { Método } \\
\text { Seleção }\end{array}$ & Classificador & Erro (\%) \\
\hline \multirow{2}{*}{ Angular } & \multirow{2}{*}{300} & 2 & CFS & SVM & $\begin{array}{l}\text { OCSVM } \\
8.3\end{array}$ \\
\hline \multirow{2}{*}{ Paralelo } & \multirow{2}{*}{300} & \multirow{2}{*}{2} & CFS & SVM & $\begin{array}{l}\text { OCSVM } \\
\text { (20 }\end{array}$ \\
\hline
\end{tabular}

Fonte: Elaborada pelo autor.

Nota-se que a taxa de erro do classificador fica abaixo de $5 \%$ empregando a metodologia com SVM e 8.3\% aplicando detecção de novidades para ambas as falhas. Novamente nota-se melhores desempenho empregando a metodologia ajustando o classificador com dados de amostras operando em condição saudável e faltosa.

É possível considerar pelos resultados que o sistema de diagnóstico para a falha de desacoplamento além de detectar anomalias no processo é capaz de identificar especifica- 
mente a falha de desacoplamento frente a dados de desalinhamento, pois atingiu taxas de erros aceitáveis para estas outras falhas. Conclui-se que é possível diferenciar a falha de desacoplamento das falhas de desalinhamento para este cenário.

\subsection{Desbalanceamento da carga}

Para o cenário de desbalanceamento foi implementado controle de velocidade baseada na Classe de Aplicação 1 do perfil PROFIdrive, empregando Telegrama Padrão 1. Diferentemente dos cenários anteriores apenas 78 atributos são extraídos dos dados de processo que trafegam na rede, uma vez que sinal de posição atual enviado do drive para o controlador não é disponibilizado neste tipo de aplicação.

Foram coletadas 1000 amostras utilizando condições de operação normal e anormal balanceadas, conforme apresentado no capítulo 5. Duas condições da carga são consideradas como desbalanceamento aceitáveis e outras duas com desbalanceamentos inaceitáveis, geradas por meio da fixação ou não de massas a certa distância de um disco cilíndrico que representa a carga acionada. Máquinas em geral podem apresentar este tipo de falha, alguns exemplos são mesas giratórias, máquinas empacotadoras, entre outras. Como nos outros cenários, diversas parametrizações da aplicação são ajustadas para a coleta de dados, conforme tabela 9 .

A tabela 22 apresenta os resultados para este cenário, considerando os algoritmos de redução de dimensionalidade e classificadores investigados na metodologia original.

Verifica-se que para este cenário novamente foi necessário um subconjunto de dois atributos utilizando o algoritmo CFS ou duas componentes principais do algoritmo PCA, para alcançar resultados satisfatórios do classificador. Os atributos selecionados pelo algoritmo CFS foram o A18 e A24, que correspondem a entropia aproximada com fator $\mathrm{p}=2$ e $\mathrm{p}=4$ do sinal de erro da velocidade respectivamente. A correlação destes atributos com a classe é 0.768 e 0.798 respectivamente, e correlação mútua de 0.822 , que resulta no valor de mérito de 0.821. Neste caso, apesar de a correlação mútua poder ser considerada elevada, a adição de um novo atributo contribuiu para um aumento significativo na acurácia do sistema.

Tanto para os atributos selecionados por CFS, quanto para duas componentes principais, o sistema atinge acurária de $100 \%$ utilizando o classificador RNA, com uma pequena melhoria de desempenho quando se utiliza algoritmo CFS, que obteve EQM de $3.4410^{-6}$, enquanto utilizando PCA obteve EQM de $1.6510^{-4}$.

Entretanto, a melhor configuração para o sistema foi utilizando o algoritmo CFS para seleção de atributos com classificador SVM, que também atingiu acurácia de 100\%, com tempo de execução muito inferior quando comparado RNA. Os hiper-parâmetros ajustados foram $\gamma=9.33$ para a função kernell e $C=837.80$ para fator de suavização. 
Tabela 22: Resultados para falha de desbalanceamento.

\begin{tabular}{|c|c|c|c|c|c|c|c|}
\hline $\begin{array}{c}\text { Núm. } \\
\text { Entradas }\end{array}$ & $\begin{array}{l}\text { Método } \\
\text { Seleção }\end{array}$ & Classif. & $\begin{array}{c}\text { Hiper- } \\
\text { parâmetros }\end{array}$ & $\begin{array}{l}\text { Acurácia (\%) } \\
\text { Média(Desv.) }\end{array}$ & FPR & FNR & $\begin{array}{c}\text { Tempo } \\
{[\mathrm{ms}]}\end{array}$ \\
\hline \multirow{3}{*}{1} & \multirow{3}{*}{ CFS } & $\mathrm{kNN}$ & $\mathrm{n}=18$ & $95.8(1.4)$ & 0.2 & 8.2 & 1.50 \\
\hline & & RNA & $\begin{array}{c}1^{a} \text { cam. }=3 \\
2^{a} \text { cam. }=20\end{array}$ & $96.2(1.3)$ & 0.4 & 7.2 & 9.15 \\
\hline & & SVM & $\begin{array}{c}\gamma=82.45 \\
\mathrm{C}=24.50\end{array}$ & $95.9(1.5)$ & 0.0 & 8.2 & 1.13 \\
\hline \multirow{3}{*}{1} & \multirow{3}{*}{ PCA } & $\mathrm{kNN}$ & $\mathrm{n}=6$ & $86.6(1.2)$ & 10.4 & 16.4 & 1.46 \\
\hline & & RNA & $\begin{array}{l}1^{a} \text { cam. }=13 \\
2^{a} \text { cam. }=19\end{array}$ & $87.1(1.6)$ & 13.6 & 12.2 & 9.28 \\
\hline & & SVM & $\begin{array}{c}\gamma=382.73 \\
\mathrm{C}=113.80\end{array}$ & $87.3(1.8)$ & 11.8 & 13.6 & 2.14 \\
\hline \multirow{3}{*}{2} & \multirow{3}{*}{ CFS } & $\mathrm{kNN}$ & $\mathrm{n}=5$ & $99.9(0.2)$ & 0.2 & 0.0 & 1.30 \\
\hline & & RNA & $\begin{array}{c}1^{a} \text { cam. }=1 \\
2^{a} \text { cam. }=14\end{array}$ & $100.0(0.0)$ & 0.0 & 0.0 & 8.77 \\
\hline & & SVM & $\begin{array}{c}\gamma=9.33 \\
\mathrm{C}=837.80\end{array}$ & $100.0(0.0)$ & 0.0 & 0.0 & 1.00 \\
\hline \multirow{3}{*}{2} & \multirow{3}{*}{ PCA } & $\mathrm{kNN}$ & $\mathrm{n}=9$ & $99.9(0.2)$ & 0.2 & 0.0 & 2.06 \\
\hline & & RNA & $\begin{array}{c}1^{a} \text { cam. }=7 \\
2^{a} \text { cam. }=18\end{array}$ & $100.0(0.0)$ & 0.0 & 0.0 & 9.09 \\
\hline & & SVM & $\begin{array}{c}\gamma=23.70 \\
\mathrm{C}=2.11\end{array}$ & $99.9(0.2)$ & 0.2 & 0.0 & 1.40 \\
\hline
\end{tabular}

Fonte: Elaborada pelo autor.

Em termos comparativos a trabalhos correlatos para detecção de falhas de desbalanceamento, Martinez-Morales et al. (2010) utilizou o sinal de corrente do motor e sinais de vibração radial e axial como variáveis de entrada em um classificador do tipo SVM, para identificar desbalanceamento, desalinhamento e falhas em rolamentos, alcançando acurácia de $100 \%$ para diferentes cargas no rotor em relação a desbalanceamento. Dwi et al. (2015) utilizou um método de RNA para determinar e localizar um desbalanço anormal utilizando dados de vibração, atingindo acurácia de 90.12\%. Outros trabalhos como Atoui et al. (2013), que utilizando FFT do sinal de sensores de vibração e Corne, Knockaert e Desmet (2017) utilizando análise da corrente do estator do motor, também obtiveram sucesso na indicação de desbalanceamento em máquinas rotativas, com análise adicional de sua severidade, porém não houve uma análise em relação ao indicador acurácia.

Verifica-se portanto que o resultado obtido foi bastante similar ao trabalho de Martinez-Morales et al. (2010), que em contrapartida teve que utilizar três tipos de sensores dedicados para coletas de dados do processo. No caso de Dwi et al. (2015), que também utilizou sensores de vibração, apesar de ter obtido valor inferior de acurácia em relação a esta tese, o autor consegue adicionalmente identificar a localização do desbalanceamento, o que este trabalho não propõe.

Em geral, verifica-se para a falha de desbalanceamento, existe uma ampla necessi- 
dade de utilização de sensores de vibração nos trabalhos correlatos, e em alguns trabalhos a análise da assinatura de corrente do motor é empregada. Entretanto, a metodologia proposta mesmo não tendo acesso a estes dados que utilizam sensores adicionais instalados nas máquinas, alcançou excelentes resultados no cenário investigado.

Em relação a utilização de estratégia de detecção de novidades, os resultados são apresentados na tabela 23 para aplicação do classificador OCSVM.

Tabela 23: Resultados para falha de desbalanceamento utilizando detecção de novidades.

\begin{tabular}{cccccc}
\hline $\begin{array}{c}\text { Núm. } \\
\text { Entradas }\end{array}$ & $\begin{array}{c}\text { Método } \\
\text { Seleção }\end{array}$ & $\begin{array}{c}\text { Acurácia (\%) } \\
\text { Média(Desv.) }\end{array}$ & RFP & RFN & $\begin{array}{c}\text { Tempo } \\
{[\mathbf{m s}]}\end{array}$ \\
\hline \multirow{2}{*}{2} & CFS & $98.2(0.8)$ & 0.2 & 3.4 & 1.30 \\
& PCA & $97.5(1.1)$ & 1.6 & 3.4 & 1.55 \\
\hline 102 & - & $88.8(3.5)$ & 22.4 & 0.0 & 3.72 \\
\hline
\end{tabular}

Fonte: Elaborada pelo autor.

Verifica-se que o algoritmo para detecção de novidades atinge valores satisfatórios empregando redução de atributos, com melhores resultados utilizando atributos selecionados por CFS. Apesar do resultado da acurácia ser inferior quando comparado ao SVM convencional utilizado anteriormente, o OCSVM obteve baixo valor de RFP $(0.2 \%)$, alcançando valores de Especificidade e Precisão muito próximos ao SVM convencional.

Novamente, verifica-se um desempenho insatisfatório para detecção de novidades empregando todo o universo de atributos, com acurácia relativamente baixa e RFP elevada quando comparada com emprego de menos atributos e trabalhos correlatos.

Assim, considera-se adequado a utilização do OCSVM para este tipo de falha no cenário investigado empregando dois atributos selecionados pelo algoritmo CFS.

Ainda para este cenário, foi investigado a capacidade de identificar especificamente a falha de desbalanceamento. Para este fim, foi inserido no sistema de diagnóstico desenvolvido dados com amostras de aplicações que apresentavam aumento excessivo de inércia em relação a condição normal de aplicação. A tabela 24 apresenta os resultados obtidos.

Tabela 24: Resultados para identificação de falha de desbalanceamento frente a dados de aumento excessivo de inércia.

\begin{tabular}{cccccc}
\hline Tipo & $\begin{array}{c}\text { Núm. Amostras } \\
\text { Testadas }\end{array}$ & $\begin{array}{c}\text { Núm. } \\
\text { Entradas }\end{array}$ & $\begin{array}{c}\text { Método } \\
\text { Seleção }\end{array}$ & Classificador & Erro (\%) \\
\hline \multirow{2}{*}{ Inércia } & 250 & 1 & CFS & SVM & 39.6 \\
& & 1 & OCSVM & 36.8
\end{tabular}

Fonte: Elaborada pelo autor.

Foram utilizados na análise 250 amostras na condição de Alta Inércia conforme tabela 7 nas condições de operação segundo os parâmetros do cenário 3, conforme tabela 9 . 
Verifica-se pelos resultados uma alta taxa de erro do sistema de diagnóstico, que informa uma condição de falha de desbalanceamento em 39.6\% das amostras para o classificador SVM e 36.8\% para o classificador OCSVM. Assim, verifica-se que o classificador não possui a capacidade de diferenciar satisfatoriamente uma falha de desbalanceamento em relação a falha de aumento excessivo de inércia.

\subsection{Desalinhamento}

Para os cenários de desalinhamento, assim como o de desbalanceamento, a Classe de Aplicação 1 foi empregada para controle de velocidade, utilizando Telegrama Padrão 1. Dois tipos de desalinhamento foram investigados, em um acoplamento flexível conectando ao eixo do motor com um redutor mecânico: desalinhamento angular e desalinhamento paralelo, conforme explicado no capítulo 5.

Para cada situação deste cenário, 600 amostras foram coletadas da rede de comunicação, considerando diversas configurações de rede e da aplicação de controle de movimento conforme mostra a 9. Os resultados e discussões são apresentados em sequência.

\subsubsection{Desalinhamento Angular}

A tabela 25 apresenta os resultados para o cenário de desalinhamento angular, que trata condição de alinhamento aceitável, ou seja desalinhamento considerado desprezível, e desalinhamento de 01 grau entre o eixo do motor e do redutor, acoplados por um acoplamento flexível.

Tabela 25: Resultados para falha de desalinhamento angular.

\begin{tabular}{|c|c|c|c|c|c|c|c|}
\hline $\begin{array}{l}\text { Núm. } \\
\text { Entradas }\end{array}$ & $\begin{array}{l}\text { Método } \\
\text { Seleção }\end{array}$ & Classif. & $\begin{array}{c}\text { Hiper- } \\
\text { parâmetros }\end{array}$ & $\begin{array}{l}\text { Acurácia (\%) } \\
\text { Média(Desv.) }\end{array}$ & RFP & RFN & $\begin{array}{c}\text { Tempo } \\
{[\mathrm{ms}]}\end{array}$ \\
\hline \multirow{3}{*}{1} & \multirow{3}{*}{ CFS } & $\mathrm{kNN}$ & $\mathrm{n}=9$ & $99.2(0.8)$ & 0.7 & 1.0 & 1.7 \\
\hline & & RNA & $\begin{array}{c}1^{a} \text { cam. }=1 \\
2^{a} \text { cam. }=14\end{array}$ & $99.2(0.8)$ & 0.7 & 1.0 & 9.03 \\
\hline & & SVM & $\begin{aligned} \gamma & =22.39 \\
\mathrm{C} & =0.007\end{aligned}$ & $99.3(0.7)$ & 0.3 & 1.0 & 0.87 \\
\hline \multirow{3}{*}{1} & \multirow{3}{*}{ PCA } & $\mathrm{kNN}$ & $\mathrm{n}=5$ & $84.7(3.6)$ & 15.3 & 15.2 & 1.30 \\
\hline & & RNA & $\begin{array}{l}1^{a} \text { cam. }=17 \\
2^{a} \text { cam. }=19\end{array}$ & $83.8(2.7)$ & 13.3 & 19.0 & 8.39 \\
\hline & & SVM & $\begin{array}{c}\gamma=634.82 \\
\mathrm{C}=16.12\end{array}$ & $86.7(2.6)$ & 13.0 & 13.7 & 0.93 \\
\hline
\end{tabular}

Fonte: Elaborada pelo autor.

Nota-se que para este cenário foi necessário apenas a seleção de um único atributo pelo algoritmo CFS, referente ao atributo A90 ( $5^{a}$ harmônica do sinal do erro de velocidade), que possui correlação com a classe de 0.925 , tendo mesmo valor para o mérito. Este valor 
pode ser considerada bastante elevado, comparado com demais valores apresentados até este ponto.

A melhor configuração do sistema de diagnóstico utiliza então este atributo como entrada no classificador tipo SVM, que obteve maior valor de acurácia, de 99.3\%. Adicionalmente, verifica-se que se obteve menor valor de RFP, e menor tempo de execução neste classificador. Os indicadores Especificidade e Precisão ficam em 99.7\%, maior que os demais classificadores, e dando ainda uma melhor indicação do desempenho do sistema para a aplicação estudada.

Neste cenário a seleção de uma única componente principal por PCA não obteve bons resultados quando aplicados aos classificadores propostos. Considerando apenas uma componente principal, obteve-se acurácia de $86.7 \%$ também com o classificador SVM. Como resultados satisfatórios foram atingidos com CFS, a metodologia proposta se encerra sem a necessidade de investigar os resultados para duas componentes principais.

\subsubsection{Desalinhamento paralelo}

Para o cenário de desalinhamento paralelo, a tabela 26 apresenta os resultados obtidos. O desalinhamento criado para condição de operação anormal foi feito inserindo um deslocamento de $0.8 \mathrm{~mm}$ entre o centro do eixo do redutor em relação ao eixo do motor.

Tabela 26: Resultados para falha de desalinhamento linear.

\begin{tabular}{|c|c|c|c|c|c|c|c|}
\hline $\begin{array}{c}\text { Núm. } \\
\text { Entradas }\end{array}$ & $\begin{array}{l}\text { Método } \\
\text { Seleção }\end{array}$ & Classif. & $\begin{array}{c}\text { Hiper- } \\
\text { parâmetros }\end{array}$ & $\begin{array}{l}\text { Acurácia (\%) } \\
\text { Média(Desv.) }\end{array}$ & FPR & FNR & $\begin{array}{c}\text { Tempo } \\
{[\mathrm{ms}]}\end{array}$ \\
\hline \multirow{3}{*}{1} & \multirow{3}{*}{ CFS } & $\mathrm{kNN}$ & $\mathrm{n}=11$ & $96.2(1.3)$ & 3.7 & 4.0 & 1.73 \\
\hline & & RNA & $\begin{array}{l}1^{a} \text { cam. }=1 \\
2^{a} \text { cam. }=1\end{array}$ & $96.1(1.7)$ & 3.7 & 4.2 & 8.03 \\
\hline & & SVM & $\begin{array}{l}\gamma=0.017 \\
\mathrm{C}=20.60\end{array}$ & $96.0(1.5)$ & 4.3 & 3.7 & 1.03 \\
\hline \multirow{3}{*}{1} & \multirow{3}{*}{ PCA } & $\mathrm{kNN}$ & $\mathrm{n}=17$ & $75.5(1.7)$ & 25.0 & 24.0 & 2.33 \\
\hline & & RNA & $\begin{array}{c}1^{a} \text { cam. }=9 \\
2^{a} \text { cam. }=11\end{array}$ & $76.0(2.1)$ & 22.0 & 26.00 & 8.21 \\
\hline & & SVM & $\begin{array}{c}\gamma=414.83 \\
\mathrm{C}=2.60\end{array}$ & $75.7(2.0)$ & 24.3 & 24.3 & 1.45 \\
\hline \multirow{3}{*}{2} & \multirow{3}{*}{ CFS } & $\mathrm{kNN}$ & $\mathrm{n}=11$ & $98.7(1.3)$ & 1.0 & 1.7 & 1.32 \\
\hline & & RNA & $\begin{array}{c}1^{a} \text { cam. }=11 \\
2^{a} \text { cam. }=1\end{array}$ & $99.0(1.0)$ & 1.3 & 0.7 & 8.18 \\
\hline & & SVM & $\begin{array}{l}\gamma=969.94 \\
\mathrm{C}=0.0001\end{array}$ & $98.8(1.7)$ & 0.0 & 2.3 & 1.24 \\
\hline \multirow{3}{*}{2} & \multirow{3}{*}{ PCA } & $\mathrm{kNN}$ & $\mathrm{n}=5$ & $96.3(0.5)$ & 3.0 & 4.3 & 1.14 \\
\hline & & RNA & $\begin{array}{l}1^{a} \text { cam. }=20 \\
2^{a} \text { cam. }=18\end{array}$ & $97.2(0.7)$ & 3.3 & 2.3 & 9.10 \\
\hline & & SVM & $\begin{array}{c}\gamma=51.63 \\
\mathrm{C}=36.68\end{array}$ & $96.5(1.5)$ & 3.3 & 3.7 & 1.36 \\
\hline
\end{tabular}

Fonte: Elaborada pelo autor. 
Nesta condição de falha, houve necessidade de utilização de conjunto de 02 atributos tanto para redução de dimensionalidade por CFS como para PCA, para se alcançar resultados satisfatórios. No caso do CFS, inicialmente foi selecionado o atributo A91, $7^{a}$ harmônica do sinal de erro da velocidade, com correlação de 0.863 com a classe, porém como acurácia não foi atingida satisfatoriamente em nenhum dos classificadores. Assim, foram selecionados um subconjunto com 02 atributos, sendo os atributos A90 e A92 que são $5^{a}$ e $9^{a}$ harmônica do sinal de erro da velocidade, possuindo correlação com a classe de 0.823 e 0.852 respectivamente, e correlação mútua de 0.705. Nota-se que neste caso, o novo subconjunto de atributos selecionados pela metodologia não engloba o atributo previamente selecionado.

O classificador com melhor resultado em relação a acurácia foi a RNA, com 11 neurônios na primeira camada e 1 neurônio na segunda camada escondida, alcançando valor de acurácia de $99.0 \%$.

Entretanto, vale ressaltar que para este cenário, o classificador SVM utilizando conjunto de 02 atributos selecionados por CFS obteve valor de acurácia de $98.8 \%$, um pouco inferior que o classificador RNA, porém bastante elevado. Além disso, obteve-se RFP no valor de 0.0\%, e valores dos indicadores Especificidade e Precisão de 100\%, melhores que estes indicadores na RNA, que são RFP de 1.3\%, especificidade e Precisão de $98.7 \%$. Portanto, o SVM poderia ser também considerado uma excelente opção para identificação deste tipo de falha, com a vantagem adicional de possuir tempo de execução inferior ao da RNA.

Comparando os resultados obtidos com a literatura correlata tanto para desalinhamento angular como paralelo, ratifica-se o bom desempenho da metodologia proposta. Martinez-Morales et al. (2010), que emprega dados de corrente do motor e vibração de sensores instalados no motor como variáveis de entrada, alcança acurácia de $97.14 \%$ na identificação de desalinhamento no eixo do motor para diferentes cargas aplicadas. Bordoloi e Tiwari (2019) utilizou mesmos tipos de variáveis, com variações de classificadores SVM que empregam otimizadores do tipo algoritmo genético para ajuste de hiper-parâmetros, alcançando acurácia entre $58.62 \%$ para casos de baixas velocidade do rotor, até $100 \%$ para diferentes velocidade e cargas no rotor.

Antonino-Daviu e Popaleny (2018) utiliza análise de assinatura avançada da corrente do motor para estudar problemas de desalinhamento, enquanto Omitaomu et al. (2007) utiliza uma abordagem chamada de Online Support Vector Regression para detecção de desalinhamento paralelo e angular, conseguindo bons resultados para ambos os casos. Corne, Knockaert e Desmet (2017) utilizando análise da corrente do estator do motor, obteve sucesso na indicação da severidade do desbalanceamento em máquinas rotativas. Todos estes trabalhos não indicam valores de acurácia na detecção de falha.

Verifica-se portante grande quantidade de trabalhos para detecção de desalinha- 
mento de eixos entre motores e cargas, destacando a utilização de sensores de vibração e corrente do motor. Nota-se que para este tipo de falha, a metodologia proposta por esta tese, atingiu resultados similares aos trabalhos supracitados, utilizando apenas variáveis de velocidade do motor.

Em seguida, busca-se a utilização da metodologia adaptada com ferramenta OCSVM para detecção de novidades neste tipo de falha. A tabela 27 apresenta os resultados para desalinhamento angular e paralelo.

Tabela 27: Resultados para falha de desalinhamento utilizando detecção de novidades.

\begin{tabular}{|c|c|c|c|c|c|c|}
\hline Tipo & $\begin{array}{c}\text { Núm. } \\
\text { Entradas }\end{array}$ & $\begin{array}{l}\text { Método } \\
\text { Seleção }\end{array}$ & $\begin{array}{l}\text { Acurácia (\%) } \\
\text { Média(Desv.) }\end{array}$ & RFP & RFN & $\begin{array}{c}\text { Tempo } \\
{[\mathrm{ms}]}\end{array}$ \\
\hline \multirow{3}{*}{ Angular } & \multirow{2}{*}{2} & CFS & $98.5(0.9)$ & 2.3 & 0.7 & 1.47 \\
\hline & & PCA & $70.5(1.7)$ & 0.7 & 58.3 & 1.55 \\
\hline & 102 & - & $82.5(2.6)$ & 35.0 & 0.0 & 2.66 \\
\hline \multirow{3}{*}{ Paralelo } & \multirow{2}{*}{ 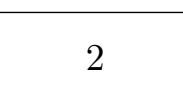 } & CFS & $91.7(2.8)$ & 1.0 & 15.7 & 1.49 \\
\hline & & PCA & $86.0(3.5)$ & 0.7 & 27.3 & 1.55 \\
\hline & 102 & - & $83.7(6.5)$ & 32.7 & 0.0 & 3.65 \\
\hline
\end{tabular}

Fonte: Elaborada pelo autor.

Os resultados obtidos mostram novamente que os atributos selecionados por CFS apresentam melhores resultados no que tange a acurácia para ambos os casos de desalinhamento.

Para alinhamento angular, obteve-se acurácia pouco abaixo quando comparada ao alcançado pela melhor configuração desta falha utilizando abordagem SVM regular, que obteve $99.3 \%$ de acurácia. Entretanto, verifica-se que apesar de se alcançar acurácia relativamente baixa utilizando PCA, a RFP foi inferior a utilizando CFS, o que tende a evitar indicações de falhas indevidamente, porém o indicador RFN $(58.3 \%)$ indica que em mais da metade dos casos o sistema pode estar trabalhando em condições desapropriadas sem a detecção do sistema de diagnóstico. Assim, entende-se que a utilização deste tipo de sistema deve-se empregar os atributos CFS, que obteve acurácia muito superior.

Em relação ao desalinhamento paralelo, verifica-se uma redução bastante significativa na acurácia em relação ao sistema de diagnóstico obtido pela metodologia proposta originalmente, que obteve melhor desempenho também com atributos selecionados por CFS e classificador RNA. Porém, mesmo com uma redução de acurácia, que ficou em $91.7 \%$, verifica-se uma baixo valor para RFP, de apenas $1.0 \%$, que é inclusive inferior ao alcançado pela RNA, na metodologia original. Assim, indicadores Especificidade e Precisão resultam em $99.0 \%$ e $98.8 \%$ respectivamente, comprovando a eficácia do sistema.

Para ambos as falhas de desalinhamento, a acurácia do sistema de detecção utilizando todos os atributos extraídos foi baixa, inferior a 85\%, o que corrobora a indicação 
de não utilizar grande quantidade de entradas para classificadores do tipo OCSVM nos cenários estudados.

Sobre a investigação de a acurácia do sistema de diagnóstico sendo exposto a dados de outras falhas, a tabela 28 apresenta os resultados para as falhas de desacoplamento e desalinhamento paralelo, quando inseridas no sistemas de diagnóstico para a falha de desalinhamento angular.

Tabela 28: Resultados para identificação de falha de desacoplamento frente a dados de desalinhamento.

\begin{tabular}{|c|c|c|c|c|c|}
\hline Tipo & $\begin{array}{c}\text { Núm. Amostras } \\
\text { Testadas }\end{array}$ & $\begin{array}{c}\text { Núm. } \\
\text { Entradas }\end{array}$ & $\begin{array}{l}\text { Método } \\
\text { Seleção }\end{array}$ & Classificador & Erro (\%) \\
\hline \multirow{2}{*}{ Paralelo } & \multirow{2}{*}{300} & \multirow{2}{*}{1} & \multirow{2}{*}{ CFS } & SVM & 8.3 \\
\hline & & & & OCSVM & 51.0 \\
\hline \multirow{2}{*}{ Desacoplamento } & \multirow{2}{*}{297} & \multirow{2}{*}{1} & \multirow{2}{*}{ CFS } & SVM & 16.5 \\
\hline & & & & OCSVM & 90.7 \\
\hline
\end{tabular}

Fonte: Elaborada pelo autor.

Para este caso foram utilizadas 300 amostras para a falha de desalinhamento paralelo, que obteve erro aceitável, em 8.3\%, entretanto não houve bom desempenho do sistema empregando detecção de novidades, alcançando erro em $51.0 \%$ das amostras testadas.

Para dados de falha de desacoplamento inseridos no sistema de diagnóstico treinado para falha de desalinhamento angular, foram utilizadas 297 amostras. o erro utilizando SVM foi de $16.5 \%$, e extremamente elevado para o sistema adaptado utilizando OCSVM, que ficou em $90.7 \%$ de erro.

Assim, conclui-se que no cenário investigado não seria possível diferenciar a falha de desalinhamento angular e desacoplamento satisfatoriamente.

A capacidade de identificar falhas específicas para o sistema desenvolvido no desalinhamento paralelo não foi possível ser investigado, uma vez que as amostras para as falhas de desalinhamento angular e desacoplamento, quando são normalizadas de acordo com os dados coletados para juste do sistema, resultam em valores muito acima da faixa entre 0 e 1, as quais o sistema foi treinando, não sendo recomendado a utilização do sistema para este tipo de condição.

\subsection{Discussões finais}

Em geral, os resultados obtidos pelo metodologia proposta obtiveram resultados satisfatórios, equivalentes a pesquisas correlatas sobre o tema, mesmo não se empregando sensores adicionais na aplicação, como é o caso da utilização de acelerômetros para análise vibratório e medidores de corrente do motor, empregados em grande parte dos trabalhos 
relacionados a conditioning monitoring. Os resultados de acurácia da metodologia proposta atingem erros de até $1 \%$ na detecção das falhas investigadas no acionamento de máquinas por meio de motores elétricos, quando implementado a partir da metodologia original proposta, isto é, utilizando dados de treinamento em condição de operação saudável e anormal.

Outro resultado importante, é que foram necessários seleção de conjunto atributos de até 02 de um total de até 102 atributos para se obter resultados satisfatórios da metodologia, ou seja, a quantidade de características extraídas dos dados de processo e que foram realmente empregada pelo classificador pode ser considerada baixa. Esta análise reforça a vantagem de utilização de um algoritmo para redução de dimensionalidade, além da questão da redução do tempo de execução para classificação de uma nova amostra e exigência de menor esforço computacional.

Entre os algoritmo utilizados para redução de dimensionalidade nos cenários estudados, a utilização de seleção de atributos utilizando a heurística descrita pelo algoritmo CFS obteve resultados iguais ou superiores ao utilizando componentes principais (PCA).

Verifica-se também que os classificadores kNN, RNA e SVM obterem resultados similares, porém em todos os casos, exceto para falha de desalinhamento paralelo, a ferramenta de aprendizagem de máquinas SVM para detecção de padrões empregando margens flexíveis e função kernel tipo gaussiano foi a que obteve os melhores resultados, sendo assim a solução mais indicada para os cenários de acionamentos de motores elétricos.

A tabela 29 apresenta um resumo dos parâmetros e resultados dos melhores classificadores para os cenários investigados.

Tabela 29: Resultados do sistema de detecção de falhas proposto.

\begin{tabular}{|c|c|c|c|c|c|}
\hline \multirow[t]{2}{*}{ Cenário } & \multirow[t]{2}{*}{ Inércia } & \multirow[t]{2}{*}{ Desacoplamento } & \multirow[t]{2}{*}{ Desbalaço. } & \multicolumn{2}{|c|}{ Desalinhamento } \\
\hline & & & & Angular & Paralelo \\
\hline Qtd. Amostras & 560 & 600 & 1000 & 600 & 600 \\
\hline Classe Aplic. & $\mathrm{AC} 4$ & $\mathrm{AC} 4$ & $\mathrm{AC} 1$ & $\mathrm{AC} 1$ & $\mathrm{AC} 1$ \\
\hline CFS & A16/A99 & A92/A98 & A24/A32 & A90 & A90/A92 \\
\hline Corr. Classe & $0.615 / 0.629$ & $-0.552 /-0.658$ & $0.774 / 0.811$ & 0.925 & $0.823 / 0.852$ \\
\hline Corr. Mútua & 0.052 & 0.287 & 0.832 & - & 0.705 \\
\hline Mérito & 0.857 & 0.754 & 0.817 & 0.925 & 0.907 \\
\hline Classificador & SVM & SVM & SVM & SVM & RNA \\
\hline Acurária & $100 \%$ & $99.5 \%$ & $100.0 \%$ & $99.3 \%$ & $99.0 \%$ \\
\hline RFP & $0.0 \%$ & $0.7 \%$ & $0.0 \%$ & $0.3 \%$ & $1.3 \%$ \\
\hline Especificidade & $100.0 \%$ & $99.3 \%$ & $100.0 \%$ & $99.7 \%$ & $98.7 \%$ \\
\hline Precisão & $100.0 \%$ & $99.3 \%$ & $100.0 \%$ & $99.7 \%$ & $98.7 \%$ \\
\hline
\end{tabular}

Fonte: Elaborada pelo autor.

Além destes resultados, verifica-se que foi possível alcançar bom desempenho utilizando a abordagem de detecção de novidades, a partir da adaptação da metodologia, 
onde não é necessário a coleta de dados da máquinas em condições de falha. O algoritmo utilizado nesta abordagem foi o OCSVM, que trata-se de uma adaptação do algoritmo SVM empregado, utilizando da mesma maneira a função kernel tipo gaussiano. O resumo dos resultados é apresentado na tabela 30.

Tabela 30: Resultados do sistema de detecção de falhas proposto.

\begin{tabular}{|c|c|c|c|c|c|}
\hline \multirow[t]{2}{*}{ Cenário } & \multirow[t]{2}{*}{ Inércia } & \multirow[t]{2}{*}{ Desacoplamento } & \multirow[t]{2}{*}{ Desbalaço. } & \multicolumn{2}{|c|}{ Desalinhamento } \\
\hline & & & & Angular & Paralelo \\
\hline Acurária & $98.4 \%$ & $83.2 \%$ & $98.2 .0 \%$ & $98.5 \%$ & $91.7 \%$ \\
\hline RFP & $0.4 \%$ & $0.7 \%$ & $0.2 \%$ & $2.3 \%$ & $1.0 \%$ \\
\hline Especificidade & $99.6 \%$ & $99.3 \%$ & $99.8 \%$ & $97.7 \%$ & $99.0 \%$ \\
\hline Precisão & $99.6 \%$ & $99.0 \%$ & $99.8 \%$ & $97.7 \%$ & $98.8 \%$ \\
\hline
\end{tabular}

Fonte: Elaborada pelo autor.

Neste caso, os sistemas de diagnóstico nos cenários estudados atingiram acurácia de 83.2 a $98.4 \%$ empregando o conjunto de atributos selecionados por CFS. Verifica-se resultados satisfatórios a partir da análise dos indicadores RFP, que obteve até $2.3 \%$ na falha de desalinhamento angular, e altos valores de Especificidade e Precisão, acima de $97.7 \%$.

Assim, esta estratégia pode render diversos ganhos aos usuários da tecnologia em relação a manutenção preditiva de suas máquinas, mesmo quando estes não possuem condições de parar o processo produtivo ou mesmo inserir falhas nas suas máquinas para ajuste do classificador.

Os resultados da estratégia de identificação de novidades, quando empregando redução de atributos por PCA e grande quantidade de atributos, se mostrou insatisfatório. Desta maneira, sugere-se a utilização dos atributos selecionados por CFS indicados por este estudo para os cenários desenvolvidos.

Justifica-se portanto, um estudo mais aprofundado sobre utilização de métodos de redução de atributos não supervisionados, como no caso do PCA, onde não é necessário a indicação da classe de cada amostra para gerar um novo conjunto de dados com número inferior de atributos.

Adicionalmente foi verificado a partir do cenário de aumento de inércia, que a quantidade de amostras coletadas foi suficiente para o ajuste do sistema, a partir da análise da curva de aprendizado. Foi aplicado a mesma regra nos demais cenários concluindo-se que em todos os casos a quantidade de amostra foi suficiente para descrever o comportamento do sistema.

É importante ressaltar que a validação dos resultados desta tese se baseia na utilização validação cruzada de 05 partições e sua aplicação realizada em 04 cenários distintos, perfazendo-se a detecção de 05 tipos de falhas comuns em aplicações de acionamentos de 
motores e máquinas elétricas.

Os bons resultados obtidos pelo sistema são corroborados uma vez que a aplicação utilizada foi desenvolvida em diferentes condições de operação, provendo maior robustez a metodologia proposta. Alguns parâmetros utilizados são o treinamento e teste do sistema com diferentes parametrizações de velocidade e acelerações máximas de operação, que podem estar relacionadas a ajustes na melhoria da eficiência do processo industrial; e tempo de ciclo da rede PROFINET, que influencia diretamente na taxa de amostragem dos dados disponíveis para ajuste do sistema, como também podem influenciar do ponto de vista do sistema de controle, conforme identificado por Dias, Sestito e Brandao (2017).

A análise em relação a capacidade dos sistemas de detecção serem capazes de identificar especificamente a falha para a qual foi projetado, mesmo frente a dados de outras possíveis falhas, obteve bom desempenho apenas para alguns cenários estudados. Assim, sugere-se o desenvolvimento de um sistema de diagnóstico para cada falha a qual se deseja monitorar a condição de operação.

A aplicação da metodologia em outros acionamentos de máquinas para detecção de falhas similares, deve ocorrer empregando todo processo indicado no capítulo 4, ou sua adaptação para a estratégia de detecção de novidades. Sugere-se a delimitação das condições de operação da máquinas e parâmetros da rede, para se alcançar melhores resultados.

Assim, a metodologia proposta é focada inicialmente em máquinas seriadas, onde o fabricante tenha possibilidade de criar as condições de falha e anomalia para treinamento do sistema de diagnóstico. Entretanto, a abordagem de detecção de novidades pode prover informações importantes sobre a condição de operação das máquinas, mesmo sem dados de condições anômalas e de falhas. 


\section{CAPÍTULO 7 CONCLUSÕES}

Esta tese investiga sobre o monitoramento, detecção e identificação de falhas e anomalias em aplicações de acionamentos de motores elétricos através de utilização de dados de processo que trafegam em redes de comunicação industrial, no caso a rede PROFINET (perfil PROFIdrive), em aplicações de controle de posição e velocidade de máquinas rotativas próprias de indústria de manufatura.

Um pesquisas bibliográfica sobre a tecnologia PROFINET foi realizada com objetivo de verificar as principais linhas de pesquisa realizadas sobre este tema no meio científico, analisando possíveis lacunas, pontos de melhoria e necessidades do usuário da tecnologia, conforme apresentado no trabalho Dias et al. (2018), que conclui da necessidade de desenvolvimento de ferramentas de diagnóstico e de pesquisas em relação aos perfis do protocolo, como o PROFIdrive.

Adicionalmente, no desenvolvimento desta tese, uma profunda investigação acerca de trabalhos sobre condition monitoring referentes a detecção e diagnóstico de falhas em máquinas rotativas foi realizado, no que tange falhas comumente observadas em máquinas rotativas encontradas no processo produtivo, ao tipo de sensores e variáveis empregadas no sistema e sobre ferramentas advindas de aprendizagem de máquinas aplicados ao sistema de diagnostico.

Algumas falhas foram então investigadas no trabalho, são elas: aumento excessivo na inércia da carga acionada, desacoplamento entre eixo do motor e carga, desbalanceamento e desalinhamento da carga. Em geral, são falhas relacionadas a problemas mecânicos que podem ocorrer por um processo de degradação em acionamentos de máquinas.

Os objetivos específicos foram alcançados, iniciando pelo modelo empregado na coleta de dados realizada via rede de comunicação industrial, que já disponibiliza dados de processo para propósitos de controle, não sendo necessário a instalação de sensores específicos adicionais nas máquinas para identificação de falhas e anomalias, como acelerômetros e transdutores de corrente. A partir destes dados foram implementados algoritmos em ambiente MATLAB para interpretação dos dados de processo do perfil PROFIdrive (posição e velocidade do motor elétrico) para os Telegramas Padrão 1 e 3, aplicados nas Classes de Aplicação 1 e 4.

O perfil PROFIdrive por se tratar de um padrão aberto para acionamentos de motores dos protocolos PROFINET e PROFIBUS, com um grande base instalada e em ascensão (ocupa $24 \%$ do mercado de redes de comunicação industrial), poderá ser 
aplicado para uma grande gama de aplicações industriais que já utilizam esta tecnologia, independente do fabricante dos controladores e drive para acionamento elétrico.

Com os dados de processo interpretados, outro algoritmo desenvolvido identifica automaticamente o ciclo de operação da máquina. Assim, cada amostra representa um ciclo de operação. Um total de até 102 características são extraídas dos sinais, formando um banco de dados para ajuste do sistema de diagnóstico.

Devido ao grande número de características, são utilizados métodos para redução da dimensionalidade destes atributos através de duas técnicas, o CFS baseado na seleção de atributos a partir da correlação de Pearson e mérito, e utilizando PCA, que calcula componentes principais dos sinais interpretados.

A solução de redução de atributos CFS, se mostrou a mais eficaz quando comparada ao PCA, resultando na seleção de características altamente correlacionadas com as falhas investigadas, sendo necessárias até dois atributos para identificação de falhas. Verifica-se que em todos os cenários investigados, a seleção de atributos por CFS resultou em melhores valores de acurácia do classificador, com exceção do classificador de novidades, OCSVM, na falha de desacoplamento.

Outro ponto bastante interessante foi que esta técnica empregou em todos os casos apenas o sinal de erro de velocidade, que foi criado a partir dos sinais de setpoint de velocidade enviado pelo controlador para o servo motor e velocidade atual, enviado no sentido oposto, não sendo necessário a utilização do sinal de posição também enviado pelo servo motor em cenários que empregam o Telegrama Padrão 3. Desta maneira, a metodologia poderia ser adaptada em futuras aplicações para extração de atributos, sendo requerido apenas o sinal do erro de velocidade, reduzindo o esforço computacional, podendo ser os demais sinais descartados. Conclui-se também que a identificação de falhas e anomalias seria possível utilizando outros Telegramas Padrão, uma vez que a informação de setpoint de velocidade e velocidade atual são disponibilizadas nos Telegramas Padrão 1, $2,3,4,5$ e 6 .

Para a redução de atributos empregando componentes principais pelo PCA não seria possível esta característica, pois a composição exige a extração de características das três variáveis interpretadas no perfil PROFIdrive e do erro de velocidade. No entanto, observa-se uma interessante característica na utilização das componentes principais, que quando plotadas induz o agrupamento das amostras de maneira a separá-las em clusters, de acordo com a aceleração e velocidade máxima parametrizada no servo motor.

Particularmente para os cenários estudados, o sistema de detecção de falhas propostos por essa metodologia obteve-se excelentes resultados, similares aos obtidos na literatura correlata com a vantagem de não necessitar de sensores adicionais. A análise de desempenho dos classificadores investigados (kNN, RNA e SVM) mostra que foi possível 
identificar falhas e anomalias nas aplicações, com destaque para o classificador tipo SVM, que obteve os melhores valores de acurácia para todos os cenários com exceção do cenário de desalinhamento paralelo, e adicionalmente obteve os menores valores de tempo de execução do classificador, que pode ser um indicador crítico para implementação de um sistema embarcado de tempo real.

Adicionalmente, a tese investigou a possibilidade de desenvolvimento de um sistema de detecção de falhas a partir de dados apenas da condição de operação saudável das máquinas, não sendo necessário a criação de condições faltosas. Para esta tarefa foi utilizado um classificador de novidades do tipo OCSVM, que trata-se de uma adaptação do classificador SVM tradicional, que foi o que obteve os melhores resultados como dito anteriormente. O sistema de detecção de novidades também obteve bons resultados, que chegaram até $98.4 \%$. Um importante ponto verificado para este tipo de classificador é que a utilização de grande quantidade de atributos resulta em uma grande queda de acurácia no sistema. Assim, verifica neste caso a importância de empregar técnicas de redução de atributos do tipo não-supervisionada, ou seja, que não necessitam da identificação da presença ou não de falha no sistema nas amostras.

Os dados coletados neste trabalho foram provenientes de bancada de experimentos desenvolvida de maneira a poder criar situações reais em máquinas empregadas em indústria de manufatura e capaz de fornecer dados de diversos tipos de falhas em cargas mecânicas acionadas por motores elétricos. Os equipamentos empregados como controlador e servo motor são equipamentos amplamente utilizados em aplicações reais. Os resultados obtidos pelo sistema são corroborados uma vez que a aplicação utilizada foi desenvolvida em diferentes condições de operação, como diferentes parametrizações de velocidade e acelerações máximas de operação e tempo de ciclo da rede PROFINET, provendo maior robustez a metodologia proposta.

Embora este trabalho tenha focado em apenas cinco tipos de falhas e anomalias considerando uma determinada potência de motor elétrico, estima-se que a metodologia proposta possa ser aplicada para outros tipos de falhas e outras potências e condições de operação de servo motores. Assim, trabalhos futuros poderão ser desenvolvidos a partir das investigações realizadas por esta tese.

Conclui desta maneira, que esta tese traz contribuições para as seguintes áreas:

- redes de comunicação industrial, no que diz respeito ao perfil PROFIdrive e protocolo PROFINET, podendo se estender também ao protocolo PROFIBUS DP;

- diagnóstico e monitoramento de operações de acionamentos de motores elétricos, largamente utilizados em indústria de manufatura;

- sistemas inteligentes de classificação e padrões e ferramentas de aprendizagem de 
máquina.

Provou-se, uma metodologia factível e implementável para o objetivo proposto. Adicionalmente, a investigação abre novas frentes de trabalho indicadas na próxima seção.

\subsection{Trabalhos Futuros}

No decorrer do desenvolvimento deste trabalho, novos temas para investigação surgiram como continuidade a pesquisa apresentada, que são apresentadas em seguida como sugestão de trabalhos futuros:

- Implementação do sistema de diagnóstico gerado pela metodologia para operar em tempo real em um sistema embarcado, possivelmente utilizando serviços de computação na nuvem, dentro do contexto da Indústria 4.0;

- Desenvolvimento de um sistema para aplicação da metodologia de forma automático objetivando ajustar o sistema detecção, principalmente para condição de detecção de novidades;

- Ampliar a investigação para outras falhas em acionamentos de máquinas elétricas, como problemas em rolamentos de mancais; e outros cenários com diferentes características de motores elétricos e cargas mecânicas;

- Aprofundar a investigação sobre outros tipos de algoritmos para redução de atributos, principalmente de maneira não supervisionada, afim de selecionar melhores atributos para emprego no sistema de detecção de novidades. Dentre eles destaca-se o algoritmo redes AutoEncoder.

- Aprofundar a investigação sobre outros tipos de classificadores de padrões, como árvore de decisão, próprios para aplicações onde não se possui grande quantidade de dados em condições anormais de operação, classificação indutiva e aprendizado Bayesiano. Adicionalmente, por esta tese ter trabalhado apenas com um único classificador para detecção de novidades, sugere-se maior foco na investigação de classificadores com este propósito, como os algoritmos Isolation Forest e Covariância Robusta.

- Adaptação da metodologia para detecção de falhas em máquinas que não operem de maneira cíclica, como em processos contínuos; 
- Investigação de outros parâmetros estatísticos para extração de atributos como transformada Wavelet, assimetria de distribuição estatísticas do sinal, entre outras; 



\section{REFERÊNCIAS}

AHA, D. W.; KIBLER, D.; ALBERT, M. K. Instance-based learning algorithms. Machine Learning, v. 6, n. 1, p. 37-66, Jan 1991. ISSN 1573-0565. Disponível em: $<$ https://doi.org/10.1007/BF00153759>.

AMIR, R. B.; GUL, S. T.; KHAN, A. Q. A comparative analysis of classical and one class svm classifiers for machine fault detection using vibration signals. In: 2016 International Conference on Emerging Technologies (ICET). [S.l.: s.n.], 2016. p. 1-6.

ANTONINO-DAVIU, J.; POPALENY, P. Detection of induction motor coupling unbalanced and misalignment via advanced transient current signature analysis. In: 2018 XIII International Conference on Electrical Machines (ICEM). [S.l.: s.n.], 2018. p. 2359-2364. ISSN 2381-4802.

ARREDONDO, P. A. D. et al. Comparative study of time-frequency decomposition techniques for fault detection in induction motors using vibration analysis during startup transient. Shock and Vibration, 2015. ISSN 1070-9622.

ATOUI, I. et al. Fault detection and diagnosis in rotating machinery by vibration monitoring using fft and wavelet techniques. In: 2013 8th International Workshop on Systems, Signal Processing and their Applications (WoSSPA). [S.l.: s.n.], 2013. p. 401-406.

BANSAL, D.; EVANS, D. J.; JONES, B. A real-time predictive maintenance system for machine systems - an alternative to expensive motion sensing technology. In: 2005 Sensors for Industry Conference. [S.l.: s.n.], 2005. p. 39-44.

BHUYAN, M. H.; BHATTACHARYYA, D. K.; KALITA, J. K. Network anomaly detection: Methods, systems and tools. IEEE Communications Surveys Tutorials, v. 16, n. 1, p. 303-336, First 2014. ISSN 1553-877X.

BORDOLOI, D.; TIWARI, R. Monitoring of induction motor mechanical and electrical faults by optimum multiclass-support vector machine algorithms using genetic algorithm. Mechanisms and Machine Science, v. 61, p. 120-132, 2019. Cited By 0. Disponível em: <https://www.scopus.com/inward/record.uri?eid=2-s2.0-85051761949\&doi=10.1007\% 2f978-3-319-99268-6_9\&partnerID=40\&md5=62b58108af06176516e427730815ac41 > .

BORGES, F. A. S. et al. Feature extraction and power quality disturbances classification using smart meters signals. IEEE Transactions on Industrial Informatics, v. 12, n. 2, p. 824-833, April 2016. ISSN 1551-3203.

BOSER, B. E.; GUYON, I. M.; VAPNIK, V. N. A training algorithm for optimal margin classifiers. In: Proceedings of the Fifth Annual Workshop on Computational Learning Theory. New York, NY, USA: ACM, 1992. (COLT '92), p. 144-152. ISBN 0-89791-497-X. Disponível em: <http://doi.acm.org/10.1145/130385.130401>.

CORNE, B.; KNOCKAERT, J.; DESMET, J. Misalignment and unbalance fault severity estimation using stator current measurements. In: 2017 IEEE 11th International 
Symposium on Diagnostics for Electrical Machines, Power Electronics and Drives (SDEMPED). [S.l.: s.n.], 2017. p. 247-253.

DEPARI, A. et al. A new instrument for real-time ethernet performance measurement. IEEE Transactions on Instrumentation and Measurement, v. 57, n. 1, p. 121-127, Jan 2008. ISSN 0018-9456.

DIAS, A. L.; SESTITO, G. S.; BRANDAO, D. Performance analysis of profibus dp and profinet in a motion control application. Journal of Control, Automation and Electrical Systems, p. 86-93, 2017. ISSN 2195-3880.

DIAS, A. L. et al. Sistemas de medição para redes de comunicação industrial baseada em ethernet. In: IV Congresso de Automação e Inovação Tecnológica Sucroenergética. [S.l.: s.n.], 2016.

Dias, A. L. et al. Panorama, challenges and opportunities in profinet protocol research. In: 2018 13th IEEE International Conference on Industry Applications (INDUSCON). [S.l.: s.n.], 2018. p. 186-193.

DRIF, M.; CARDOSO, A. J. M. Stator fault diagnostics in squirrel cage three-phase induction motor drives using the instantaneous active and reactive power signature analyses. IEEE Transactions on Industrial Informatics, v. 10, n. 2, p. 1348-1360, May 2014. ISSN 1551-3203.

DWI, H. et al. Artificial neural network based identification system for abnormal vibration of motor rotating disc system. In: 2015 International Electronics Symposium (IES). [S.l.: s.n.], 2015. p. 251-256.

DWIPUTRANTO, T. H.; SETIAWAN, N. A.; AJI, T. B. Machinery equipment early fault detection using artificial neural network based autoencoder. In: 2017 3rd International Conference on Science and Technology - Computer (ICST). [S.l.: s.n.], 2017. p. 66-69.

EBRAHIMI, B. M. et al. Advanced eccentricity fault recognition in permanent magnet synchronous motors using stator current signature analysis. IEEE Transactions on Industrial Electronics, v. 61, n. 4, p. 2041-2052, April 2014. ISSN 0278-0046.

ENERGéTICA, E. de P. Balanço Energético Nacional 2018 Ano Base 2017. [S.l.], 2018.

Feng, H. et al. Principal component analysis based filtering for scalable, high precision k-nn search. IEEE Transactions on Computers, v. 67, n. 2, p. 252-267, Feb 2018. ISSN 0018-9340.

FERRARI, P. et al. Large profinet io rt networks for factory automation: A case study. In: ETFA2011. [S.l.: s.n.], 2011. p. 1-4. ISSN 1946-0740.

FOURNIER, E. et al. Current-based detection of mechanical unbalance in an induction machine using spectral kurtosis with reference. IEEE Transactions on Industrial Electronics, v. 62, n. 3, p. 1879-1887, March 2015. ISSN 0278-0046.

GHANBARI, T. Autocorrelation function-based technique for stator turn-fault detection of induction motor. IET Science, Measurement Technology, v. 10, n. 2, p. 100-110, 2016. ISSN 1751-8822. 
GUYON, I. et al. Gene selection for cancer classification using support vector machines. Machine Learning, v. 46, n. 1, p. 389-422, Jan 2002. ISSN 1573-0565. Disponível em: <https://doi.org/10.1023/A:1012487302797>.

Hagan, M. T.; Menhaj, M. B. Training feedforward networks with the marquardt algorithm. IEEE Transactions on Neural Networks, v. 5, n. 6, p. 989-993, Nov 1994. ISSN 1045-9227.

HAI, Y.; TSUI, K.; ZUO, M. J. Gear crack level classification based on multinomial logit model and cumulative link model. In: Proceedings of the IEEE 2012 Prognostics and System Health Management Conference (PHM-2012 Beijing). [S.l.: s.n.], 2012. p. 1-6. ISSN 2166-5656.

HALL, M. A. Correlation-based Feature Selection for Machine Learning. april 1999. Tese (Doutorado) — University of Waikato, Waikato, april 1999. Disponível em: <https://www.cs.waikato.ac.nz>.

HAYKIN, S. Neural Networks and Learning Machines. 3. ed. [S.l.]: Pearson Prentice Hall, 2009. ISBN 978-0-13-147139-9.

HENAO, H. et al. Trends in fault diagnosis for electrical machines: A review of diagnostic techniques. IEEE Industrial Electronics Magazine, v. 8, n. 2, p. 31-42, June 2014. ISSN 1932-4529.

HMS. Industrial Ethernet is now bigger than fieldbuses. 2018.

Disponível em: <https://www.anybus.com/about-us/news/2018/02/16/

industrial-ethernet-is-now-bigger-than-fieldbuses $>$.

JARDINE, A. K.; LIN, D.; BANJEVIC, D. A review on machinery diagnostics and prognostics implementing condition-based maintenance. Mechanical Systems and Signal Processing, v. 20, n. 7, p. 1483 - 1510, 2006. ISSN 0888-3270. Disponível em: <http://www.sciencedirect.com/science/article/pii/S0888327005001512>.

JOHNSON, R.; WICHERN, D. Applied Multivariate Statistical Analisys. 6. ed. [S.l.]: Pearson Prentice Hall, 2007. ISBN 0131877151.

KHANNA, R.; AWAD, M. Efficient Learning Machines: Theories, Concepts, and Applications for Engineers and System Designers. [S.l.: s.n.], 2015. ISBN 1430259892.

KOHAVI, R. A study of cross-validation and bootstrap for accuracy estimation and model selection. In: Proceedings of the 14th International Joint Conference on Artificial Intelligence - Volume 2. San Francisco, CA, USA: Morgan Kaufmann Publishers Inc., 1995. (IJCAI'95), p. 1137-1143. ISBN 1-55860-363-8. Disponível em: $<$ http://dl.acm.org/citation.cfm?id=1643031.1643047>.

KRAL, C.; PIRKER, F.; PASCOLI, G. The impact of inertia on rotor faults effects theoretical aspects of the vienna monitoring method. In: 2007 IEEE International Symposium on Diagnostics for Electric Machines, Power Electronics and Drives. [S.l.: s.n.], 2007. p. 77-82.

LI, X.; WANG, K.; JIANG, L. The application of ae signal in early cracked rotor fault diagnosis with pwvd and svm. JSW, v. 6, p. 1969-1976, 102011. 
LIBONI, L. H. B. Diagnóstico de Falhas em Motores de Indução Trifásicos Baseado em Decomposição em Componentes Ortogonais de Aprendizagem de Máquinas. 2017. Tese (Doutorado) — Universidade de São Paulo, São Paulo, 2017. Disponível em: <http://www.teses.usp.br>.

LIU, R. et al. Artificial intelligence for fault diagnosis of rotating machinery: A review. Mechanical Systems and Signal Processing, v. 108, p. 33 - 47, 2018. ISSN 0888-3270. Disponível em: <http://www.sciencedirect.com/science/article/pii/S0888327018300748>.

LORENA, A.; CARVALHO, A. Uma introdução às support vector machines. Revista de Informática Teórica e Aplicada, 2007.

MARTINEZ-MORALES, J. D. et al. Data fusion for multiple mechanical fault diagnosis in induction motors at variable operating conditions. In: 2010 7th International Conference on Electrical Engineering Computing Science and Automatic Control. [S.l.: s.n.], 2010. p. 176-181.

MCCOY, G. A.; DOUGLASS, J. G. Premium efficiency motor selection and application guide - a handbook for industry. Washington State University Energy Program for the US Department of Energy's Office of Energy Efficiency and Renewable Energy, 2014.

McNames, J. A fast nearest-neighbor algorithm based on a principal axis search tree. IEEE Transactions on Pattern Analysis and Machine Intelligence, v. 23, n. 9, p. 964-976, Sep. 2001. ISSN 0162-8828.

METWALLEY, S. M.; ABOUEL-SEOUD, S. A. Condition based maintenance optimization for faulty gearbox under continuous noise monitoring. British Journal of Applied Science Technology, v. 3, p. 320-339, 2013.

MUNZ, G.; CARLE, G. Distributed network analysis using topas and wireshark. In: NOMS Workshops 2008 - IEEE Network Operations and Management Symposium Workshops. [S.l.: s.n.], 2008. p. 161-164.

NEPOMUCENO, L. Tecnicas de Manutencao Preditiva. [S.l.]: Blucher, 2014. v. 1. ISBN 9788521200925.

OLIVERI, P. Class-modelling in food analytical chemistry: Development, sampling, optimisation and validation issues - a tutorial. Analytica Chimica Acta, v. 982 , p. 9 19, 2017. ISSN 0003-2670. Disponível em: < http://www.sciencedirect.com/science/article/ pii/S0003267017306050>.

OMITAOMU, O. A. et al. Online support vector regression approach for the monitoring of motor shaft misalignment and feedwater flow rate. IEEE Transactions on Systems, Man, and Cybernetics, Part C (Applications and Reviews), v. 37, n. 5, p. 962-970, Sep. 2007. ISSN 1094-6977.

PANDARAKONE, S. E. et al. Development of a methodology for bearing fault scrutiny and diagnosis using svm. In: 2017 IEEE International Conference on Industrial Technology (ICIT). [S.l.: s.n.], 2017. p. 282-287.

PATIL, M. S. et al. Experimental studies using response surface methodology for condition monitoring of ball bearings. Journal of Tribology, v. 132, May 2010. ISSN 0742-4787. 
PRIETO, M. D. et al. Bearing fault detection by a novel condition-monitoring scheme based on statistical-time features and neural networks. IEEE Transactions on Industrial Electronics, v. 60, n. 8, p. 3398-3407, Aug 2013. ISSN 0278-0046.

PROFIBUS NUTZERORGANISATION E.V. Profile Drive Technology PROFIdrive Profile - Technical Specification for PROFIBUS and PROFINET - Version 4.2). [S.l.], 2015.

RIPLEY, B. D.; HJORT, N. L. Pattern Recognition and Neural Networks. 1st. ed. New York, NY, USA: Cambridge University Press, 1996. ISBN 0521460867.

SAMPAIO, D. L.; NICOLETTI, R. Detection of cracks in shafts with the approximated entropy algorithm. Mechanical Systems and Signal Processing, v. 72-73, p. 286 302, 2016. ISSN 0888-3270. Disponível em: < http://www.sciencedirect.com/science/ article/pii/S0888327015004860>.

SANTOS, F. M. C. Identificação de falhas em motores de indução trifásicos usando sistemas inteligentes. march 2013. Tese (Doutorado) — University of São Paulo, São Paulo, march 2013. Disponível em: <http://www.teses.usp.br>.

SCHAFER, I.; FELSER, M. Precision of ethernet measurements based on software tools. In: 2007 IEEE Conference on Emerging Technologies and Factory Automation (EFTA 2007). [S.l.: s.n.], 2007. p. 510-515. ISSN 1946-0740.

SCHOLKOFT, B. et al. Estimating the Support of a High-Dimensional Distribution. [S.1.], 2001. v. 13.

SESTITO, G. S. et al. A method for anomalies detection in real-time ethernet data traffic applied to profinet. IEEE Transactions on Industrial Informatics, v. 14, n. 5, p. 2171-2180, May 2018. ISSN 1551-3203.

SILVA, I.; SPATTI, D.; FLAUZINO, R. Redes Neurais Artificiais para Engenharia e Ciências Aplicadas. [S.l.]: Artliber, 2010. ISBN 9788588098534.

SILVA, I. et al. Neural Networks and Learning Machines. [S.l.]: Springer, 2016. ISBN 978-3-319-43162-8.

SNOEK, J.; LAROCHELLE, H.; ADAMS, R. P. Practical bayesian optimization of machine learning algorithms. In: PEREIRA, F. et al. (Ed.). Advances in Neural Information Processing Systems 25. Curran Associates, Inc., 2012. p. 2951-2959. Disponível em: < http://papers.nips.cc/paper/ 4522-practical-bayesian-optimization-of-machine-learning-algorithms.pdf $>$.

Soualhi, A.; Medjaher, K.; Zerhouni, N. Bearing health monitoring based on hilbert-huang transform, support vector machine, and regression. IEEE Transactions on Instrumentation and Measurement, v. 64, n. 1, p. 52-62, Jan 2015. ISSN 0018-9456.

SUETAKE, M. Sistemas Inteligentes para Monitoramento e Diagnóstico de Falhas em Motores de Indução Trifásico. 2012. Tese (Doutorado) - Universidade de São Paulo, São Paulo, 2012. Disponível em: <http://www.teses.usp.br>. 
TAHIR, M. M. et al. Classification of unbalance and misalignment faults in rotor using multi-axis time domain features. In: 2016 International Conference on Emerging Technologies (ICET). [S.l.: s.n.], 2016. p. 1-4.

TAX, D. M.; DUIN, R. P. Support vector data description. Machine Learning, v. 54, n. 1, p. 45-66, Jan 2004. ISSN 1573-0565. Disponível em: <https://doi.org/10.1023/B: MACH.0000008084.60811.49>.

TURCATO, A. et al. Ferramenta em software baseado em web para pré-processamento de tráfego de redes real time ethernet. In: $9^{\mathbf{o}}$ Congresso de Inovação, Ciência e Tecnologia do IFSP. [S.l.: s.n.], 2018.

TURCATO, A. C. Desenvolvimento de uma metodologia baseada em redes neurais artificiais para a identificação de anomalias em redes de comunicação Profinet. 2015. Dissertação (Mestrado) — Universidade de São Paulo, São Carlos, 2015. Disponível em: <http://www.teses.usp.br/teses/disponiveis/18/18153/ tde-04082015-112148/>.

VANRAJ et al. Intelligent predictive maintenance of dynamic systems using condition monitoring and signal processing techniques \#x2014; a review. In: 2016 International Conference on Advances in Computing, Communication, Automation (ICACCA) (Spring). [S.l.: s.n.], 2016. p. 1-6.

VAPNIK, V. Statistical learning theory. [S.l.]: Wiley, 1998. ISBN 978-0-471-03003-4.

WITTEN, I.; FRANCK, E. Data Mining: Practical Machine Learning Tools and Techniquies. 2. ed. [S.l.]: Elsevier Science, 2015. (The Morgan Kaufmann Series in Data Management Systems). ISBN 9780080477022.

YANG, M.; LI, G. Analysis of profinet io communication protocol. In: 2014 Fourth International Conference on Instrumentation and Measurement, Computer, Communication and Control. [S.l.: s.n.], 2014. p. 945-949.

YANG, W. et al. Research on a simple, cheap but globally effective condition monitoring technique for wind turbines. In: . [S.l.: s.n.], 2008. p. $1-5$.

YONGJIE, Z. et al. Research on early fault diagnostic method of wind turbines. TELKOMNIKA, v. 11, n. 5, p. 2330-2341, 2013. ISSN 2302-4046. 